LARISSA RODRIGUES DAMIANI

FILMES DE ÓXIDO DE ÍNDIO DOPADO COM ESTANHO DEPOSITADOS POR MAGNETRON SPUTTERING

São Paulo 


\section{FILMES DE ÓXIDO DE ÍNDIO DOPADO COM ESTANHO DEPOSITADOS POR MAGNETRON SPUTTERING}

Dissertação apresentada à Escola

Politécnica da Universidade de São Paulo para a obtenção do título de Mestre em Engenharia Elétrica

Área de concentração: Microeletrônica

Orientador: Prof. Livre-Docente

Ronaldo Domingues Mansano

\section{São Paulo}


Este exemplar foi revisado e alterado em relação à versão original, sob responsabilidade única do autor e com a anuência de seu orientador.

São Paulo, 14 de janeiro de 2010.

Assinatura do autor

Assinatura do orientador

FICHA CATALOGRÁFICA

Damiani, Larissa Rodrigues

Filmes de óxido de índio dopado com estanho depositados por magnetron sputtering / L.R. Damiani. -- ed.rev. -- São Paulo, 2010.

$112 \mathrm{p}$.

Dissertação (Mestrado) - Escola Politécnica da Universidade de São Paulo. Departamento de Engenharia de Sistemas Eletrônicos.

1. Filmes finos 2. Processos de microeletrônica I. Universidade de São Paulo. Escola Politécnica. Departamento de Engenharia de Sistemas Eletrônicos II. t. 
Dedico este trabalho aos meus pais. 


\section{AGRADECIMENTOS}

Agradeço, em primeiro lugar, ao meu amigo e orientador Prof. Dr. Ronaldo Domingues Mansano por todo apoio, conhecimento, paciência e compreensão dispensados, principalmente nos momentos de maior dificuldade.

Aos grandes amigos que encontrei ao longo destes anos e que tanto me ajudaram: Marina Sparvoli, Juliana Cardoso, Michel Veiga, Peter Polak, Luiz Rasia, Alex Nunes e Sergio Lopera.

Ao amigo e conselheiro Prof. Dr. Roberto Koji Onmori, que esteve presente desde o início, sempre que precisei, e sem o qual eu talvez não tivesse seguido o caminho que escolhi.

Ao Prof. Dr. Marcos Massi, pelo carinho e atenção dispensados no meu Exame de Qualificação.

Ao Prof. Dr. Jose Fernando Diniz Chubaci do LACIFID-IFUSP, por todo o apoio técnico e moral.

Ao Prof. Dr. Luis da Silva Zambom, pela ajuda geral, tanto na utilização da sala limpa quanto em métodos de caracterização.

Aos técnicos do LSI-EPUSP Nelson Ordonez, Carlos Araújo e Rubens Pereira pela paciência e carinho.

Ao técnico do IFUSP Antônio Carlos Silveira pelas conversas, risadas e dicas preciosas.

Ao amigo Álvaro Diego Maia e ao Prof. Dr. Alain Quivy, do LNMS-IFUSP, pela ajuda e atenção.

À Prof. ${ }^{a}$ Dr. ${ }^{a}$ Maria Cecília Salvadori, do LFF-IFUSP, pela ajuda com as medições de EDX.

A todos os alunos de graduação e de pós-graduação da EPUSP com os quais tive contato e que tanto me ensinaram.

À minha família, que sempre me incentivou e me trouxe muito amor.

Aos meus amigos de infância e adolescência, que ainda hoje estão presentes em minha vida.

À CAPES e à Comissão de Bolsas, pelo apoio financeiro. 


\section{RESUMO}

O óxido de índio dopado com estanho é um semicondutor degenerado de alta transparência no espectro visível e alta condutância elétrica. Por suas propriedades, ele é utilizado como eletrodo transparente em diversas aplicações. Algumas destas aplicações exigem que os filmes sejam depositados sobre substratos poliméricos, que degradam em temperaturas acima de $100{ }^{\circ} \mathrm{C}$. Por este motivo, métodos de deposição que utilizam baixas temperaturas são necessários. O objetivo deste trabalho é o desenvolvimento de técnicas de deposição de filmes de óxido de índio dopado com estanho, em baixas temperaturas $\left(<100{ }^{\circ} \mathrm{C}\right)$, pelo método de magnetron sputtering de rádio fequência. Filmes foram obtidos sobre substratos de silício, vidro e policarbonato, e suas propriedades físicas, elétricas, ópticas, químicas e estruturais foram analisadas por perfilometria, elipsometria, curvas corrente-tensão, prova de quatro pontas, medidas de efeito Hall, difratometria de raios-X e espectrofotometria. Filmes depositados sobre silício e vidro tiveram resistividade elétrica mínima da ordem de $10^{-4} \Omega$.cm, enquanto a resistividade do filme obtido sobre policarbonato foi da ordem de $10^{-3} \Omega . \mathrm{cm}$. A transmitância óptica média no espectro visível das amostras variou de 66 a 87 \%. Do ponto de vista estrutural, as amostras tenderam a apresentar fase amorfa e cristalina, com orientação preferencial ao longo da direção [100]. De modo geral, as amostras obtidas de 75 a $125 \mathrm{~W}$ tiveram as melhores propriedades para serem utilizadas em aplicações que exijam eletrodos transparentes, considerando aspectos elétricos e ópticos.

Palavras-chave: Óxido de índio dopado com estanho. Óxidos condutores transparentes. Filmes finos. Sputtering. 


\begin{abstract}
Indium-tin oxide is a degenerate semiconductor that shows high transmittance in the visible region of the spectrum and high electrical conductance. Because of its properties, this material is used as transparent electrode in a wide variety of applications. Some of these applications demand the indium-tin oxide layer to be deposited over polymer substrates, which degrade at temperatures above $100{ }^{\circ} \mathrm{C}$. Because of this degradation problem, deposition methods at low temperatures are needed. The purpose of this work is the development of low temperature $\left(<100{ }^{\circ} \mathrm{C}\right)$ indium-tin oxide deposition processes by radio frequency magnetron sputtering method. Thin films were deposited over silicon, glass and polycarbonate substrates, and their physical, electrical, optical, chemical and structural properties were analyzed by surface high step meter, ellipsometry, current-voltage curves, four-point probe analysis, Hall effect measurements, X-ray diffractometry and spectrophotometry. Films deposited over silicon and glass substrates showed minimal electrical resistivity in the order of $10^{-4} \Omega . \mathrm{cm}$, while the resistivity of the film obtained over polycarbonate was in the order of $10^{-3} \Omega . \mathrm{cm}$. The average transmittance in the visible spectrum varied over the range 66 to $87 \%$. According to the structural study, the films present both amorphous and crystalline phases, with crystallites showing preferential orientation along the [100] direction. In general, films deposited with power varying over the range 75 to $125 \mathrm{~W}$ showed the best results to be applied as transparent electrodes, considering electrical and optical aspects.
\end{abstract}

Keywords: Indium-tin oxide. Transparent conductive oxides. Thin films. Sputtering. 


\section{LISTA DE FIGURAS}

Figura 1 - Ligação iônica que representa a forma estequiométrica do óxido de índio $\left(\operatorname{In}_{2} \mathrm{O}_{3}\right)$, mostrando os elétrons da camada de valência do índio (3 elétrons) e do

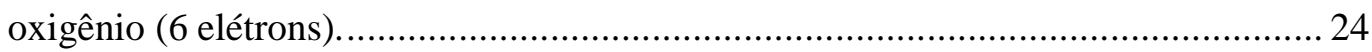

Figura 2 - Luz incidente, refletida e transmitida por uma amostra.................................... 30

Figura 3 - Exemplo de obtenção do band gap óptico $\left(E_{o p t}\right)$ por meio do gráfico de absorbância em função do comprimento de onda

Figura 4 - Estrutura típica de uma célula solar orgânica, onde o ITO funciona como

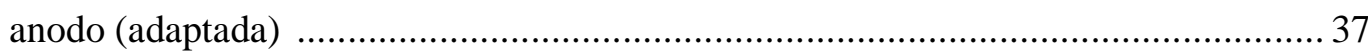

Figura 5 - Estrutura de um OLED fabricado com ITO como anodo (adaptada) .................. 38

Figura 6 - Célula de cristal líquido, usada na fabricação de LCDs, usando eletrodos de

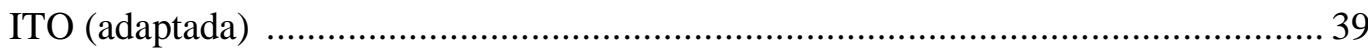

Figura 7 - Funcionamento de uma célula típica de cristal líquido (adaptada) ...................... 40

Figura 8 - Exemplo de funcionamento de tela sensível ao toque resistiva (adaptada) .......... 41

Figura 9 - Equipamento de RF magnetron sputtering utilizado para a deposição dos filmes de ITO.

Figura 10 - Câmara do sistema de RF magnetron sputtering utilizado para depositar os

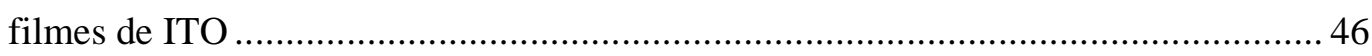

Figura 11 - Alvo de ITO da Kurt J. Lesker Company utilizado para a deposição de

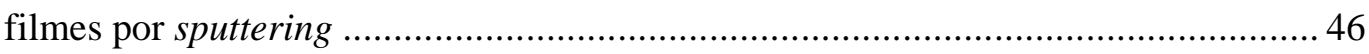

Figura 12 - Esquema de funcionamento da prova de quatro pontas, usada para medir a resistência de folha das amostras (adaptada)

Figura 13 - Degrau formado entre o substrato e o filme de ITO, usado para medidas de espessura por perfilometria

Figura 14 - Esquema das amostras de ITO com contatos de alumínio depositados por

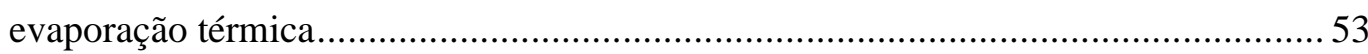

Figura 15 - Contatos de prata e fios de cobre feitos sobre os filmes de ITO em amostras de $5 \times 5 \mathrm{~mm}$.

Figura 16 - Taxa de deposição em funcão da $P_{R F}$ para fluxo de argônio em 5 mTorr, com destaque da equação da reta de ajuste linear dos pontos experimentais $\left(D R_{E X P}\right)$ 
Figura 17 - Resistência de folha e resitividades das amostras de ITO/Si obtidas com $P_{R F}$ variando de 25 a $100 \mathrm{~W}$. Para $P_{R F}=25 \mathrm{~W}$, foi condiderada a amostra obtida com $T_{D}=120 \mathrm{~min}$

Figura 18 - Espectro de contagens em função da energia obtido pelo microscópio eletrônico de varredura para as amostra de ITO/Si obtidas com $P_{R F}=75 \mathrm{~W}$.

Figura 19 - Porcentagem atômica (considerando apenas In, Sn e O) em função da $P_{R F}$ para as amostras de ITO/Si obtidas com $P_{R F}$ variando de 25 a $100 \mathrm{~W}$

Figura 20 - Difração de raios-X de 20 a $65^{\circ}$ para amostras de ITO/Si obtidas com $P_{R F}=$ 75 e $100 \mathrm{~W}$

Figura 21 - Difração de raios-X de 20 a $65^{\circ}$ para amostras de ITO/Si obtidas com $P_{R F}=$ 25 e $50 \mathrm{~W}$

Figura 22 - Espessura e erro relativo da espessura em função do tempo de deposição para amostras de ITO/Vidro obtidas com $P_{R F}=75 \mathrm{~W}$ e $T_{D}$ variando de 30 a $120 \min$.

Figura 23 - Espessura e erro relativo da espessura em função do tempo de deposição para amostras de ITO/Si obtidas com $P_{R F}=75 \mathrm{~W}$ e $T_{D}$ variando de 30 a $120 \mathrm{~min} . . . .68$

Figura 24 - Resistência de folha e erro relativo da resistência de folha em função do tempo de deposição para amostras de ITO/Si obtidas com $P_{R F}=75 \mathrm{~W}$ e $T_{D}$ variando de 30 a $120 \mathrm{~min}$

Figura 25 - Resistividade das amostras de ITO/Si com $P_{R F}=75 \mathrm{~W}$ e $T_{D}$ variando de 30 a $120 \mathrm{~min}$ 70

Figura 26 - Resistência de folha e erro relativo da resistência de folha em função do tempo de deposição para amostras de ITO/Vidro obtidas com $P_{R F}=75 \mathrm{~W}$ e $T_{D}$ variando de 30 a $120 \mathrm{~min}$

Figura 27 - Resistividade das amostras de ITO/Si com $P_{R F}=75 \mathrm{~W}$ e $T_{D}$ variando de 30 a $120 \min$ 71

Figura 28 - Porcentagem atômica em função da espessura para amostras de ITO/Si obtidas com $P_{R F}=75 \mathrm{~W}$ e $T_{D}$ variando de 30 a $120 \mathrm{~min}$

Figura 29 - Densidade $(N)$ e mobilidade $(\mu)$ de portadores das amostras de ITO/Vidro obtidas com $P_{R F}=75 \mathrm{~W}$ e $T_{D}$ variando de 30 a $120 \mathrm{~min}$

Figura 30 - Difração de raios-X das amostras de ITO/Si obtidas com $P_{R F}=75 \mathrm{~W}$ e $T_{D}$ variando de 30 a $120 \mathrm{~min}$

Figura 31 - Difração de raios-X das amostras de ITO/vidro obtidas com $P_{R F}=75 \mathrm{~W}$ e

$T_{D}=120 \min$ 
Figura 32 - Curvas $I-V$ das amostras de ITO/Si obtidas com $P_{R F}=75 \mathrm{~W}$ e $T_{D}$ variando de 30 a $120 \min$

Figura 33 - Porcentagem de transmitância óptica $(\% T)$ em função do comprimento de onda $(\lambda)$ das amostras de ITO/vidro obtidas com $P_{R F}=75 \mathrm{~W}$ e $T_{D}$ variando de 30 a 120 min, assim como a transmitância média $\left(\% T_{a}\right)$ calculada para o espectro visível $(380<\lambda<750 \mathrm{~nm})$

Figura 34 - Porcentagem de transmitância média no espectro visível $\left(\% T_{a}\right)$ em função da espessura $(t)$, em comparação com a resistividade $(\rho)$ das amostras obtidas com $P_{R F}=75 \mathrm{~W}$ e $T_{D}$ variando de 30 a $120 \mathrm{~min}$ 78

Figura 35 - Gráfico do coeficiente de absorção $(\alpha)$ em função do comprimento de onda ( $\lambda$ ) para as amostras de ITO/vidro obtidas com $P_{R F}=75 \mathrm{~W}$ e $T_{D}$ variando de $30 \mathrm{a}$ $120 \mathrm{~min}$, destacando $\alpha$ para $550 \mathrm{~nm}$ 79

Figura 36 - Gráfico do coeficiente de extinção $(\kappa)$ em função do comprimento de onda para as amostras de ITO/vidro obtidas com $P_{R F}=75 \mathrm{~W}$ e $T_{D}$ variando de 30 a $120 \mathrm{~min}$, destacando $\kappa$ para $550 \mathrm{~nm}$

Figura 37 - Absorbância óptica em função da energia $(E)$ das amostras de ITO/vidro obtidas com $P_{R F}=75 \mathrm{~W}$ e $T_{D}$ variando de 30 a $120 \mathrm{~min}$, com a indicação do band gap óptico obtido pela extrapolação da reta.

Figura 38 - Figura de mérito das amostras de ITO/Vidro obtidas com $P_{R F}=75 \mathrm{~W}$ e $T_{D}$ variando de 30 a $120 \mathrm{~min}$ 82

Figura 39 - Resistência de folha e resistividade em função da $P_{R F}$ para amostras de ITO/Vidro obtidas com $P_{R F}$ variando de 100 a $200 \mathrm{~W}$

Figura 40 - Resistência de folha e resistividade em função da $P_{R F}$ para amostras de ITO/Si obtidas com $P_{R F}$ variando de 100 a $200 \mathrm{~W}$

Figura 41 - Porcentagem atômica das amostras de ITO/Si obtidas com $P_{R F}$ variando de 100 a $200 \mathrm{~W}$ 88

Figura 42 - Densidade e mobilidade de portadores das amostras de ITO/Vidro obtidas com $P_{R F}$ variando de 100 a $200 \mathrm{~W}$

Figura 43 - Difração de raios-X das amostras de ITO/Si obtidas com $P_{R F}=175 \mathrm{~W}$ e $200 \mathrm{~W}$ e ITO/Vidro obtida com $P_{R F}=200 \mathrm{~W}$

Figura 44 - Difração de raios-X das amostras de ITO/Si obtidas com $P_{R F}=100,125$ e $150 \mathrm{~W}$

Figura 45 - Curvas $I-V$ das amostras de ITO/Si obtidas com $P_{R F}$ variando de 100 a $200 \mathrm{~W}$ 
Figura 46 - Porcentagem de transmitância óptica $(\% T)$ em função do comprimento de onda $(\lambda)$ das amostras de ITO/vidro obtidas com $P_{R F}$ variando de 100 a $200 \mathrm{~W}$, assim como a transmitância média $\left(\% T_{a}\right)$ calculada para o espectro visível $(380<\lambda<750 \mathrm{~nm})$

Figura 47 - Gráfico do coeficiente de absorção $(\alpha)$ em função do comprimento de onda ( $\lambda$ ) para as amostras de ITO/vidro obtidas com $P_{R F}$ variando de 100 a $200 \mathrm{~W}$, destacando $\alpha$ para $550 \mathrm{~nm}$

Figura 48 - Gráfico do coeficiente de extinção $(\kappa)$ em função do comprimento de onda para as amostras de ITO/vidro obtidas com $P_{R F}$ variando de 100 a $200 \mathrm{~W}$, destacando $\kappa$ para $550 \mathrm{~nm}$

Figura 49 - Absorbância óptica das amostras de ITO/vidro obtidas $P_{R F}$ variando de 100 a $200 \mathrm{~W}$, com a indicação do band gap óptico obtido pela extrapolação da reta

Figura 50 - Figura de mérito das amostras de ITO/Vidro obtidas com $P_{R F}$ variando de 100 a $200 \mathrm{~W}$

Figura 51 - Porcentagem de transmitância óptica $(\% T)$ em função do comprimento de onda $(\lambda)$ da amostra de ITO/Lexan ${ }^{\circledR}$ obtida com $P_{R F}=75 \mathrm{~W}$ e $T_{D}=90 \mathrm{~min}$, assim como a transmitância média $\left(\% T_{a}\right)$ calculada para o espectro visível $(380<\lambda<750 \mathrm{~nm})$ 


\section{LISTA DE TABELAS}

Tabela 1 - Descrição da finalidade das soluções utilizadas para a limpeza dos substratos. .... 43

Tabela 2 - Parâmetros da primeira série de deposições, de ITO/Si com $P_{R F}$ de 25 a $100 \mathrm{~W}$

Tabela 3 - Parâmetros da segunda série de deposições, de ITO/Si e ITO/vidro com $P_{R F}=75 \mathrm{~W}$ e $T_{D}$ variando de 30 a 120 min e de ITO/Lexan ${ }^{\circledR} \operatorname{com} P_{R F}=75 \mathrm{~W}$ e $T_{D}=90 \mathrm{~min}$

Tabela 4 - Parâmetros da terceira série de deposições, de ITO/Si e ITO/vidro com $P_{R F}$ de 100 a $200 \mathrm{~W}$

Tabela 5 - Espessura, rugosidade média e rugosidade pico-vale das amostras de ITO/Si obtidas de 25 a $100 \mathrm{~W}$

Tabela 6 - Espessura e índice de refração obtidos por elipsometria das amostras de ITO/Si obtidas com $P_{R F}$ variando de 25 a $100 \mathrm{~W}$

Tabela 7 - Resistência de folha e resistividade das amostras de ITO/Si com $P_{R F}$ variando de 25 a $100 \mathrm{~W}$

Tabela 8 - Porcentagem atômica dos filmes de ITO/Si de obtidos com $P_{R F}$ variando de 25 a $100 \mathrm{~W}$.....

Tabela 9 - Espessura, erro quadrático da espessura, rugosidade média e rugosidade picovale das amostras de ITO/Si e ITO/Vidro obtidas com $P_{R F}=75 \mathrm{~W}$ e diferentes tempos de deposição.

Tabela 10 - Espessura e índice de refração obtidos por elipsometria das amostras de ITO/Si obtidas com $P_{R F}=75 \mathrm{~W}$

Tabela 11 - Resistência de folha e resistividade das amostras de ITO/Si e ITO/vidro obtidas $P_{R F}=75 \mathrm{~W}$.

Tabela 12 - Porcentagem atômica dos filmes de ITO/Si obtidos com $P_{R F}=75 \mathrm{~W}$ e $T_{D}$ variando de 30 a $120 \mathrm{~min}$.

Tabela 13 - Densidade e mobilidade de portadores das amostras de ITO/Vidro obtidas com $P_{R F}=75 \mathrm{~W}$ e $T_{D}$ variando de 30 a $120 \mathrm{~min}$

Tabela 14 - Figura de mérito das amostras de ITO/vidro obtidas com $P_{R F}=75 \mathrm{~W}$ e $T_{D}$ variando de 30 a 120 min, juntamente com os parâmetro utilizados no cálculo 
Tabela 15 - Espessura, rugosidade média e rugosidade pico-vale das amostras de ITO/Si e ITO/Vidro obtidas com $P_{R F}$ variando de 100 a $200 \mathrm{~W}$

Tabela 16 - Espessura e índice de refração obtidos por elipsometria das amostras de ITO/Si obtidas com $P_{R F}$ variando de 100 a $200 \mathrm{~W}$

Tabela 17 - Resistência de folha e resistividade das amostras de ITO/Vidro e ITO/Si obtidas com $P_{R F}$ variando de 100 a $200 \mathrm{~W}$

Tabela 18 - Porcentagem atômica das amostras de ITO/Si obtidas com $P_{R F}$ variando de 100 a $200 \mathrm{~W}$

Tabela 19 - Densidade e mobilidade de portadores das amostras de ITO/Vidro obtidas com $P_{R F}$ variando de 100 a $200 \mathrm{~W}$ 88

Tabela 20 - Figura de mérito das amostras de ITO/Vidro obtidas com $P_{R F}$ variando de 100 a $200 \mathrm{~W}$

Tabela 21 - Espessura, rugosidade média e rugosidade pico-vale das amostras de ITO/Lexan ${ }^{\circledR}$ e ITO/vidro obtidas com $P_{R F}=75 \mathrm{~W}$ e $T_{D}=90 \mathrm{~min}$

Tabela 22 - Resistência de folha e resistividade das amostras de ITO/Lexan ${ }^{\circledR}$ e ITO/vidro obtidas com $P_{R F}=75 \mathrm{~W}$ e $T_{D}=90 \mathrm{~min}$ 98

Tabela 23 - Figura de mérito das amostras de ITO/Lexan ${ }^{\circledR}$ e ITO/vidro obtidas com $P_{R F}=75 \mathrm{~W}$ e $T_{D}=90 \mathrm{~min}$, juntamente com os parâmetro utilizados no cálculo 99 


\section{LISTA DE ABREVIATURAS E SIGLAS}

\begin{tabular}{ll} 
ATO & Antimony Tin Oxide \\
AZO & Aluminum Zinc Oxide \\
CRT & Cathode Ray Tube \\
DC & Direct Current \\
FTO & Fluorine Tin Oxide \\
GZO & Gallium Zinc Oxide \\
ITO & Indium Tin Oxide \\
IZO & Indium Zinc Oxide \\
LCD & Liquid Crystal Display \\
LVDT & Linear Variable Differential Transformer \\
OLED & Organic Light Emitting Diode \\
P3HT & Poly(3-hexylthiophene) \\
PCBM & Phenyl C61 Butyric Acid Methyl Ester \\
PEDOT & Poly(3,4-ethylenedioxythiophene) \\
PET & Poly(ethylene terephthalate) \\
PLD & Pulsed Laser Deposition \\
p-Si & Silício dopado tipo p \\
PSS & Poly(styrenesulfonate) \\
RF & Radio Frequency \\
TCO & Transparent Conductive Oxide \\
\hline
\end{tabular}




\section{LISTA DE SÍMBOLOS}

\begin{tabular}{|c|c|}
\hline${ }^{\circ} \mathrm{C}$ & Graus Celcius \\
\hline$\Omega$ & Ohm \\
\hline $\mathrm{m}$ & Metro \\
\hline$\sigma$ & Condutividade elétrica \\
\hline$N$ & Densidade de portadores livres \\
\hline $\mathrm{e}$ & Carga do elétron \\
\hline$\mu$ & Mobilidade de portadores livres \\
\hline S & Siemen \\
\hline$\rho$ & Resistividade \\
\hline$R_{S}$ & Resistência de folha \\
\hline$R_{\Omega}$ & Resistência elétrica \\
\hline$L$ & Comprimento da estrutura tridimensional \\
\hline$A_{s t}$ & Seção transversal da estrutura tridimensional \\
\hline$W_{0}$ & Largura da estrutura tridimensional \\
\hline$t$ & Espessura do filme \\
\hline sq & Quadrado \\
\hline$\square$ & Quadrado \\
\hline$\vec{v}$ & Velocidade de arraste dos portadores \\
\hline$\vec{E}$ & Campo elétrico \\
\hline $\mathrm{V}$ & Volt \\
\hline s & Segundo \\
\hline$\alpha$ & Coeficiente de absorção \\
\hline$T$ & Transmitância óptica \\
\hline$\lambda$ & Comprimento de onda \\
\hline$\kappa$ & Coeficiente de extinção \\
\hline$n$ & Índice de refração real \\
\hline$v$ & Velocidade da luz em um determinado meio \\
\hline$c$ & Velocidade da luz no vácuo \\
\hline$n_{f}$ & Índice de refração do filme \\
\hline$n_{s}$ & Índice de refração do substrato \\
\hline
\end{tabular}




\begin{tabular}{|c|c|}
\hline n' & Índice de refração imaginário \\
\hline$R$ & Radiação refletida \\
\hline$I$ & Intensidade de luz transmitida \\
\hline$I_{0}$ & Intensidade de luz incidente \\
\hline$\% T$ & Porcentagem de transmitância óptica \\
\hline$A$ & Absorbância óptica \\
\hline$E_{\text {opt }}$ & Band gap óptico \\
\hline$E_{g}$ & Band gap intrínseco \\
\hline$m_{r}^{*}$ & Massa efetiva reduzida \\
\hline$h$ & Constante de Planck \\
\hline $\mathrm{eV}$ & Elétron-volt \\
\hline$v$ & Frequência de oscilação do fóton incidente \\
\hline$R_{A}$ & Rugosidade média \\
\hline$R_{R M S}$ & Rugosidade RMS \\
\hline$R_{P V}$ & Rugosidade pico-vale \\
\hline$y_{i}$ & Ordenada de afastamento vertical \\
\hline$z$ & número de pontos considerados \\
\hline$y_{\operatorname{máx}}$ & Pico mais alto \\
\hline$y_{\min }$ & Vale mais baixo \\
\hline$\theta$ & Ângulo \\
\hline$\Phi$ & Figura de mérito \\
\hline$T_{a}$ & Transmitância média na faixa do espectro visível \\
\hline$V_{D C}$ & Potencial negativo DC autoinduzido \\
\hline$"$ & Polegada \\
\hline$P_{R F}$ & Potência de rádio frequência \\
\hline$T_{F}^{o}$ & Temperatura final do substrato \\
\hline $\mathrm{W}$ & Watt \\
\hline$T_{D}$ & Tempo de deposição \\
\hline$D_{P}$ & Densidade de potência \\
\hline$d_{T}$ & Diâmetro do alvo \\
\hline (®) & Marca registrada \\
\hline$B$ & Espaçamento entre pontas internas \\
\hline$F^{*}$ & Fator de correção geométrico para resistência de folha \\
\hline $\mathrm{N}$ & Newton \\
\hline
\end{tabular}




\begin{tabular}{|c|c|}
\hline$\AA$ & Ângstron \\
\hline$I-V$ & Corrente-tensão \\
\hline$\vec{E}_{\text {Hall }}$ & Campo elétrico produzido por efeito Hall \\
\hline$\vec{j}$ & Densidade de corrente \\
\hline$\vec{B}$ & Densidade de fluxo magnético \\
\hline$\vec{R}_{\text {Hall }}$ & Coeficiente Hall \\
\hline A & Ampère \\
\hline $\mathrm{T}$ & Tesla \\
\hline$\theta_{B}$ & Difração de Bragg \\
\hline$\theta_{I}$ & Ângulo de incidência \\
\hline$\theta_{R}$ & Ângulo de espalhamento \\
\hline$d$ & Distância interplanar dos planos cristalográficos \\
\hline$n_{r}$ & Ordem de reflexão \\
\hline$D R_{E X P}$ & Taxa de deposição experimental \\
\hline $\min$ & Minuto \\
\hline$D R$ & Taxa de deposição \\
\hline o & Grau \\
\hline$\% \Delta t$ & Erro quadrático relativo da espessura \\
\hline$\Delta t$ & Erro quadrático absoluto da espessura \\
\hline$\% \Delta R_{S}$ & Erro quadrático relativo da resistência de folha \\
\hline$\% T_{a}$ & Porcentagem de transmitância média no espectro visível \\
\hline$E$ & Energia \\
\hline
\end{tabular}




\section{SUMÁRIO}

1. INTRODUÇÃ

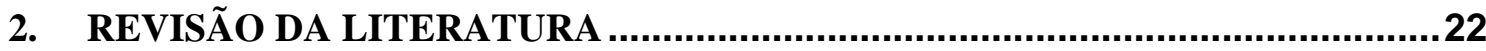

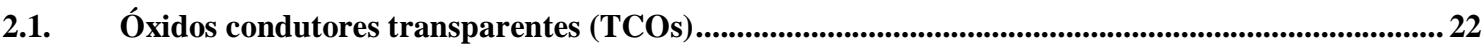

2.2. Óxido de índio dopando com estanho (ITO) ..............................................................................................23

2.3. ITO em relação a outros materiais condutores transparentes ........................................................... 24

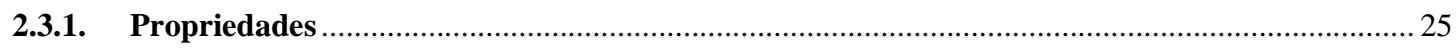

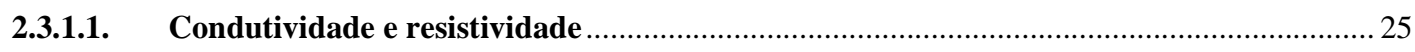

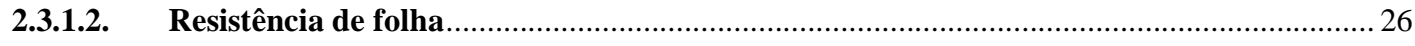

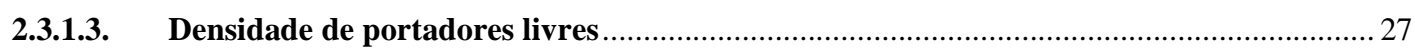

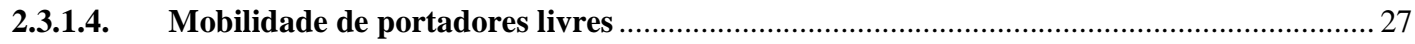

2.3.1.5. Coeficiente de absorção e coeficiente de extinção ………………………………………..... 28

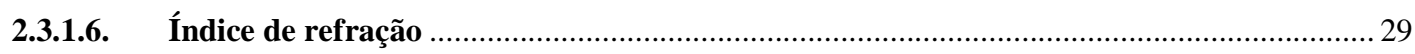

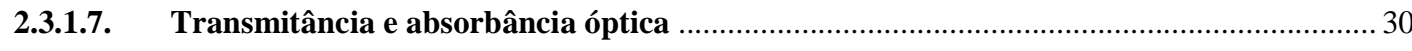

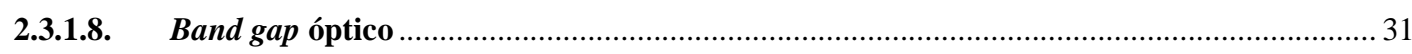

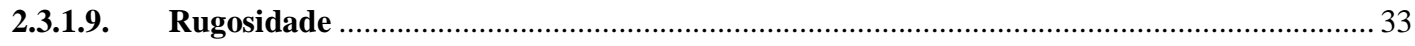

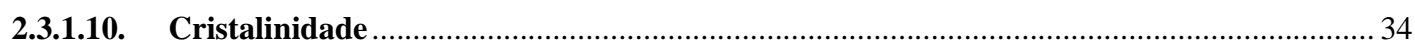

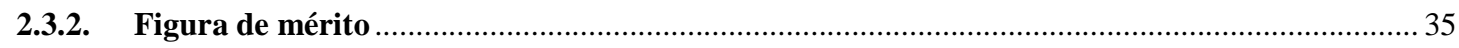

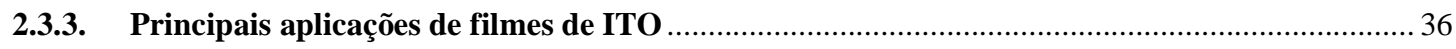

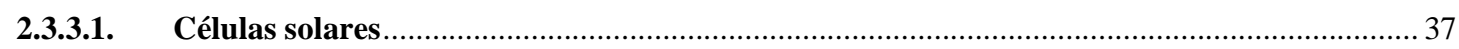

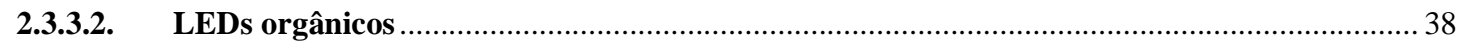

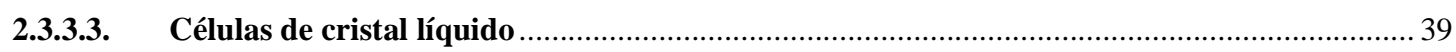

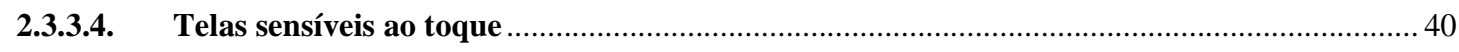

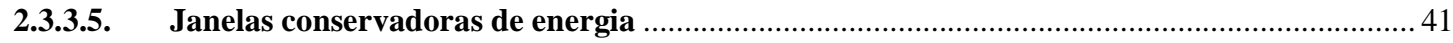

3. MATERIAIS E MÉTODOS ................................................................. 42

3.1. PROCESSOS DE FABRICAÇÃO ........................................................... 42

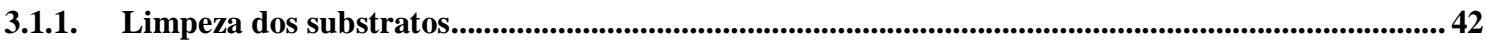

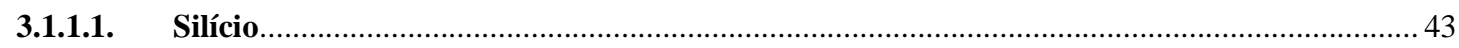

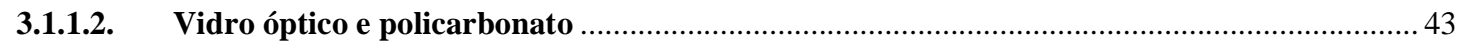

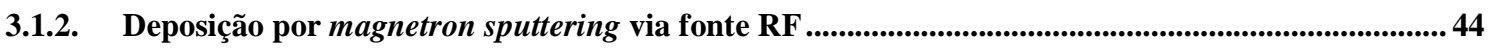


3.1.2.1. Deposição de ITO sobre silício variando potência RF de 25 a $100 \mathrm{~W}$.

3.1.2.2. Deposição de ITO sobre Vidro, ITO sobre silício e ITO sobre policarbonato variando o

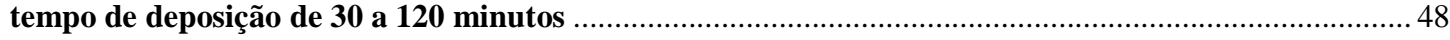

3.1.2.3. Deposição de ITO sobe vidro e ITO sobre silício variando a potência RF de 100 a 200 W .. 49

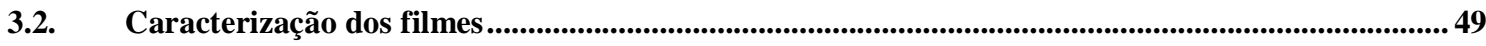

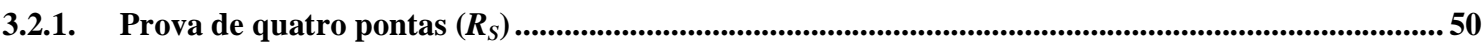

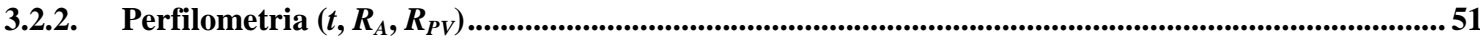

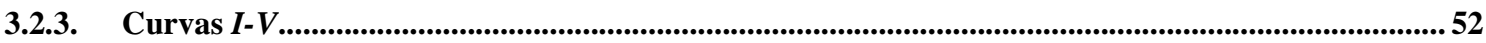

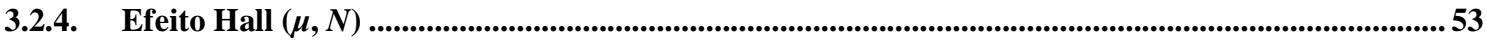

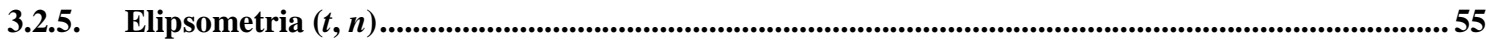

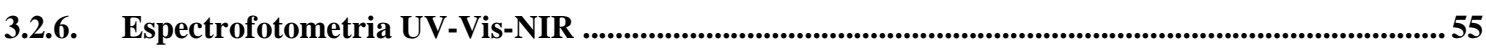

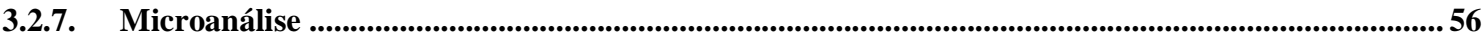

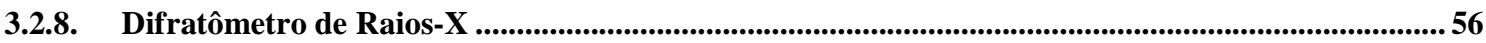

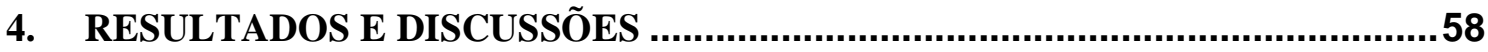

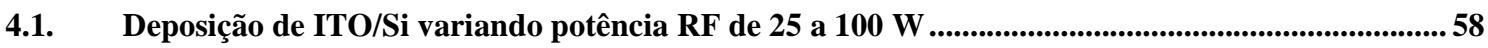

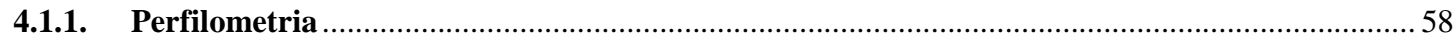

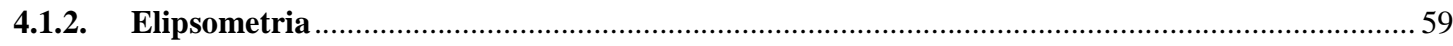

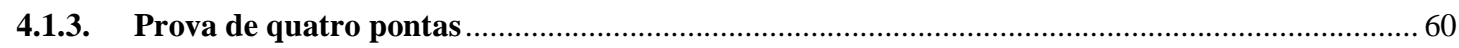

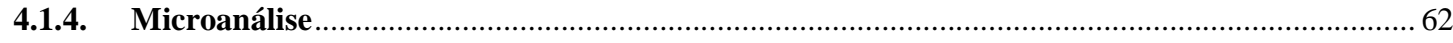

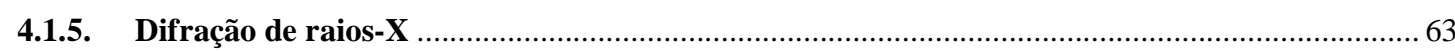

4.2. Deposição de ITO sobre vidro e ITO sobre silício a com potência RF = 75 W variando o tempo de

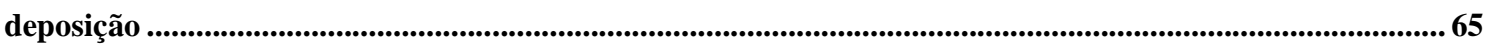

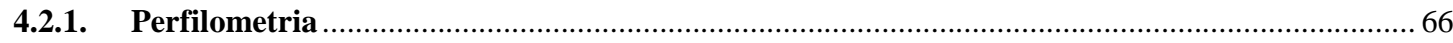

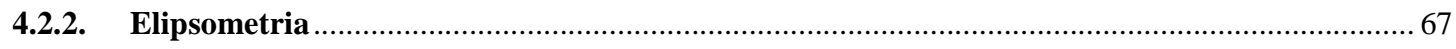

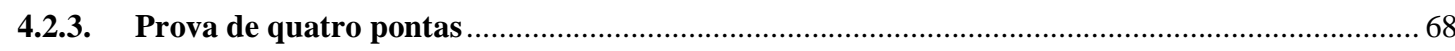

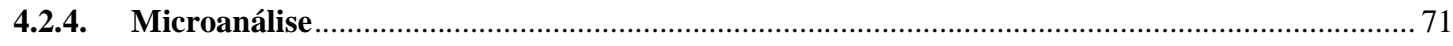

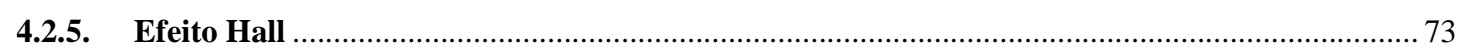

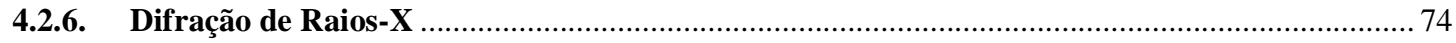

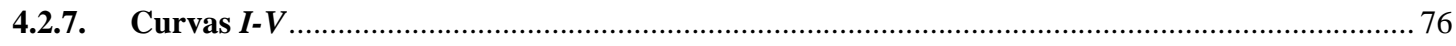

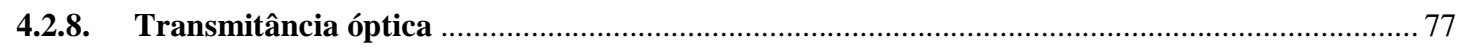

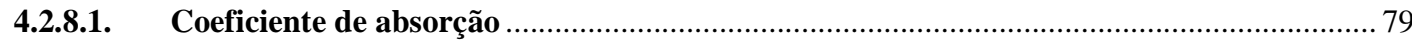

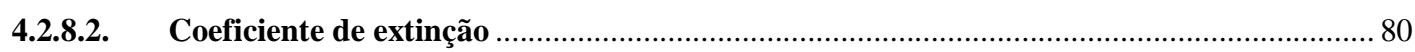




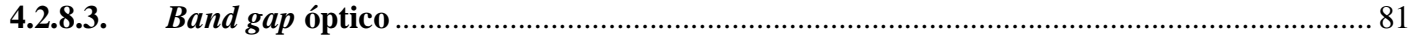

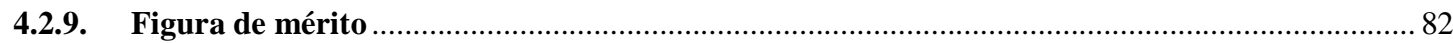

4.3. Deposição de ITO sobre vidro e ITO sobre silício com potência RF variando de 100 a $200 \mathrm{~W}$.....83

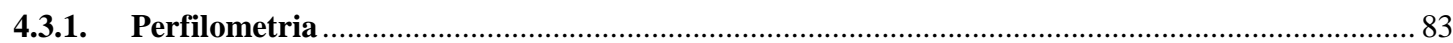

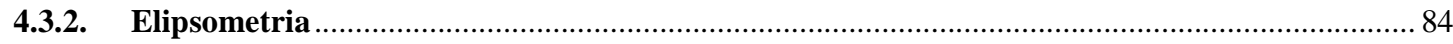

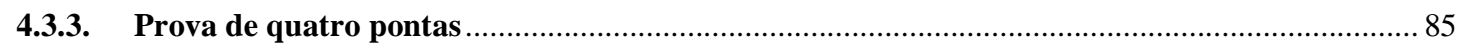

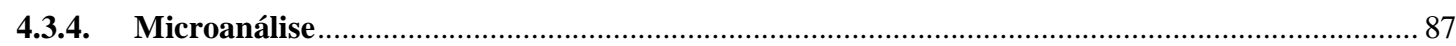

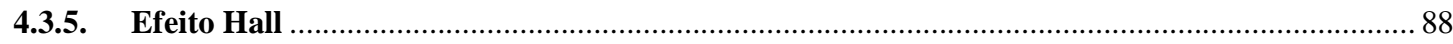

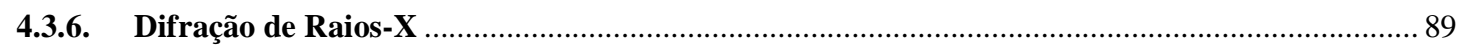

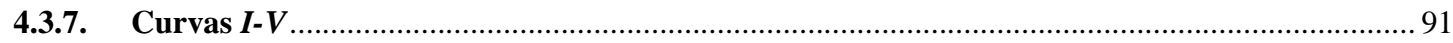

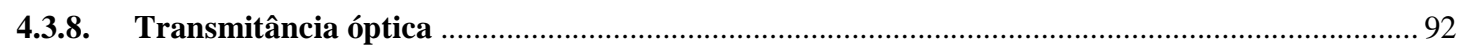

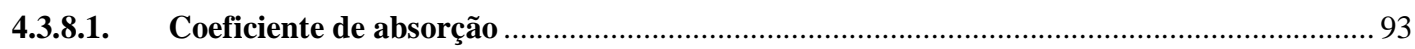

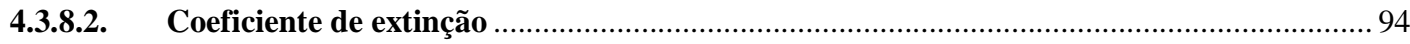

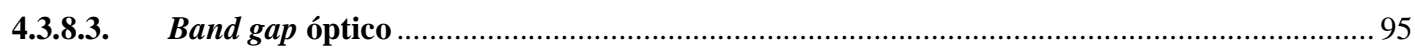

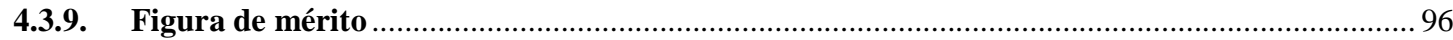

4.4. Deposição de ITO sobre policarbonato $\left(\right.$ Lexan $\left.{ }^{\circledR}\right)$ com potência $R F=75$ W ................................... 97

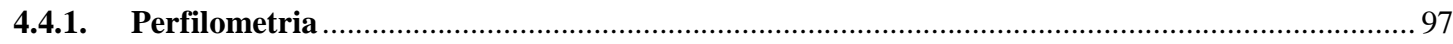

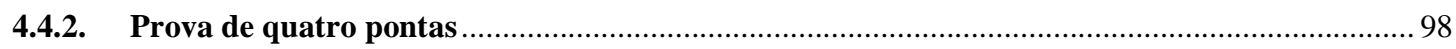

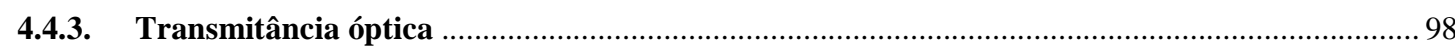

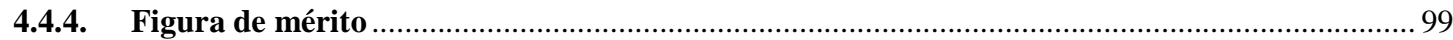

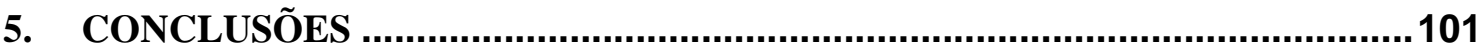

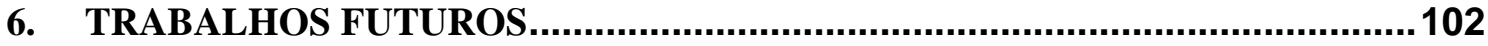

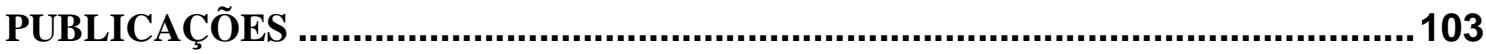

REFERÊNCIAS BIBLIOGRÁFICAS ........................................................ 104 


\section{INTRODUÇÃO}

O óxido de índio dopado com estanho (ITO, do termo em inglês Indium-Tin Oxide) é um material semicondutor degenerado de alto band gap, transparente à faixa visível do espectro solar, que pertence a uma classe de materiais denominada óxidos condutores transparentes (TCOs, de Transparent Conductive Oxides).

Estes óxidos transparentes têm a propriedade de refletir radiação eletromagnética na região do infravermelho e de possuir baixa resistividade elétrica (geralmente da ordem de $10^{-4} \Omega . \mathrm{cm}$ ), o que os torna bons condutores elétricos. Devido às suas propriedades intrínsecas, filmes de TCOs são comumente utilizados como eletrodos transparentes em diversos dispositivos optoeletrônicos, como diodos emissores de luz orgânicos (OLEDs) ${ }^{1}$, células solares $^{2}$, janelas inteligentes (smart windows) ${ }^{3}$, janelas refletoras de calor ${ }^{4}$, etc.

Dentre os TCOs, o ITO é ainda o mais usado e conhecido, sendo utilizado em ambiente industrial tanto para recobrimento de vidros quanto para construção de dispositivos eletrônicos. Suas propriedades foram amplamente estudadas no mundo todo, sendo o ITO o TCO mais utilizado no meio acadêmico. No Brasil, no entanto, ainda há poucos grupos de pesquisa dedicados à obtenção de filmes finos de ITO, apesar de haver muitos pesquisadores que utilizam lâminas comerciais para a fabricação dos dispositivos mencionados anteriormente.

Camadas de ITO podem ser produzidas através de diversas técnicas de deposição, como magnetron sputtering de corrente contínua (DC) ${ }^{5}$ e rádio frequência (RF) ${ }^{6}$, spray pirólise ${ }^{7}$ e laser pulsado (PLD) ${ }^{8}$. Dentre estes métodos, o magnetron sputtering é uma das técnicas mais atrativas, devido à boa reprodutibilidade dos filmes e à possibilidade de deposição uniforme sobre grandes áreas. Os principais fatores que influenciam na deposição de filmes de ITO por magnetron sputtering são a potência elétrica, a temperatura do substrato e a pressão parcial de gás de processo ${ }^{9}$. A maioria dos filmes é depositada por meio de sputtering reativo, caracterizado por uma pequena porcentagem de gás reativo (comumente oxigênio ou hidrogênio) adicionada ao gás inerte (argônio) no processo de deposição. Com estes parâmetros otimizados, é possível conseguir camadas de altíssima transmitância óptica (> 90\%) e baixa resistividade (da ordem de $10^{-4}$ a $10^{-5} \Omega . \mathrm{cm}$ ). No entanto, em deposições que utilizam alvos cerâmicos, é possível utilizar apenas argônio como gás de processo ${ }^{6,10}$.

Processos de magnetron sputtering são tipicamente realizados com substratos aquecidos a temperaturas maiores do que $200{ }^{\circ} \mathrm{C}$, já que esta condição permite melhores 
resultados em termos de transparência e condutividade. No entanto, certas aplicações, como células solares orgânicas e dispositivos sobre substratos poliméricos ${ }^{10}$, requerem deposições em baixas temperaturas $\left(<100^{\circ} \mathrm{C}\right)$, pois altas temperaturas podem danificar o dispositivo ou o próprio substrato ${ }^{6}$. Por isso, o aprimoramento de técnicas de deposição sem aquecimento intencional do substrato se torna necessário para atender esta demanda.

O objetivo deste trabalho é desenvolver técnicas de deposição de ITO, em baixas temperaturas, pelo método de RF magnetron sputtering. Parâmetros como a densidade de potência RF, taxa e tempo de deposição e tipo de substrato foram variados, a fim de observar os parâmetros ideais de obtenção dos filmes com suas melhores propriedades elétricas e ópticas. A qualidade das lâminas obtidas foi analisada através da caracterização física, química, óptica, elétrica e estrutural das mesmas. Foram desenvolvidos processos de deposições de filmes finos de ITO sobre substratos de silício tipo p, vidro óptico e policarbonato, através de parâmetros controlados.

Este trabalho está dividido em 5 capítulos. No capítulo 2, é apresentada a revisão da literatura pertinente ao trabalho, com uma introdução a condutores transparentes, conceitos básicos sobre ITO, técnicas de deposição e principais aplicações. No capítulo 3 é descrito todo o procedimento experimental deste trabalho, desde a preparação das amostras até os métodos de utilização dos equipamentos de análise. No capítulo 4 são apresentados os resultados obtidos através das técnicas de caracterização visando analisar a influência dos parâmetros de deposição nas características dos filmes. No capítulo 5 são apresentadas as principais conclusões do trabalho. Por fim, no capítulo 6 são sugeridos trabalhos futuros capazes de aprimorar e complementar este estudo. 


\section{REVISÃO DA LITERATURA}

Neste capítulo, é apresentada a revisão bibliográfica sobre filmes de óxido de índio dopado com estanho, destacando suas principais propriedades, além de exemplos das principais aplicações deste tipo de filme. Também são abordados outros tipos de TCOs e o que está sendo feito hoje na pesquisa e na indústria.

\section{1. Óxidos condutores transparentes (TCOs)}

Óxidos condutores transparentes, como o próprio nome sugere, são óxidos que, quando depositados na forma de filmes finos, tornam-se transparentes à faixa visível do espectro solar e têm a capacidade de conduzir corrente elétrica, ao contrário da maioria dos materiais transparentes, que se comportam como isolantes elétricos.

TCOs são semicondutores degenerados, ou seja, apresentam na camada de condução uma quantidade de elétrons próxima à de um metal devido à alta concentração de portadores livres do material.

O primeiro documento sobre a obtenção de um TCO foi publicado em 1907, onde Badeker ${ }^{11}$ relatou que um filme de cádmio metálico obtido por sputtering sofreu oxidação térmica devido ao recozimento em ambiente atmosférico. O filme tornou-se transparente ao ser oxidado, mas manteve-se eletricamente condutor. Desde então, estes filmes vêm sendo estudados, e a lista de materiais com características semelhantes aumentou consideravelmente, assim como a qualidade dos filmes obtidos. No entanto, o óxido de cádmio $(\mathrm{CdO})$ não é extensamente utilizado devido à sua alta toxicidade e potencialidade cancerígena ${ }^{12}$, apesar de ainda ser estudado ${ }^{13}$.

Dentre os TCOs mais utilizados, tanto na área acadêmica quanto industrialmente, estão o óxido de zinco $(\mathrm{ZnO})$ dopado, óxido de estanho $\left(\mathrm{SnO}_{2}\right)$ dopado e o óxido de índio $\left(\mathrm{In}_{2} \mathrm{O}_{3}\right)$ dopado.

O óxido de zinco é normalmente dopado com alumínio ( $\mathrm{ZnO}: \mathrm{Al}$, conhecido como

AZO) ${ }^{14}$, gálio (ZnO:Ga, ou GZO) ${ }^{15}$ ou índio (ZnO:In, ou IZO) ${ }^{16}$. O óxido de estanho é comumente encontrado com dopagem por flúor $\left(\mathrm{SnO}_{2}: \mathrm{F} \text {, chamado de FTO }\right)^{17}$ ou antimônio 
$\left(\mathrm{SnO}_{2}: \mathrm{Sb} \text {, ou ATO }\right)^{18}$. O óxido de índio, normalmente dopado com estanho $\left(\operatorname{In}_{2} \mathrm{O}_{3}: \mathrm{Sn}\right.$, ou ITO), será discutido na seção 2.2. Todos estes materiais apresentam condutividade tipo n.

Portanto, atualmente é de extremo interesse que se desenvolvam outros tipos de TCOs que apresentem condutividade tipo p, já que isto possibilita a formação de junções p-n transparentes. Alguns estudos foram feitos baseados na dopagem tipo p dos óxidos de índio, zinco ${ }^{19}$ e estanho ${ }^{20}$, mas sem grandes sucessos devido à condutividade tipo $\mathrm{n}$ intrínseca destes materiais. Recentemente, alguns estudos promissores foram feitos com outros tipos de

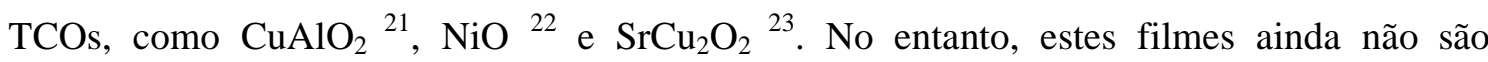
produzidos com qualidade óptica e elétrica comparável à dos TCOs tipo n.

\section{2. Óxido de índio dopado com estanho (ITO)}

O ITO $\left(\mathrm{In}_{2} \mathrm{O}_{3}: \mathrm{Sn}\right)$ é um semicondutor degenerado tipo $\mathrm{n}$ transparente ao espectro visível. A camada de filme depositado deve conter alta densidade de portadores para conduzir, mas uma população excessiva de portadores produz absorção óptica. Portanto, em geral, maiores condutividades elétricas são obtidas com menor transmissão na região visível ${ }^{24}$.

O óxido de índio puro (sem dopagem por estanho) é um material que exibe comportamento isolante na forma estequiométrica $\operatorname{In}_{2} \mathrm{O}_{3}$, mostrada na Figura 1. No entanto, quando preparado com deficiência de oxigênio, pode alcançar um alto nível de dopagem tipo $\mathrm{n}$ devido aos defeitos intrínsecos, como vacâncias de oxigênio ${ }^{25}$. Devido a esta propriedade, o óxido de índio não-estequiométrico é um material intrinsecamente tipo n. No caso do ITO, quando o óxido de índio é também dopado por estanho, este atua como uma impureza doadora, por se tratar de um elemento tetravalente (estanho) dopando um elemento trivalente (índio).

Portanto, dois mecanismos de geração de elétrons condutores são possíveis em filmes de ITO. O primeiro se dá através das lacunas de oxigênio na estrutura do óxido de índio, que fornecem no máximo 2 elétrons livres ${ }^{26}$, formando estruturas do tipo $\operatorname{In}_{2} \mathrm{O}_{3-\mathrm{x}}$. O segundo acontece por meio da substituição randômica de íons $\operatorname{In}^{3+}$ por íons $\mathrm{Sn}^{4+}$, provendo um elétron à camada de condução ${ }^{27}$, formando moléculas $\operatorname{In}_{2-\mathrm{x}} \mathrm{Sn}_{\mathrm{x}} \mathrm{O}_{3}$. Portanto, filmes de ITO devem ser estruturas não-estequiométricas, o que permite que os filmes sejam bons condutores. 


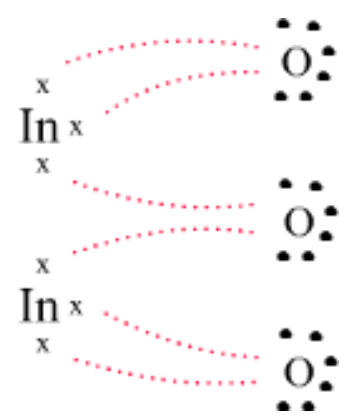

Figura 1 - Ligação iônica que representa a forma estequiométrica do óxido de índio $\left(\operatorname{In}_{2} \mathrm{O}_{3}\right)$, mostrando os elétrons da camada de valência do índio ( 3 elétrons) e do oxigênio ( 6 elétrons).

Há um limite máximo de estanho que pode ser adicionado ao ITO, já que o estanho não só provê elétrons, mas também reduz a mobilidade dos mesmos. O nível adequado de dopagem por estanho é, em média, de 5 a $10 \%{ }^{28}$. O limite de vacâncias de oxigênio também deve ser controlado, pois a deficiência de oxigênio no filme, além de prover elétrons livres, diminui a transmitância óptica do mesmo.

\subsection{ITO em relação a outros materiais condutores transparentes}

Dentre todos os TCOs conhecidos, o ITO é o mais estudado e utilizado. A razão pela qual ele é tão popular deve-se principalmente à ótima combinação de transparência e condutividade, que ainda não foi superada por outros materiais.

No entanto, sua escolha não é feita confortavelmente, pois o ITO é um material relativamente caro em relação aos outros TCOs disponíveis ${ }^{29}$. Isto é devido à escassez do índio, principal elemento de sua composição química. A principal demanda de índio se deve ao seu uso como TCO, sendo que, atualmente, cerca de $84 \%$ do consumo mundial de índio é destinado à produção industrial de LCDs ${ }^{30}$.

Estuda-se hoje, portanto, materiais mais abundantes e baratos capazes de substituir o ITO, sem que haja comprometimento no desempenho dos dispositivos. Estes materiais incluem outros óxidos transparentes condutores (como os citados na seção 2.1), nanotubos de carbono ${ }^{31}$ (que são promissores para aplicações como células solares por possuírem a propriedade de transmitir radiação eletromagnética também na faixa do infravermelho, onde o ITO normalmente reflete) ${ }^{32}$ e polímeros condutores como PEDOT:PSS (que apresentam 
propriedades mecânicas favoráveis para serem utilizados em dispositivos flexíveis, apesar da ainda baixa condutividade) ${ }^{33}$.

\subsubsection{Propriedades}

São discutidas neste subitem as principais propriedades relevantes às características dos filmes de ITO, destacando a definição e a importância de cada uma, assim como resultados de trabalhos anteriores obtidos na literatura.

\subsubsection{Condutividade e resistividade}

Condutividade elétrica $(\sigma)$ é definida como a medida da habilidade de um material de conduzir corrente elétrica, definida de modo a não depender da geometria ${ }^{34}$. De acordo com a equação de Boltzmann, a condutividade de um material semicondutor é dada pela eq.(1).

$$
\sigma=N e \mu\left[\frac{S}{c m}\right]
$$

onde $N$ representa a densidade de portadores livres, $\mu$ a mobilidade dos portadores e $e$ a carga do elétron ${ }^{35}$. Portanto, a condutividade é diretamente proporcional à densidade e à mobilidade de portadores.

A resistividade $(\rho)$, parâmetro comumente encontrado na literatura para designar propriedades elétricas dos filmes, é expressa como o inverso da condutividade, de acordo com a eq.(2). $\rho$ define a capacidade de um material de se opor à passagem de corrente elétrica.

$$
\rho=\frac{1}{\sigma}[\Omega . c m]
$$


Para aplicações de filmes de ITO como eletrodos transparentes, é desejável ter resistividade da ordem de pelo menos $10^{-3} \Omega . \mathrm{cm}$, mas filmes com resistividade da ordem de até $10^{-5} \Omega . c m$ já foram reportados na literatura ${ }^{36}$.

Altos valores de condutividade implicam em baixa emissão térmica, o que é favorável a aplicações como isolante térmico de janelas e estruturas similares.

O nível de dopagem por estanho e a quantidade de oxigênio na composição do filme afetam notavelmente a condutância. Em geral, quanto mais oxigênio houver, mais resistivo o filme se torna, de acordo com o que foi explicado na seção 2.2.

\subsubsection{Resistência de folha}

A resistência de folha $\left(R_{S}\right)$ é um parâmetro de caracterização elétrica que indica o valor da resistência do filme por superfície de área quadrada qualquer.

Considerando uma estrutura tridimensional, a resistência elétrica $\left(R_{\Omega}\right)$ de dada porção do material é dada pela eq.(3), onde $L$ é o comprimento e $A_{s t}$ é a área de seção transversal.

$$
R_{\Omega}=\rho \frac{L}{A_{s t}}[\Omega]
$$

$A_{s t}$ pode ser dividida em largura $\left(W_{0}\right)$ e espessura do filme $(t)$, como mostra a eq.(4).

$$
A_{s t}=W_{0} t\left[\mathrm{~cm}^{2}\right]
$$

Substituindo (4) em (3), e considerando que $L=W_{0}$ para termos um quadrado, temos a relação descrita na eq.(5).

$$
R_{\Omega}=R_{S}=\frac{\rho}{t}\left[\frac{\Omega}{s q}\right]
$$


Portanto, $R_{S}$ é expressa como a razão entre a resistividade do material e a espessura do filme. Como para qualquer superfície quadrada $R_{\Omega}=R s$, a unidade de $R s$ é $\Omega$. Para evitar confusão entre $R_{\Omega}$ e $R_{S}$, a resistência de folha é geralmente especificada em $\Omega /$ sq (ou $\Omega / \square$ ).

Em geral, o valor de $R_{S}$ diminui conforme a espessura do filme aumenta, pois a resistividade do material tende a se manter constante, embora também seja influenciada. No entanto, a eq.(5) aponta a necessidade de baixa resistividade para atingir baixo valor de $R s$, a não ser que $t$ tenha um valor muito alto. Tal camada, na maioria dos casos, absorveria muita luz, diminuindo muito a transmitância óptica ${ }^{37}$.

Em certas aplicações, como em eletrodos para diodos emissores de luz (LEDs), é desejável que os filmes de ITO tenham um baixo valor de $R_{S}$, pois isto pode possibilitar uma melhor coleta dos portadores ${ }^{38}$.

Os valores de $R_{S}$ encontrados na literatura variam consideravelmente, de 5 a $200 \Omega / \square$.

\subsubsection{Densidade de portadores livres}

A densidade de portadores $(N)$ expressa o número de partículas livres portadoras de carga elétrica por unidade de volume. No caso de semicondutores tipo n, como o ITO, os portadores em questão são os elétrons.

Altos valores de $N$ favorecem o aumento da condutividade do material, de acordo com a eq.(1). No entanto, a transmitância óptica é geralmente prejudicada, pois densidade alta de portadores sugere que há pouco oxigênio na composição do filme, já que as vacâncias de oxigênio contribuem para a geração de portadores na banda de condução.

Para filmes de ITO, valores da ordem de $10^{20}$ a $10^{21} \mathrm{~cm}^{-3}$ são comumente encontrados

na literatura ${ }^{39}$. Estes altos valores permitem que os filmes de ITO sejam utilizados como condutores em aplicações que exijam eletrodos transparentes.

\subsubsection{Mobilidade de portadores livres}

A mobilidade de portadores livres $(\mu)$ indica a facilidade com que os portadores se movimentam, e é definida como a constante de proporcionalidade entre a velocidade de 
arraste dos portadores $(\vec{v})$ e o campo elétrico $(\vec{E})$ que os coloca em movimento, de acordo com a relação mostrada na eq. $(6)^{40}$.

$$
\mu=\frac{\vec{v}}{\vec{E}}\left[\frac{\mathrm{cm}^{2}}{V . s}\right]
$$

Portanto, altos valores de $\mu$ favorecem o aumento da condutividade do material, com mostra a eq.(1). A densidade de portadores em filmes de ITO é normalmente alta, mas a mobilidade $\left(5-70 \mathrm{~cm}^{2} / \mathrm{V}\right.$.s) é bem menor do que a de semicondutores convencionais, como o silício. Por este motivo, a condutividade dos filmes ainda é significantemente menor do que a condutividade de metais típicos.

A razão pela qual a mobilidade destes filmes é baixa é a presença, em grande concentração, de defeitos estruturais, como vacâncias, átomos intersticiais e contornos de grão. Estes defeitos atuam como centros de espalhamento e aprisionamento de elétrons ${ }^{41}$. Portanto, a mobilidade de portadores é uma das propriedades elétricas mais delicadas de serem controladas e previstas, devido à grande influência sofrida por diversos fatores que caracterizam o filme.

Em geral, há um aumento no valor de $\mu$ com uma melhora na cristalinidade dos filmes devido à redução do espalhamento devido a defeitos. No entanto, $\mu$ pode tender a diminuir com o aumento de $N$, pois uma grande densidade de portadores geralmente implica em alta concentração de vacâncias no filme.

\subsubsection{Coeficiente de absorção e coeficiente de extinção}

O coeficiente de absorção $(\alpha)$ descreve a extensão a que a intensidade de um feixe de energia é reduzida ao passar por um material ${ }^{34} \mathrm{em}$ dado comprimento de onda. Portanto, para filmes transparentes, $\alpha$ deve ser relativamente baixo no espectro visível.

Conhecendo-se a espessura do filme $(t), \alpha$ pode ser encontrado através da análise de transmitância óptica $(T)$, de acordo com a eq.(7).

$$
\alpha(\lambda)=-\frac{\ln T(\lambda)}{t}\left[\mathrm{~cm}^{-1}\right]
$$


De acordo com trabalhos anteriores, filmes de ITO apresentam valores de $\alpha$ da ordem de $10^{3} \mathrm{~cm}^{-1}$ para comprimentos de onda próximos de $550 \mathrm{~nm}^{42}$ (ponto do espectro de luz visível de maior sensibilidade do olho humano).

O coeficiente de extinção $(\kappa)$ é proporcional ao coeficiente de absorção $(\alpha)$ em dado comprimento de onda $(\lambda)$, de acordo com a eq.(8).

$$
\kappa(\lambda)=\frac{\alpha(\lambda) \lambda}{4 \pi}
$$

Para filmes não absorventes, $\kappa$ deve ser próximo de zero (da ordem de $10^{-2}$ ) na faixa do espectro visível.

\subsubsection{6. Índice de refração}

Quando a luz passa de um meio material para outro meio, duas coisas podem ocorrer. A primeira é a mudança da velocidade da luz. A segunda é a mudança da direção de propagação, quando a incidência não é oblíqua. A passagem da luz de um meio para outro se chama refração.

Índice de refração $(n)$ é uma relação entre a velocidade da luz $(v)$ em um determinado meio e a velocidade da luz no vácuo $(c)^{43}$, como mostra a eq.(9).

$$
n=\frac{c}{v}
$$

Para filmes de ITO, o índice de refração apresenta valores em torno de 2, independente do comprimento de onda (dentro do espectro visível) da luz aplicada ${ }^{44,45}$. Esta propriedade permite que filmes de ITO sejam usados como camadas antirrefletoras sobre substratos de silício, pois a relação entre os índices de refração do substrato e do filme para tal aplicação é dada pela eq.(10). 


$$
n_{f}=\sqrt{n_{s}}
$$

onde $n_{f}$ é o índice de refração do filme e $n_{s}$ é o índice de refração do substrato. Para o silício, $n_{s} \approx 4^{45}$.

Para filmes com alto coeficiente de absorção, o índice de refração deve ser denotado como um número imaginário $n$ ', dado pela eq.(11), onde $\kappa$ é o coeficiente de extinção do material $^{46}$.

$$
n^{\prime}=n(1-\kappa i)
$$

Se o valor de $\kappa$ for desprezível em relação ao valor de $n$, geralmente ele é desconsiderado. Como filmes de ITO devem possuir pouca absorção no espectro visível, seu índice de refração é geralmente expresso apenas pela parte real.

\subsubsection{Transmitância e absorbância óptica}

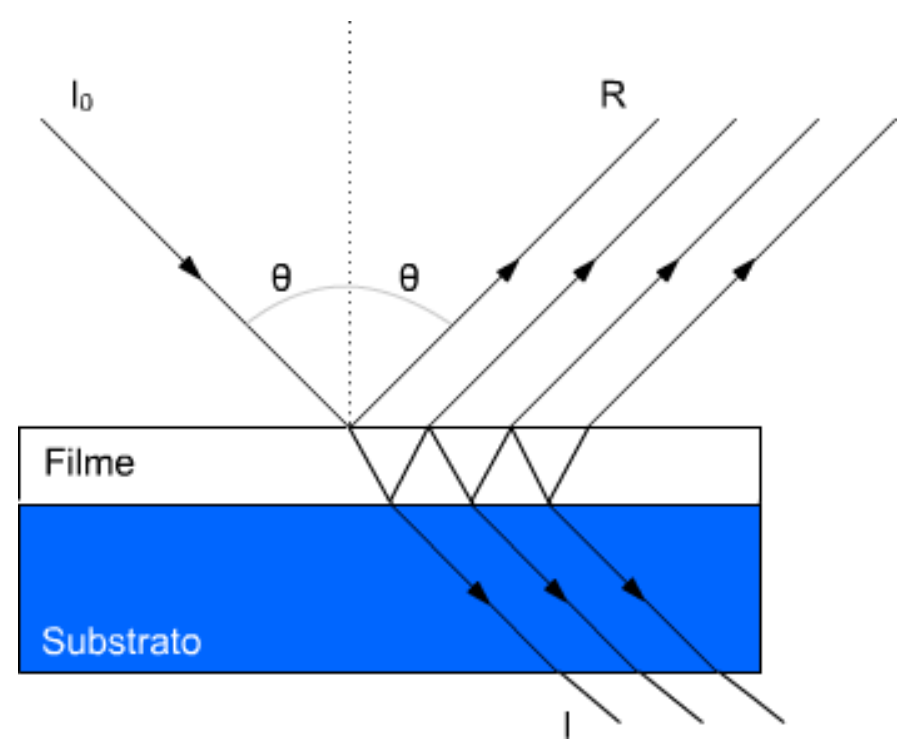

Figura 2 - Luz incidente, refletida e transmitida por uma amostra 
A transmitância óptica $(T)$ é a medida da quantidade de radiação eletromagnética incidente, em um específico comprimento de onda $(\lambda)$, que atravessa um meio, desconsiderado a radiação refletida $(R)$ e a radiação absorvida, de acordo com a Figura 2.

$T$ é definida, portanto, como a razão entre a intensidade de luz transmitida $(I)$ e a intensidade de luz incidente $\left(I_{0}\right)^{34}$. A transmitância é comumente expressa em porcentagem (\%T), como é mostrado na eq.(12).

$$
T(\lambda)=\frac{\% T(\lambda)}{100}=\frac{I(\lambda)}{I_{0}(\lambda)}
$$

A absorbância óptica $A$ é um logaritmo na base decimal do inverso de $T^{34}$, e será usada neste trabalho para a determinação do band gap óptico. A é expressa de acordo com a eq.(13).

$$
A(\lambda)=-\log \left(\frac{I(\lambda)}{I_{0}(\lambda)}\right)
$$

Os valores de transmitância óptica para filmes de ITO devem ser os mais altos possíveis na região do espectro visível $(380<\lambda<750 \mathrm{~nm})$, sendo que bons filmes possuem $\% \mathrm{~T}>80 \%$.

Em geral, a espessura das camadas aumenta proporcionalmente à absorção do material, diminuindo assim sua transmitância. Isto é atribuído ao espalhamento óptico causado por caminhos ópticos mais longos ${ }^{47}$.

A quantidade de oxigênio no filme também é um fator importante. Quanto mais oxigênio, mais transparente o filme se torna devido ao preenchimento das vacâncias de oxigênio do filme ${ }^{48}$.

\subsubsection{Band gap óptico}

Em geral, os filmes de ITO são transparentes na região visível até a absorção fundamental começar, em comprimentos de onda próximos à energia correspondente do band gap óptico $\left(E_{\text {opt }}\right)$. O relativamente alto valor de $E_{\text {opt }}$ é devido ao efeito Burstein-Moss ${ }^{49}$. 
O efeito Burstein-Moss resulta do princípio da exclusão de Pauli, e é visto em semicondutores como um aumento do band gap com o aumento da concentração de portadores. A mudança ocorre porque a energia de Fermi fica na banda de condução para semicondutores degenerados tipo n. Os estados ocupados bloqueiam a excitação óptica ou térmica. Consequentemente, o band gap muda para uma energia maior ${ }^{50}$. O efeito é dado pela relação apresentada na eq.(14) ${ }^{51}$.

$$
E_{o p t}-E_{g}=\frac{\pi^{2} h^{2}}{2 m_{r}^{*}}\left(\frac{3 N}{\pi}\right)^{2 / 3}[e V]
$$

Onde $E_{g}, m_{r}{ }^{*}$ e $h$ são o band gap intrínseco, a massa efetiva reduzida e a constante de Planck, respectivamente. Sabe-se que o aumento na borda de absorção é também é devido ao aumento de desordens em filmes semicondutores. Por isso, em geral, amostras amorfas apresentam valores de band gap óptico inferiores ao de filmes policristalinos ${ }^{52}$.

Da teoria de bandas do estado sólido, o bang gap de transição direta pode ser descrito em função da energia de fóton incidente, de acordo com a eq.(15), onde $h$ é a constante de Planck e $v$ é a frequência de oscilação ${ }^{51}$.

$$
(\alpha h v)^{2} \propto h v-E_{o p t}
$$

Uma forma mais simples de se obter $E_{\text {opt }}$ é feita com o gráfico da absorbância por meio da extrapolação da reta formada no eixo de absorção ultravioleta do material com o eixo de comprimento de onda, como é mostrado na Figura $3^{53}$, retirada da literatura, que mostra o gráfico de absorbância de uma amostra de $\mathrm{SnO}_{2}$. $E_{\text {opt }}$ é então obtido por meio da eq(16), onde $h$ é a constante de Planck, $c$ é a velocidade da luz no vácuo e $\lambda$ é comprimento de onda. No exemplo, $E_{\text {opt }}$ resulta em $3,4 \mathrm{eV}$.

$$
E_{\text {opt }}=\frac{h c}{\lambda}[e V]
$$




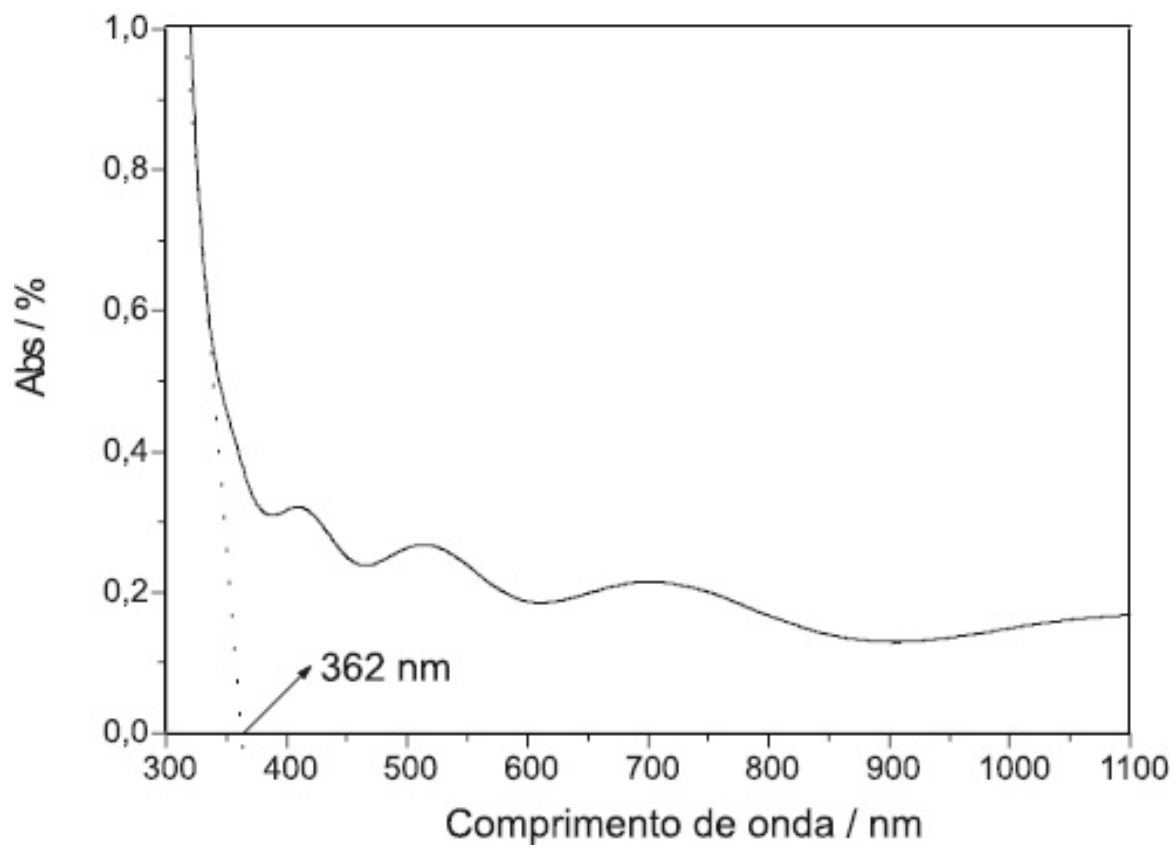

Figura 3 - Exemplo de obtenção do band gap óptico $\left(E_{o p t}\right)$ por meio do gráfico de absorbância em função do comprimento de onda ${ }^{53}$

Valores de $E_{\text {opt }}$ para filmes de ITO encontrados na literatura variam de 3,2 a $4,14 \mathrm{eV}^{54}$, sendo que a maioria dos trabalhos aponta valores em torno de $3,6 \mathrm{eV}^{44}$.

\subsubsection{Rugosidade}

A rugosidade é o conjunto de irregularidades, isto é, pequenas saliências (picos) e reentrâncias (vales) que caracterizam uma superfície. Há várias formas de medir a rugosidade de um filme ${ }^{55}$. As principais são as medidas da rugosidade média aritmética $\left(R_{A}\right)$, rugosidade média quadrática $\left(R_{R M S}\right)$ e rugosidade pico-vale $\left(R_{P V}\right)^{56}$.

$R_{A}$ é o tipo de rugosidade mais conhecido e utilizado, e é definido como a média aritmética dos valores absolutos das ordenadas de afastamento vertical $\left(y_{i}\right)$, dos pontos do perfil de rugosidade em relação à linha média, dentro do percurso de medição, onde $z$ é o número de pontos considerados. Este parâmetro fornece uma boa descrição geral da variação de altura da superfície. Matematicamente, $R_{A}$ é dada pela eq.(17). 


$$
R_{A}=\frac{1}{z} \sum_{i=1}^{z}\left|y_{i}\right|[n m]
$$

$R_{R M S}$ representa o desvio-padrão da distribuição dos pontos de afastamento vertical da superfície, e é, portanto, um parâmetro importante para descrever a superfície. Este parâmetro é mais sensitivo do que $R_{A}$ a grandes variações da linha média, e é apresentado na eq.(18).

$$
R_{R M S}=\sqrt{\frac{1}{z} \sum_{i=1}^{z} y_{i}^{2}}[\mathrm{~nm}]
$$

$R_{P V}$ denota a diferença entre o pico mais alto $\left(y_{\max }\right)$ e o vale mais baixo $\left(y_{\min }\right)$ dentro do percurso de medição, de acordo com a eq.(19).

$$
R_{P V}=y_{\text {máx }}-y_{\text {min }}[\mathrm{nm}]
$$

Para aplicações de filmes de ITO como eletrodos para OLEDs, por exemplo, o controle da rugosidade da superfície é essencial. Como as camadas orgânicas funcionais são depositadas diretamente no filme, a superfície do ITO é transferida a qualquer camada orgânica subsequente. A utilização de altas temperaturas (de 300 a $500{ }^{\circ} \mathrm{C}$ ) na deposição ou no recozimento geralmente aumenta a rugosidade dos filmes de ITO ${ }^{57}$. Por isso, técnicas deposição que utilizam baixas temperaturas são mais aconselhadas.

A redução do tamanho do grão em estruturas policristalinas ou a formação de um filme amorfo também são favoráveis para atingir uma superfície com baixa rugosidade ${ }^{57}$.

Valores da literatura para $R_{A}$ variam consideravelmente, de 1 a $28 \mathrm{~nm}^{44,47}$, dependendo dos processos de deposição utilizados. Para filmes comerciais, $R_{A}$ tem valores na faixa de $0,5-1,0 \mathrm{~nm}, R_{R M S}$ varia de $0,7-1,2 \mathrm{~nm}$ e $R_{P V}$ varia de $8-16 \mathrm{~nm}^{58}$.

\subsubsection{Cristalinidade}

A cristalinidade dos materiais diz respeito à disposição dos átomos ou moléculas constituintes nas três direções do espaço. Filmes de ITO podem ser amorfos (em que os 
constituintes não possuem ordenação espacial) ou policristalinos (compostos por vários cristalitos, de diversos tamanhos e orientações).

$\mathrm{O}$ arranjo dos átomos no substrato depende da energia que lhes é fornecida pela temperatura ou pela transferência do momento quando os átomos chegam ao substrato. Logo, acredita-se que o aumento da temperatura do substrato assim como o aumento da potência RF (o qual promove maior energia cinética aos átomos e/ou moléculas que chegam ao filme em formação) contribuam para uma maior cristalização dos filmes e um aumento no tamanho dos cristalitos 59 .

As melhores propriedades elétricas de filmes de ITO são obtidas no estado policristalino, presumidamente devido à ativação do dopante, já que em filmes amorfos, íons $\mathrm{Sn}^{4+}$ não substituem íons $\mathrm{In}^{3+}$, e em muitos casos se combinam com oxigênio, formando um complexo neutro. No entanto, mesmo no estado amorfo, materiais à base de $\operatorname{In}_{2} \mathrm{O}_{3}$ possuem alta mobilidade de elétrons livres, que tende a aumentar com a cristalinidade ${ }^{60}$.

Os picos de maior intensidade esperados para estruturas policristalinas de ITO são $2 \theta$ $\approx 30,5^{\circ}$ e $2 \theta \approx 35,4^{\circ}$, referentes aos picos (222) e (400) de $\operatorname{In}_{2} \mathrm{O}_{3}$, respectivamente. Outros picos encontrados para $\operatorname{In}_{2} \mathrm{O}_{3}$ são $2 \theta \approx 21^{\circ}(211), 2 \theta \approx 51^{\circ}$ (440) e $2 \theta \approx 60,7^{\circ}(622){ }^{61}$. O pico de difração (222) indica uma orientação cristalográfica preferencial ao longo da direção [111], enquanto o pico (400) indica orientação preferencial ao longo da direção [100]. Embora não exista consenso na literatura, em geral, filmes depositados por sputtering têm orientação preferencial ao longo da direção [100] devido à alta energia das partículas pulverizadas do alvo $\left(5-10\right.$ eV) em relação a outros métodos de deposição ${ }^{62}$.

\subsubsection{Figura de mérito}

Figura de mérito $(\Phi)$ é uma expressão numérica usada para caracterizar o desempenho de materiais ou dispositivos em relação a outros do mesmo tipo. Portanto, $\Phi$ deve relacionar os parâmetros mais significativos à performance do dispositivo em questão.

Como um TCO eficiente deve exibir alta condutividade elétrica combinada à baixa absorção de luz visível independentemente da aplicação desejada, uma figura de mérito simples e eficaz para medir a eficiência de camadas transparentes condutoras foi proposta por Haake ${ }^{63}$, e é dada pela eq.(20). 


$$
\Phi=\frac{T_{a}^{10}}{R_{S}}\left[\Omega^{-1}\right]
$$

onde $T_{a}$ é a transmitância média na faixa do espectro visível e $R_{S}$ é a resistência de folha.

$T_{a}$ é elevada à décima potência para que haja maior equilíbrio entre transmitância e resistência de folha. Apenas a razão entre os dois parâmetros favoreceria $R_{S}$, e $\Phi$ atingiria seus valores máximos apenas com filmes de espessuras muito altas.

Esta figura de mérito é amplamente utilizada na literatura ${ }^{64,65,66}$, e será usada neste trabalho para medir a eficiência dos filmes de ITO depositados sobre substratos transparentes, já que este trabalho não visa uma aplicação específica.

Valores para filmes comerciais encontram-se geralmente na ordem de $10^{-2} \Omega^{-1}$, sendo que quanto mais alto for o valor de $\Phi$, melhor é a qualidade do filme, levando em conta apenas duas das principais propriedades ópticas e elétricas.

No entanto, outras características como rugosidade do filme, uniformidade da espessura e nível de reflexão óptica na região do infravermelho podem ser de grande importância na escolha do melhor filme, dependendo da aplicação a qual a amostra de ITO se destina. Portanto, deve-se considerar o valor de $\Phi$ apenas como referência, e não como um fator decisivo para afirmar qual é o filme de melhor qualidade.

\subsubsection{Principais aplicações de filmes de ITO}

São mostrados aqui exemplos das principais aplicações para filmes finos de ITO. Todos os exemplos foram retirados da literatura, sendo que os dispositivos aqui mostrados não são fabricados neste trabalho. Todos os dispositivos que utilizam substrato de vidro podem também ser fabricados com qualquer outro substrato transparente. 


\subsubsection{Células solares}

Uma estrutura típica de célula solar orgânica utilizando heterojunção é mostrada na Figura $4{ }^{67}$. Neste exemplo, os fótons provenientes da luz solar devem atravessar a camada de vidro, a camada de ITO e a camada de transporte de lacunas (PEDOT:PSS), sendo assim absorvidos pela camada ativa (heterojunção P3HT/PCBM). Com a absorção de luz pela camada ativa, são produzidos excitons, pares elétron-lacuna conectados entre si e, portanto, impossibilitados de se movimentarem separadamente. Para gerar portadores de cargas livres, os excitons devem ser desassociados ${ }^{68}$. A assimetria das funções de trabalho do anodo (ITO) e catodo ( $\mathrm{LiF} / \mathrm{Al})$ cria um campo elétrico interno, de forma que lacunas se movimentam em direção à camada de ITO e elétrons sigam em direção à camada LiF/Al. Conectando externamente os eletrodos, uma corrente elétrica é gerada ${ }^{67}$.

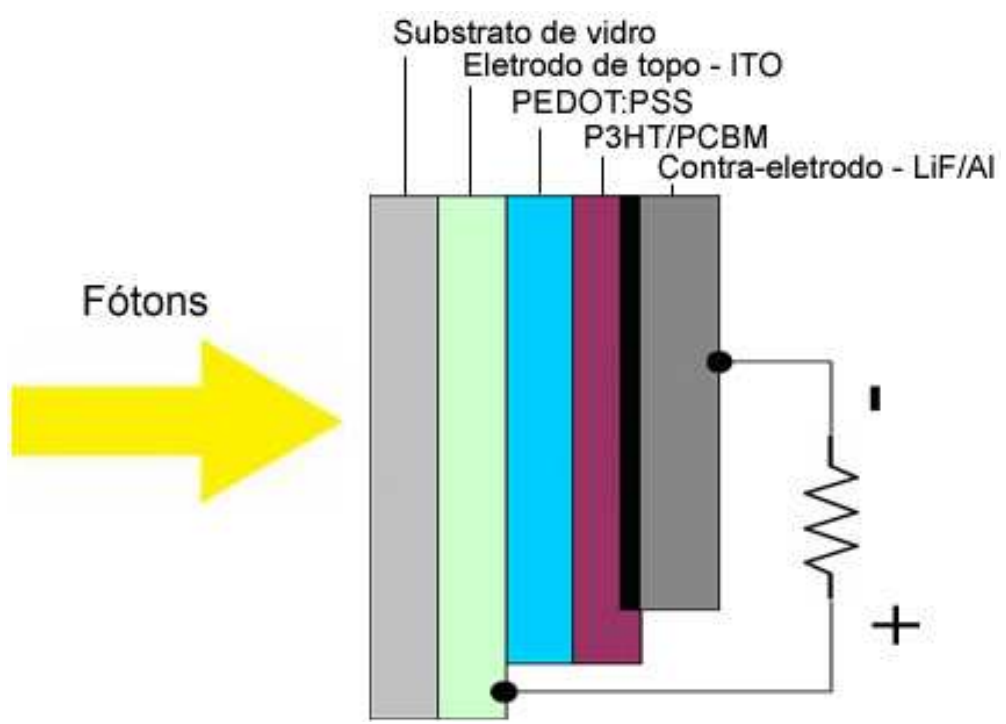

Figura 4 - Estrutura típica de uma célula solar orgânica, onde o ITO funciona como anodo (adaptada) ${ }^{67}$

Em células solares de ITO sobre silício, o ITO atua como camada antirrefletora devido ao seu índice de refração (esta propriedade é comentada na seção 2.3.1.6). Por meio de sua alta condutividade, o ITO também aprimora a coleta de corrente nestes dispositivos ${ }^{69}$.

Em 2008, a empresa americana Konarka começou a produzir industrialmente painéis solares flexíveis, que utilizam células solares orgânicas sobre substratos poliméricos. Os painéis são, em geral, portáteis e dobráveis, e podem ser usados para recarregar equipamentos eletrônicos ${ }^{70}$. 


\subsubsection{LEDs orgânicos}

Diodos orgânicos emissores de luz (OLEDs) são dispositivos feitos pelo posicionamento de uma camada orgânica eletroluminescente (ou camada emissiva) entre dois eletrodos de funções de trabalho diferentes, normalmente um anodo transparente (ITO) e um catodo metálico (A1). Camadas orgânicas adicionais podem ser utilizadas para diferentes funções, como camadas de transporte de portadores ${ }^{71}$.

Um exemplo de OLED fabricado com anodo de ITO é apresentado na Figura $5^{72}$. Com a aplicação de uma tensão elétrica aos eletrodos, lacunas e elétrons são injetados na camada eletroluminescente $\mathrm{Alq}_{3}$ (tris(8-hidroxiquinolina)alumínio). Quando estes são recombinados, são formados excitons que emitem luz visível. A cor da luz emitida depende do material eletroluminescente utilizado na fabricação do dispositivo. Neste exemplo, é emitida apenas luz verde.

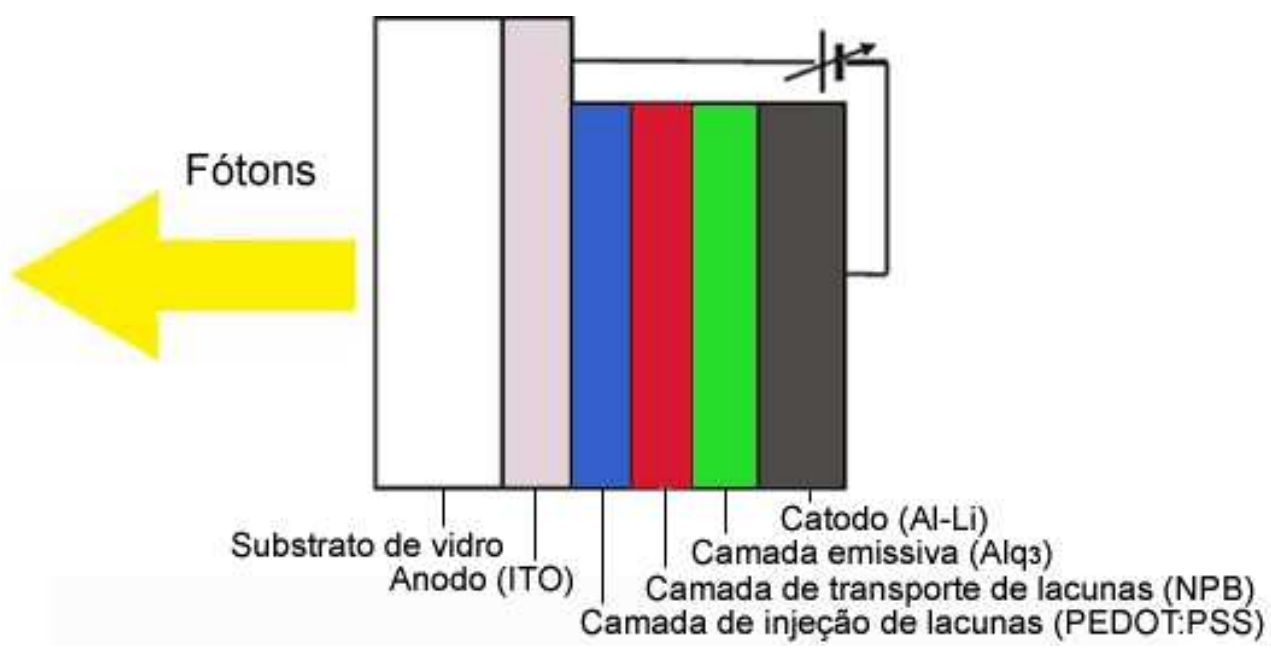

Figura 5 - Estrutura de um OLED fabricado com ITO como anodo (adaptada) ${ }^{72}$

Displays de tela plana feitos de OLEDs são fabricados comercialmente por empresas como Kodak ${ }^{73}$, que utiliza estes displays principalmente em câmeras digitais. A Sony foi a pioneira na comercialização de televisores de OLEDs, em 2007, com o modelo XEL-1, de 11 "74. A Samsung apresentou, em 2008, o protótipo do primeiro televisor de 40" de alta definição $(1920 \times 1080$ pixels $)$ que também utiliza a tecnologia ${ }^{75}$. Além disso, estes displays já são encontrados em celulares, players de música e vídeo e nos mais diversos aparelhos eletrônicos. 


\subsubsection{Células de cristal líquido}

As células de cristal líquido são utilizadas na fabricação de displays de cristal líquido (LCDs). Ao contrário dos OLEDs, não são capazes de produzir luz própria, necessitando de uma fonte de luz para formarem imagens.

A célula consiste basicamente em uma camada de cristal líquido que se encontra entre duas camadas de substrato transparente recoberto com ITO e duas camadas polarizadoras de luz, nas extremidades, como é mostrado no exemplo da Figura $6^{76}$. Também há duas camadas de alinhamento que direcionam as moléculas de cristal líquido em um ângulo capaz de deixar a luz passar pelos dois polarizadores.

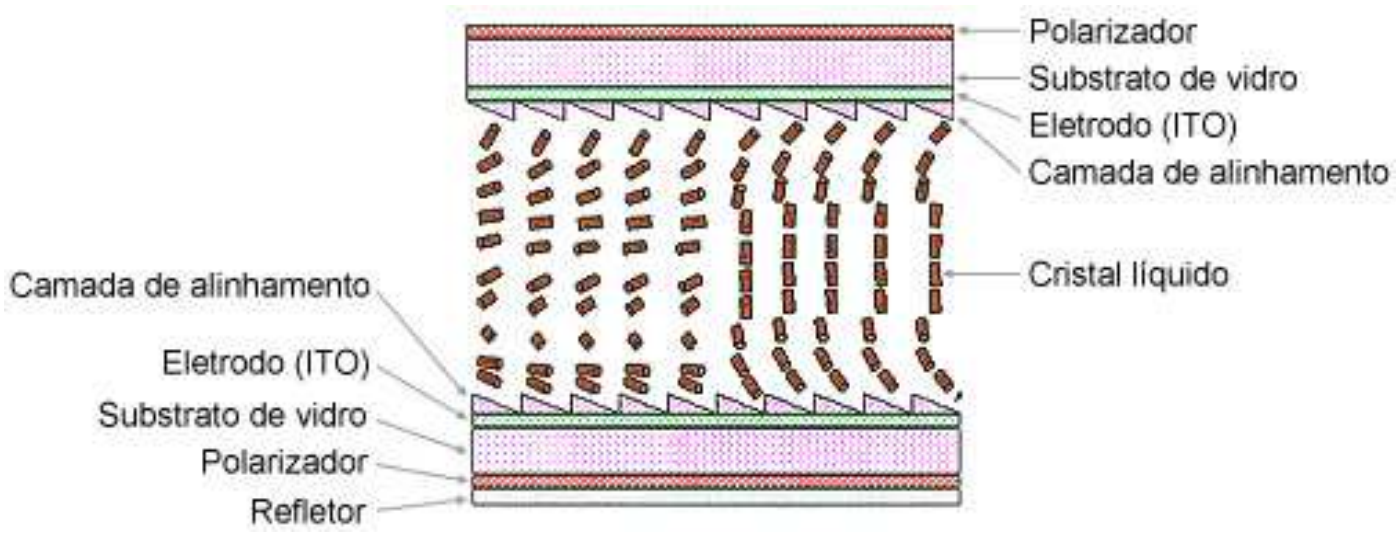

Figura 6 - Célula de cristal líquido, usada na fabricação de LCDs, usando eletrodos de ITO (adaptada) ${ }^{76}$

Portanto, no estado $O F F$ (sem aplicação de voltagem nos eletrodos), a luz é transmitida, passando pelos dois polarizadores. No estado ON (quando uma tensão é aplicada aos eletrodos de ITO), as moléculas de cristal líquido são forçadas na direção do campo elétrico, o que impede a passagem da luz pelo segundo polarizador. O funcionamento de uma célula de cristal líquido é apresentado na Figura $7^{76}$.

Comercialmente, os LCDs começaram a ser produzidos na década de 90, substituindo gradualmente os displays de tubo de raios catódicos (CRT). Hoje, representam cerca de $80 \%$ do mercado mundial, incluindo pequenos displays de aparelhos eletrônicos, monitores de laptops e desktops e também televisores ${ }^{77}$. No entanto, espera-se que LCDs sejam substituídos por displays de OLEDs no futuro, pois estes consomem menos energia por gerarem luz própria ${ }^{78}$ e apresentam um maior contraste na imagem. 


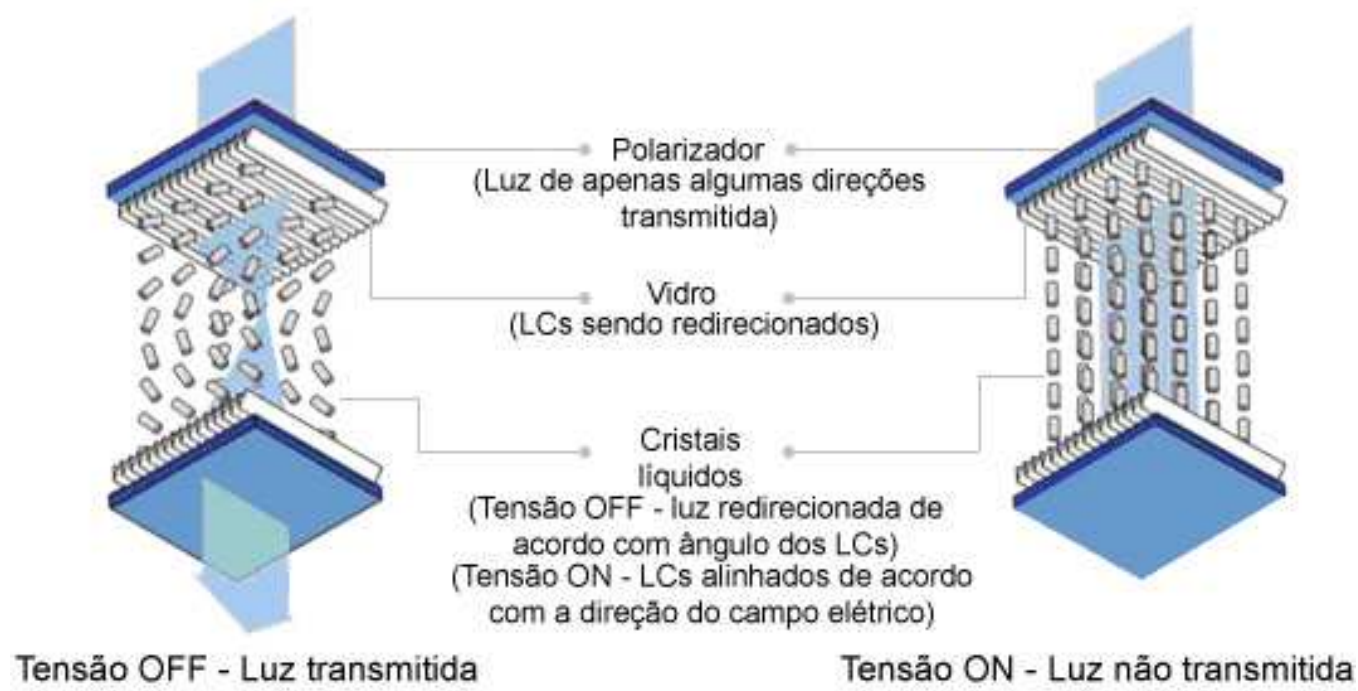

Figura 7 - Funcionamento de uma célula típica de cristal líquido (adaptada) ${ }^{76}$

\subsubsection{Telas sensíveis ao toque}

Telas sensíveis ao toque (mais conhecidas pelo termo em inglês touch screens) são dispositivos que permitem ao operador ativar uma mudança de programa ou hardware pelo toque em um local específico da tela. Estes displays são muito utilizados em terminais de consulta e em caixas eletrônicos de bancos.

Há vários tipos de tela sensível ao toque, como resistiva, capacitiva e de infravermelho. Dentre elas, a mais simples e mais utilizada é a resistiva.

Um exemplo de touch screen resistiva é mostrado na Figura $8^{79}$. A tela consiste de duas camadas condutoras transparentes (ITO, no exemplo) separadas por uma camada de spacer dots, que impedem as camadas condutoras de se encostarem quando não há pressão na tela. Geralmente, o substrato usado no painel é flexível (PET, no exemplo). Quando um objeto pressiona o painel, as duas camadas de ITO se conectam, criando um contato elétrico entre as camadas. Este contato é registrado como evento de toque por um controlador ${ }^{79,80}$. 


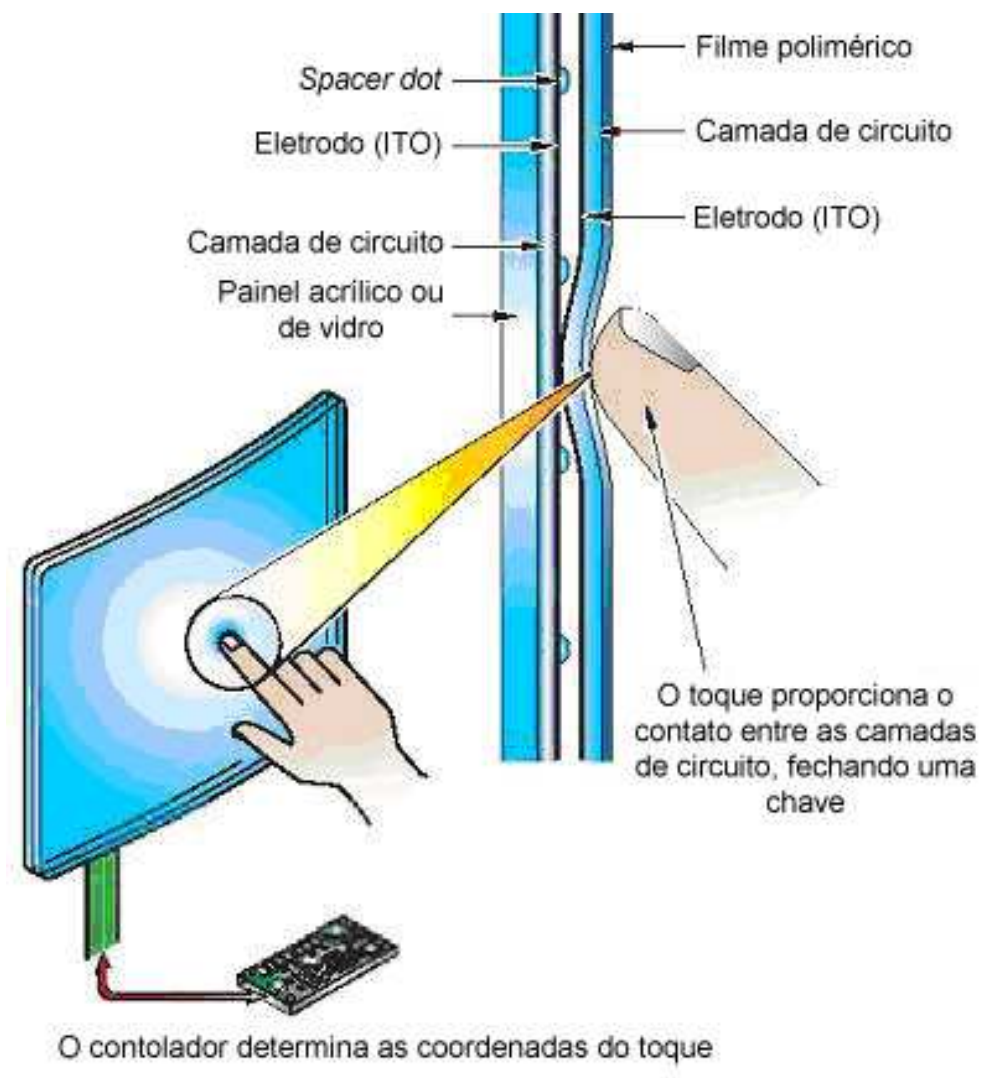

Figura 8 - Exemplo de funcionamento de tela sensível ao toque resistiva (adaptada) ${ }^{79}$

\subsubsection{Janelas conservadoras de energia}

Janelas conservadoras de energia são basicamente vidros recobertos por um material transparente (como o ITO), que têm a propriedade de transmitir radiação visível e refletir radiação infravermelha. Portanto, praticamente todo o espectro visível proveniente dos raios solares é admitido, mas a maior parte do calor irradiado pelos objetos aquecidos no interior não é capaz de deixar o ambiente. Isto ajuda a reduzir custos com aquecimento em países frios $^{81}$. 


\section{MATERIAIS E MÉTODOS}

Neste capítulo são apresentados os métodos e equipamentos utilizados para a obtenção e caracterização das amostras, assim como o procedimento experimental realizado para a deposição das lâminas de ITO sobre substratos de silício, vidro óptico e policarbonato.

\subsection{Processos de fabricação}

São abordados aqui os processos de fabricação utilizados para a obtenção dos filmes de ITO sobre diferentes substratos.

\subsubsection{Limpeza dos substratos}

Antes de iniciar as deposições por sputtering, é necessário fazer a limpeza das lâminas utilizadas como substratos para as camadas de ITO, com o intuito de remover impurezas que possam comprometer a qualidade dos filmes.

Foram utilizados três tipos de substrato: silício tipo p, orientação (100), com 75 mm de diâmetro, $360 \mu \mathrm{m}$ de espessura com resistividade entre 1-10 $\Omega . \mathrm{cm}$; vidro óptico B270 Scotch com $1 \mathrm{~mm}$ de espessura e diâmetro de $75 \mathrm{~mm}$; policarbonato Lexan ${ }^{\circledR}$, com $4 \mathrm{~mm}$ de espessura e área de $25 \mathrm{~cm}^{2}$.

$\mathrm{Na}$ Tabela 1, é descrita a função de cada reagente usado no processo ${ }^{82}$. A água usada nas soluções seguintes é deionizada (água DI), com resistividade de 18,2 M $2 . c m$. A deionização é feita para que íons, sais, metais e outras substâncias sejam removidas, provendo água com um nível altíssimo de pureza para a operação de processos ${ }^{83}$. 
Tabela 1 - Descrição da finalidade das soluções utilizadas para a limpeza dos substratos.

\begin{tabular}{cc}
\hline Solução & Finalidade \\
$4 \mathrm{H}_{2} \mathrm{SO}_{4}+1 \mathrm{H}_{2} \mathrm{O}_{2}$ & Remoção de gordura da superfície dos substratos \\
$20 \mathrm{H}_{2} \mathrm{O}+1 \mathrm{HF}$ & Remoção do óxido nativo $\left(\mathrm{SiO}_{2}\right)$ das lâminas de silício \\
$4 \mathrm{H}_{2} \mathrm{O}+1 \mathrm{H}_{2} \mathrm{O}_{2}+1 \mathrm{NH}_{4} \mathrm{OH}$ & Remoção de gordura e metais do grupo 1B e 3B $(\mathrm{Cu}, \mathrm{Ag}, \mathrm{Zn}$, \\
\hline
\end{tabular}

\subsubsection{Silício}

Para a limpeza das lâminas de silício, foi adotada a seguinte sequência, denominada "limpeza piranha":

- lavagem em água DI corrente (5 minutos, em temperatura ambiente).

- $4 \mathrm{H}_{2} \mathrm{SO}_{4}+1 \mathrm{H}_{2} \mathrm{O}_{2}\left(10\right.$ minutos a $\left.115^{\circ} \mathrm{C}\right)$.

- lavagem em água DI corrente (5 minutos, em temperatura ambiente).

- $20 \mathrm{H}_{2} \mathrm{O}+1 \mathrm{HF}$ (até a lâmina sair seca da solução, em temperatura ambiente).

\subsubsection{Vidro óptico e policarbonato}

A seguinte receita foi adotada para a limpeza das lâminas virgens de vidro óptico:

- lavagem em água DI corrente (5 minutos, em temperatura ambiente).

- $4 \mathrm{H}_{2} \mathrm{O}+1 \mathrm{H}_{2} \mathrm{O}_{2}+1 \mathrm{NH}_{4} \mathrm{OH}\left(10\right.$ minutos a $\left.80{ }^{\circ} \mathrm{C}\right)$.

- lavagem em água DI corrente (5 minutos, em temperatura ambiente).

- Secagem com jato de nitrogênio. 


\subsubsection{Deposição por magnetron sputtering via fonte $\mathbf{R F}$}

Neste trabalho, um equipamento de RF magnetron sputtering planar projetado e montado no Laboratório de Sistemas Integráveis da EP-USP, mostrado na Figura 9, foi utilizado para a deposição dos filmes finos.

Este método de deposição por plasma é considerado como um dos mais apropriados para a deposição de filmes de ITO, devido à boa reprodutibilidade dos filmes e à possibilidade de deposição uniforme sobre grandes áreas ${ }^{9}$.

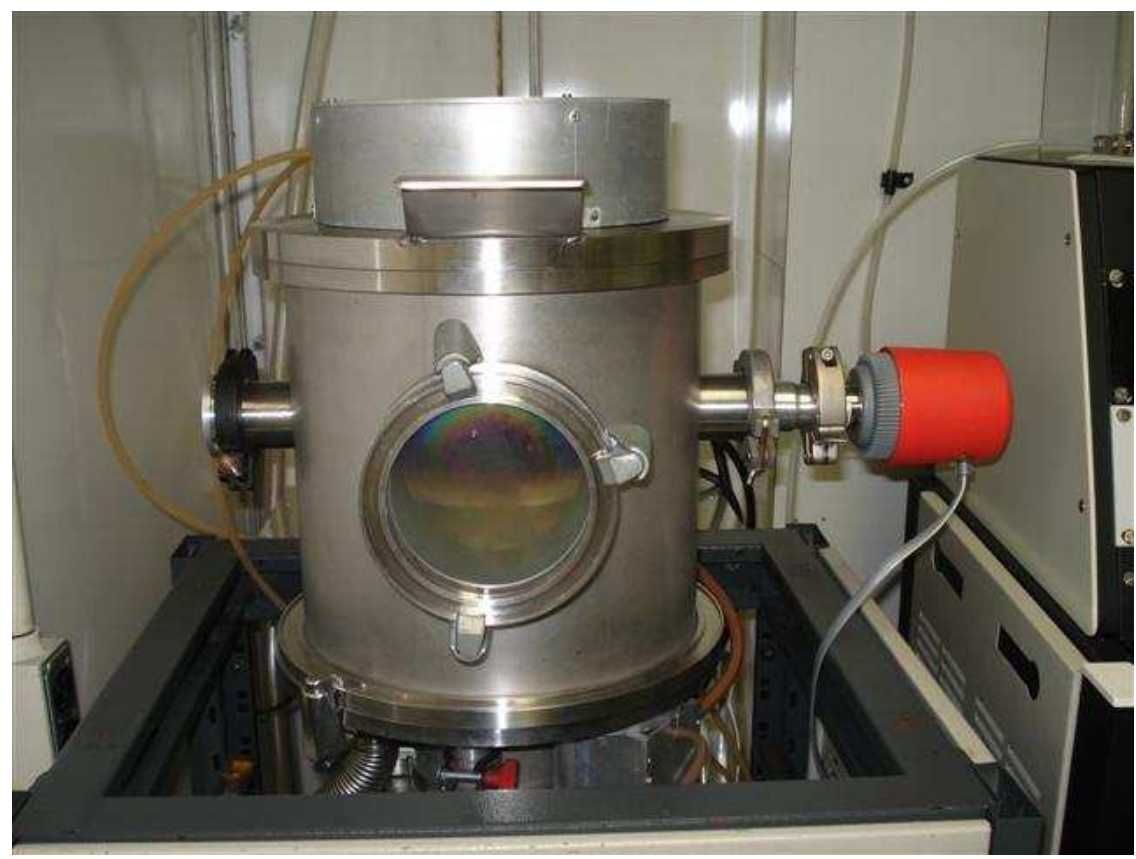

Figura 9 - Equipamento de RF magnetron sputtering utilizado para a deposição dos filmes de ITO

Em um equipamento de RF sputtering planar, o substrato é posicionado em uma câmara de baixa pressão entre dois eletrodos. O processo é iniciado em uma descarga luminescente, produzida na câmara de vácuo por uma fonte de potência RF (de freqüência $=13,56 \mathrm{MHz}$ ), sob pressão de processo controlada por fluxo de gás (geralmente argônio). Um potencial negativo $\mathrm{DC}\left(V_{D C}\right)$ autoinduzido pelo plasma, é utilizado para direcionar os íons para a superfície do catodo, onde se encontra o alvo (um bloco do material que se deseja depositar). O $V_{D C}$ é gerado por meio da aplicação do sinal RF nos eletrodos, que gera o plasma. O plasma atua como um retificador que produz uma tensão negativa média no 
menor dos dois eletrodos, que onde se encontra o alvo. $\mathrm{O}$ anodo, região onde se encontra $\mathrm{o}$ substrato, fica aterrado ${ }^{84}$.

Devido ao bombardeamento de íons $\mathrm{Ar}^{+}$produzidos na descarga, ocorre a erosão do alvo, fenômeno conhecido como pulverização catódica (ou sputtering). A ionização dos átomos de argônio no plasma se processa pelas colisões com elétrons. Para se aumentar a eficiência desta ionização, pode-se confinar os elétrons perto do alvo por meio de um forte campo magnético, mantido entre a superfície do catodo e o alvo. Elétrons oriundos do plasma fazem caminhos espiralados e viajam distâncias muito maiores antes de atingir o alvo do que fariam sem a presença do campo, e fazem, portanto, muito mais colisões com átomos de argônio na região ${ }^{85}$.

Neste caso, a técnica é denominada magnetron sputtering, e tem como objetivo aumentar a taxa de deposição do processo e permitir que sejam feitos processos de deposição em baixas pressões (da ordem de $10^{-3}$ Torr). Um esquema da câmara do sistema de sputtering similar ao utilizado neste trabalho é mostrado na Figura 10. A conexão de vácuo, indicada na figura, é ligada a uma bomba turbomolecular capaz de evacuar a câmara até a ordem de $10^{-7}$ Torr.

Foi utilizado um alvo de sputtering circular da Kurt J. Lesker Company com 99,99 \% de pureza, composição $90 \% \mathrm{In}_{2} \mathrm{O}_{3}$ e $10 \% \mathrm{SnO}_{2}$ em porcentagem de massa, 6 " de diâmetro e 0,25 " de espessura, idêntico ao mostrado na Figura $11^{86}$.

Previamente a cada deposição, a câmara foi evacuada a uma pressão de fundo da ordem de $10^{-6}$ Torr (aproximadamente $5.10^{-6}$ Torr). A pressão de processo adotada foi de $5,0 \pm 0,5$ mTorr, controlada pela vazão de gás, a $24 \pm 1 \mathrm{sccm}$. Argônio puro foi usado como gás de processo, caracterizando-o como não-reativo. Os substratos foram posicionados a $10 \mathrm{~cm}$ de distância do alvo.

Em nenhum caso houve aquecimento intencional dos substratos, e os processos iniciaram com temperatura próxima a $20^{\circ} \mathrm{C}$. No entanto, pôde-se constatar através do termopar acoplado à câmara que os substratos foram aquecidos a, no máximo, $100{ }^{\circ} \mathrm{C}$ durante o processo, sendo a temperatura diretamente proporcional à potência de rádio frequência $\left(P_{R F}\right)$ aplicada e ao tempo de processo. Esta temperatura é considerada baixa para processos de deposição por sputtering, e está de acordo com o objetivo do trabalho, que visa o desenvolvimento de técnicas de deposição em baixas temperaturas. $\mathrm{O}$ termopar acoplado ao equipamento deve ser desligado durante o processo e religado apenas quando a $P_{R F}$ é desligada. A temperatura é medida na superfície do substrato, ou seja, na superfície oposta à 
do filme depositado. Por isso, a medida da temperatura final do substrato $\left(T_{F}^{o}\right)$ de cada processo é estimada com um erro de $10 \%$.

Em parte da superfície de cada lâmina, foi posicionado um fragmento de outro substrato qualquer, com o intuito de deixar um degrau entre o substrato e o filme depositado, tornando possível a medição da espessura do filme através da perfilometria.

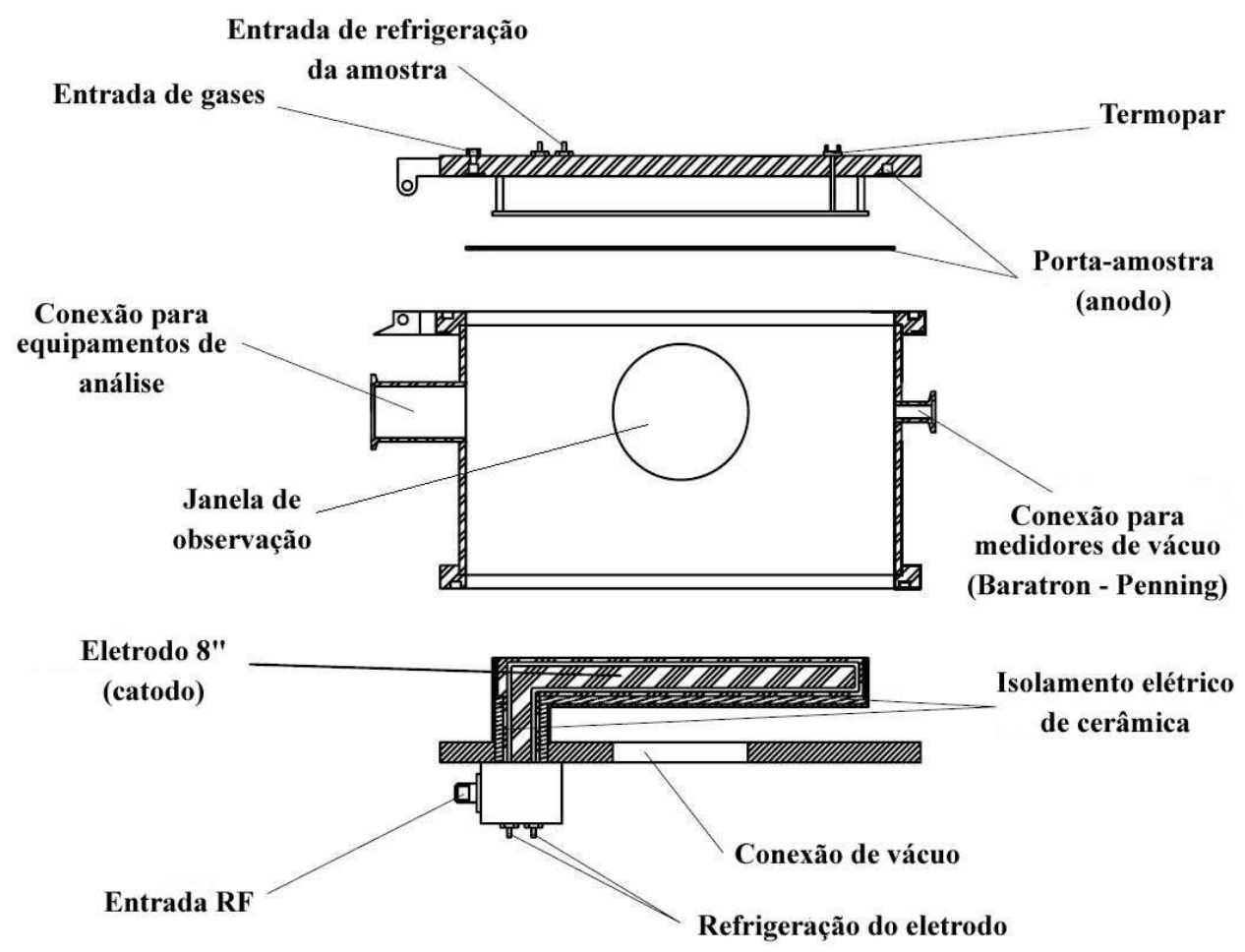

Figura 10 - Câmara do sistema de RF magnetron sputtering utilizado para depositar os filmes de ITO

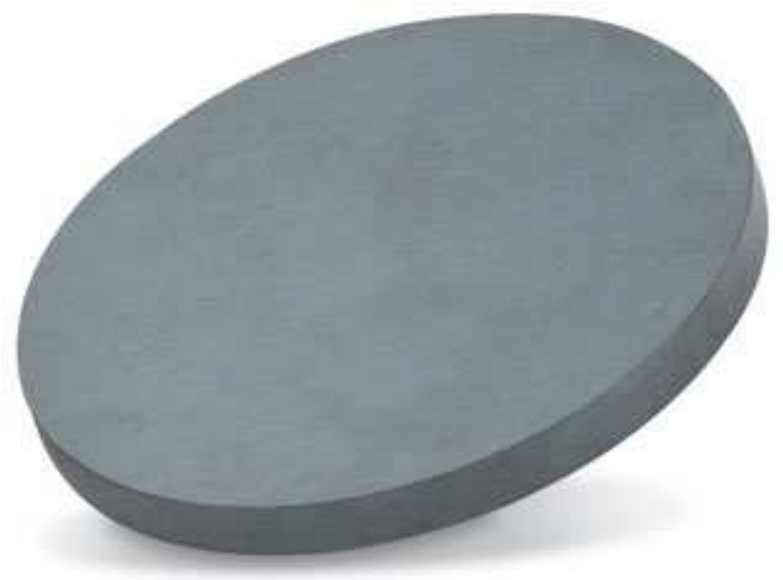

Figura 11 - Alvo de ITO da Kurt J. Lesker Company utilizado para a deposição de filmes por sputtering 


\subsubsection{Deposição de ITO sobre silício variando potência RF de 25 a 100 W}

Esta primeira série de deposições visa à determinação da influência da potência de rádio frequência $\left(P_{R F}\right)$ na obtenção de camadas de ITO utilizando o equipamento de sputtering em questão. A faixa de potência escolhida varia de 25 a $100 \mathrm{~W}$. O substrato escolhido para esta etapa foi o silício, por ser um substrato de superfície pouco rugosa e livre de contaminações, o que torna mais simples a caracterização das lâminas. Por ser um substrato opticamente absorvente, é dada ênfase às propriedades elétricas.

A partir desta série, foi possível fazer o levantamento da taxa de deposição, composição química e propriedades ópticas, elétricas e estruturais dos filmes, como será discutido posteriormente.

Na Tabela 2 são mostrados os parâmetros de deposição utilizados, que são a potência RF $\left(P_{R F}\right)$ empregada e o tempo de deposição $\left(T_{D}\right)$ de cada processo, assim como o potencial negativo $\left(V_{D C}\right)$ aplicado ao catodo durante a deposição e a temperatura final $\left(T_{F}^{o}\right)$ de cada experimento. É também apresentado o cálculo da densidade de potência $\left(D_{P}\right)$ em relação à área do alvo, calculada a partir do diâmetro do alvo $\left(d_{T}\right)$, de acordo com a eq.(21).

$$
D_{P}=\frac{4 P_{R F}}{\pi\left(d_{T}\right)^{2}}\left[\frac{W}{\mathrm{~cm}^{2}}\right]
$$

\begin{tabular}{cccccc} 
Tabela 2 - Parâmetros da primeira série de deposições, de ITO/Si com $\boldsymbol{P}_{\boldsymbol{R}}$ de 25 a 100 \\
\hline Substrato & $\mathbf{P}_{\mathbf{R F}}(\mathbf{W})$ & $\mathbf{D}_{\mathbf{P}}\left(\mathbf{W} / \mathbf{c m}^{2}\right)$ & $\mathbf{T}_{\mathbf{D}}(\mathbf{m i n})$. & $\mathbf{T}_{\mathbf{F}}^{\mathbf{0}}\left({ }^{\mathbf{0}} \mathbf{C}\right)$ & $\mathbf{V}_{\mathbf{D C}}(\mathbf{V})$ \\
& $25,0 \pm 0,5$ & $0,137 \pm 0,003$ & $30,0 \pm 0,5$ & $20 \pm 2$ & $-28,0 \pm 0,5$ \\
\multirow{4}{*}{ Silício } & $50 \pm 1$ & $0,274 \pm 0,005$ & $120,0 \pm 0,5$ & $30 \pm 3$ & $-28,0 \pm 0,5$ \\
& $75 \pm 1$ & $0,411 \pm 0,005$ & $30,0 \pm 0,5$ & $40 \pm 4$ & $-47 \pm 1$ \\
& $100 \pm 2$ & $0,55 \pm 0,01$ & $30,0 \pm 0,5$ & $80 \pm 8$ & $-62 \pm 1$ \\
\hline
\end{tabular}

Para $P_{R F}=25 \mathrm{~W}$, uma amostra com tempo de deposição $T_{D}=120$ minutos foi obtida devido à baixíssima espessura obtida no filme depositado em 30 minutos. Isto dificulta a medida da espessura da lâmina por perfilometria, e inviabiliza a utilização deste parâmetro nos substratos transparentes utilizados neste trabalho, devido à rugosidade dos substratos ser bem mais alta do que a rugosidade das lâminas de silício. 


\subsubsection{Deposição de ITO sobre Vidro, ITO sobre silício e ITO sobre policarbonato variando o tempo de deposição de 30 a 120 minutos}

De acordo com os resultados da caracterização da primeira série de deposições (seção 3.1.2.1), que serão comentados posteriormente na seção 4.1, foram depositados filmes sobre substratos de vidro óptico. Novas amostras de ITO sobre silício também foram obtidas, com o intuito de facilitar a caracterização e analisar se o processo possui uma boa reprodutibilidade. Com as amostras de vidro, análises diferentes foram feitas devido à transparência do substrato, como será comentado na seção 4.2.

O objetivo desta série de deposições é avaliar a influência da espessura dos filmes em suas diversas propriedades, assim como avaliar a influência exercida pelo substrato na qualidade dos filmes e confirmar a possibilidade de deposição sobre substratos poliméricos. Para isso, foi adotada uma potência fixa de $75 \mathrm{~W}$, com a variação do tempo de deposição de cada processo. Filmes foram obtidos sobre vidro e silício para facilitar a caracterização dos mesmos. Para o tempo de $90 \mathrm{~min}$, foi também depositado um filme sobre o substrato polimérico Lexan ${ }^{\circledR}$. Os processos adotados aqui estão apresentados na Tabela 3.

A sequência do processo de deposição descrita na seção anterior foi mantida, utilizando aproximadamente $5.10^{-6}$ Torr de pressão de fundo, 5 mTorr de pressão de processo e $100 \%$ argônio como gás de processo.

O tempo de deposição $\left(T_{D}\right)$ de cada processo, o potencial negativo $\left(V_{D C}\right)$ aplicado ao catodo, a temperatura final $\left(T_{F}^{o}\right)$ de cada experimento e o cálculo da densidade de potência $\left(D_{P}\right)$ em relação à área do alvo são mostrados na Tabela 3. Os pequenos desvios no potencial aplicado ao catodo para cada processo foram associados a variações na $P_{R F}$ ajustada inicialmente, devido à potência refletida pelo equipamento durante o processo. No entanto, os desvios são pequenos e não comprometem a reprodutibilidade das lâminas obtidas.

Tabela 3 - Parâmetros da segunda série de deposições, de ITO/Si e ITO/vidro com $P_{R F}=75 \mathrm{~W}$ e $T_{D}$ variando de 30 a $120 \mathrm{~min}$ e de ITO/Lexan ${ }^{\circledR} \operatorname{com} P_{R F}=75 \mathrm{~W}$ e $T_{D}=90 \mathrm{~min}$

\begin{tabular}{cccccccc}
\hline Substrato & $\mathbf{P}_{\mathbf{R F}}(\mathbf{W})$ & $\mathbf{D}_{\mathbf{P}}\left(\mathbf{W} / \mathbf{c m}^{2}\right)$ & $\mathbf{T}_{\mathbf{D}}(\mathbf{m i n})$. & $\mathbf{T}_{\mathbf{F}}^{\mathbf{o}}\left({ }^{\mathbf{0}} \mathbf{C}\right)$ & \multicolumn{3}{c}{$\mathbf{V}_{\mathbf{D C}}(\mathbf{V})$} \\
Vidro/Si & $75 \pm 1$ & $0,411 \pm 0,005$ & $30,0 \pm 0,5$ & $70 \pm 7$ & $-67 \pm 1$ & $-67 \pm 1$ & - \\
Vidro/Si & $75 \pm 1$ & $0,411 \pm 0,005$ & $60,0 \pm 0,5$ & $75 \pm 8$ & $-66 \pm 1$ & $-67 \pm 1$ & - \\
Vidro/Si/Lexan $^{\circledR}$ & $75 \pm 1$ & $0,411 \pm 0,005$ & $90,0 \pm 0,5$ & $80 \pm 8$ & $-66 \pm 1$ & $-67 \pm 1$ & $-66 \pm 1$ \\
Vidro/Si & $75 \pm 1$ & $0,411 \pm 0,005$ & $120,0 \pm 0,5$ & $85 \pm 8$ & $-68 \pm 1$ & $-66 \pm 1$ & - \\
\hline
\end{tabular}




\subsubsection{Deposição de ITO sobe vidro e ITO sobre silício variando a potência RF de 100 a $200 \mathrm{~W}$}

Com a base da caracterização dos processos anteriores, foi desenvolvida uma nova séria de deposições para avaliar a influência de potências mais altas, de 100 a $200 \mathrm{~W}$. O tempo de cada deposição foi calculado por meio da eq.(29) (seção 4.1.2)para que os filmes obtivessem espessuras similares. Filmes foram obtidos sobre silício e vidro para que fosse possível a caracterização óptica completa, já que é esperado uma piora nas características ópticas devido à menor proporção de oxigênio em filmes obtidos com potências altas.

A seqüência do processo de deposição descrita na seção anterior foi mantida, utilizando aproximadamente $5.10^{-6}$ Torr de pressão de fundo, 5 mTorr de pressão de processo e $100 \%$ argônio como gás de sputtering.

A potência RF $\left(P_{R F}\right)$ empregada, tempo de deposição $\left(T_{D}\right)$ de cada processo, o potencial negativo $\left(V_{D C}\right)$ aplicado ao catodo durante a deposição, a temperatura final $\left(T_{F}^{o}\right)$ de cada experimento e o cálculo da densidade de potência $\left(D_{P}\right)$ em relação à área do alvo são mostrados na Tabela 4.

Tabela 4 - Parâmetros da terceira série de deposições, de ITO/Si e ITO/vidro com $P_{R F}$ de 100 a $200 \mathrm{~W}$

\begin{tabular}{ccccccc}
\hline Substrato & $\mathbf{P}_{\mathbf{R F}}(\mathbf{W})$ & $\mathbf{D}_{\mathbf{P}}\left(\mathbf{W} / \mathbf{c m}^{2}\right)$ & $\mathbf{T}_{\mathbf{D}}(\mathbf{m i n})$. & $\mathbf{T}_{\mathbf{F}}^{\mathbf{o}}\left({ }^{\mathbf{o}} \mathbf{C}\right)$ & \multicolumn{2}{c}{$\mathbf{V}_{\mathbf{D C}}(\mathbf{V})$} \\
Vidro/Si & $100 \pm 2$ & $0,55 \pm 0,01$ & $44,0 \pm 0,5$ & $80 \pm 8$ & $-77 \pm 1$ & $-77 \pm 1$ \\
Vidro/Si & $125 \pm 2$ & $0,68 \pm 0,01$ & $34,0 \pm 0,5$ & $80 \pm 8$ & $-96 \pm 1$ & $-96 \pm 1$ \\
Vidro/Si & $150 \pm 3$ & $0,82 \pm 0,02$ & $28,0 \pm 0,5$ & $85 \pm 9$ & $-109 \pm 1$ & $-109 \pm 1$ \\
Vidro/Si & $175 \pm 3$ & $0,96 \pm 0,02$ & $24,0 \pm 0,5$ & $90 \pm 9$ & $-121 \pm 2$ & $-121 \pm 2$ \\
Vidro/Si & $200 \pm 3$ & $1,10 \pm 0,02$ & $21,0 \pm 0,5$ & $90 \pm 9$ & $-135 \pm 2$ & $-135 \pm 2$ \\
\hline
\end{tabular}

\subsection{Caracterização dos filmes}

São discutidas aqui as técnicas utilizadas para a caracterização dos filmes de ITO obtidos sobre diversos substratos. 


\subsubsection{Prova de quatro pontas $\left(\boldsymbol{R}_{S}\right)$}

O equipamento utilizado para a realização de medidas de resistência de folha $\left(R_{S}\right)$ dos filmes foi a prova de quatro pontas FPP-5000 da Veeco. Com ele, é possível realizar medidas em lâminas de até 6" de diâmetro.

O aparelho, que tem seu funcionamento ilustrado na Figura 12, possui quatro pontas de prova alinhadas, que entram em contato com a superfície da amostra no momento da medição.

Uma corrente é aplicada nas duas pontas externas, e a tensão sobre as pontas internas é então medida. As pontas têm espaçamento $B$ idêntico entre si.

Com este equipamento, é possível realizar diversas medidas elétricas, assim como espessura e tipo de portadores do filme. Neste trabalho, a prova de quatro pontas foi utilizada para a obtenção da resistência de folha das camadas, que é definida como a resistência elétrica de uma área quadrada do filme, independente da dimensão do quadrado. A resistência de folha é dada pela eq.(22).

$$
R_{S}=F^{*} \frac{V}{I}\left[\frac{\Omega}{s q}\right]
$$

onde $F^{*}$ é o fator de correção geométrico para a resistência de folha. Para o caso presente, em que a medida é feita com quatro pontas dispostas linearmente, igualmente espaçadas, a corrente sendo injetada pelas duas pontas da extremidade e a queda de potencial sendo medidas nas pontas internas, o fator de correção $\mathrm{F}^{*}$ é apresentado na eq.(23) ${ }^{87}$.

$$
F^{*}=\frac{\pi}{\ln (2)}=4,532
$$




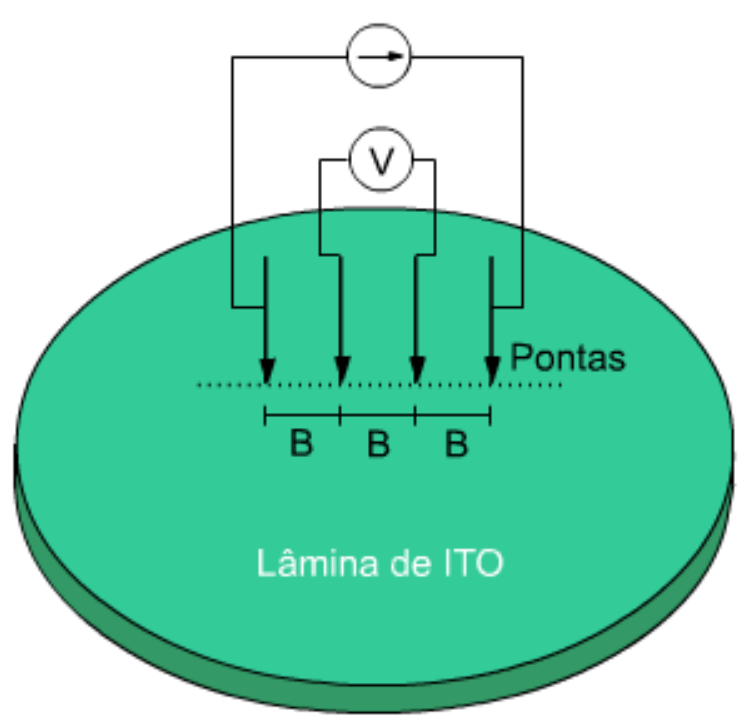

Figura 12 - Esquema de funcionamento da prova de quatro pontas, usada para medir a resistência de folha das amostras (adaptada) ${ }^{87}$

\subsubsection{Perfilometria $\left(t, R_{A}, R_{P V}\right)$}

Para medidas de espessura e rugosidade das amostras, foi utilizado o perfilômetro Dektak 3030 da Veeco.

O funcionamento do equipamento dá-se eletromecanicamente, por meio da varredura da superfície do filme por uma agulha com ponta de diamante. A agulha é ligada mecanicamente a um LVDT (Linear Variable Differential Transformer), um dispositivo eletromecânico que produz uma tensão de saída proporcional à posição de um núcleo móvel.

À medida que a mesa de alta precisão move a amostra, a ponta faz a varredura do filme. Variações na espessura do filme fazem com que a agulha seja movida verticalmente. Sinais elétricos correspondentes aos movimentos da agulha são produzidos à medida que a posição do núcleo do LVDT muda. Um sinal analógico proporcional à variação de posição é produzido pelo LVDT e convertido em sinal digital por um conversor analógico/digital. Os sinais digitais da medida são então plotados em um gráfico no monitor do equipamento, podendo ser manipulados, medidos e impressos.

Para que sejam possíveis medidas de espessura através do perfilômetro, é necessário que haja um degrau formado pelo filme de ITO e o substrato na amostra, de acordo com a Figura 13. 
Para isso, uma pequena área dos substratos das amostras obtidas por sputtering foi mascarada com a sobreposição de outra lâmina de silício, impedindo que o filme de ITO fosse depositado em toda a superfície dos substratos.

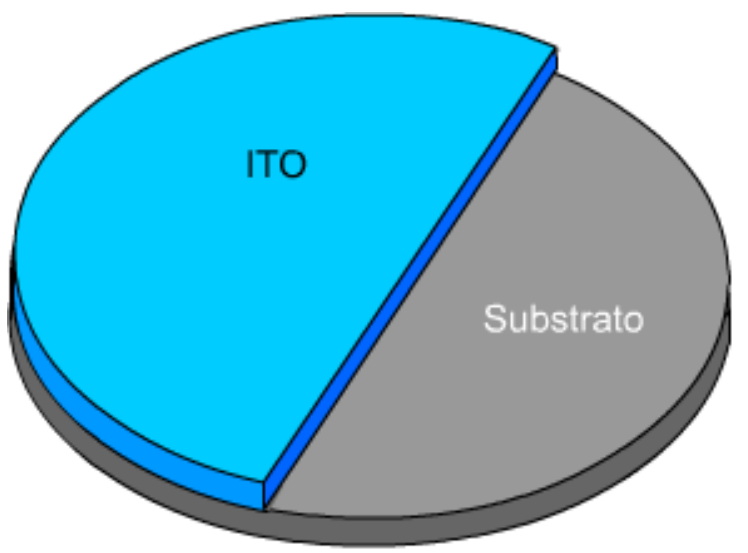

Figura 13 - Degrau formado entre o substrato e o filme de ITO, usado para medidas de espessura por perfilometria

Como o filme depositado na faixa de encontro entre a o substrato e a lâmina de mascaramento possui espessura um pouco maior do que no resto da área do substrato, a varredura foi feita com alguns milímetros de comprimento.

Todas as medidas de espessura foram realizadas com a utilização dos seguintes parâmetros: $2 \mathrm{~mm}$ de comprimento de varredura, $0,1 \mathrm{mN}$ de força da ponta, velocidade média (aproximadamente $40 \mu \mathrm{m} / \mathrm{s}$ ), $1310 \mathrm{k} \AA$ de range vertical de medida e perfil de medida de subida de degrau.

Para medidas de rugosidade, os seguintes parâmetros foram adotados: $500 \mu \mathrm{m}$ de comprimento de varredura, $0,1 \mathrm{mN}$ de força da ponta, velocidade baixa (aproximadamente $10 \mu \mathrm{m} / \mathrm{s})$ e $655 \mathrm{k} \AA$ de range vertical de medida.

\subsubsection{Curvas $I-V$}

O levantamento das curvas $I-V$ das amostras de ITO sobre silício foi feito através de um picoamperímetro pA meter/DC 4140B, da $H P$. O equipamento pode aplicar tensões de -40 a $40 \mathrm{~V}$ na amostra através de uma ponta posicionada em cima do contato onde se deseja aplicar a tensão. Para este trabalho, foram utilizadas tensões de -2 a 2 V. A geração do gráfico $I$ - $V$ é feito por software através da medição da corrente presente na base da amostra. Por 
característica do equipamento, devem ser depositados contatos ser de alumínio para diminuir a resistência da ponta e manter a área de aplicação do campo constante.

Após a deposição das lâminas, contatos cilíndricos de alumínio de diâmetro igual a $1 \mathrm{~mm}$ foram depositados por evaporação térmica, com a auxílio de uma máscara, na superfície dos filmes de ITO. Uma camada de alumínio foi depositada pela mesma técnica de deposição na superfície do substrato. Esta configuração, mostrada na Figura 14, permite a obtenção das curvas $I-V$ das amostras de cima pra baixo, ou seja, com tensão sendo aplicada nos pontos de alumínio e corrente sendo medida na base.

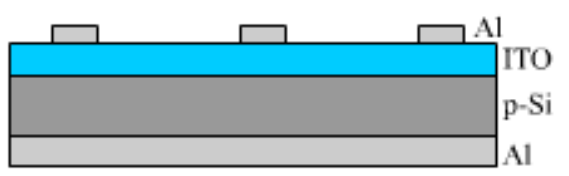

Figura 14 - Esquema das amostras de ITO com contatos de alumínio depositados por evaporação térmica

\subsubsection{Efeito Hall $(\mu, N)$}

Com a utilização de uma fonte de potência MPS-50 e de um controlador de circuito Van der Pauw modelo H-50, ambos da Advanced Energy, foram obtidas medidas de densidade de portadores $(N)$ e mobilidade de portadores $(\mu)$.

O efeito Hall ocorre quando um material condutor ou semicondutor está imerso em um forte campo magnético perpendicular à direção da corrente elétrica que percorre o material. $\mathrm{O}$ efeito consiste na produção de uma diferença de potencial entre as superfícies opostas do material na direção transversal às do campo e da corrente. O campo elétrico produzido, $\vec{E}_{\text {Hall }}$, associado à diferença de potencial, pode ser obtido do produto apresentado na eq.(24), onde

$\vec{j}$ é a densidade de corrente, $\vec{B}$ é a densidade de fluxo magnético e $\vec{R}_{\text {Hall }}$ é uma constante chamada coeficiente Hall ${ }^{34}$.

$$
\vec{E}_{\text {Hall }}=-\vec{R}_{\text {Hall }} \vec{j} \vec{B}
$$


A partir da determinação de $\vec{R}_{\text {Hall }}$, a concentração de portadores e a mobilidade de portadores são derivadas das relações descritas na eq.(25) e eq.(26), onde e é a carga do elétron e $\rho$ é a resistividade.

$$
\begin{gathered}
N=\frac{1}{e \vec{R}_{\text {Hall }}} \\
\mu=\frac{1}{N e \rho}
\end{gathered}
$$

O método de medida de efeito Hall proposto por Van der Pauw ${ }^{88}$ é comumente utilizado para medir resistência de folha, densidade de portadores, mobilidade de portadores e tipo de portadores. Para a realização das medidas, é necessário que quatro contatos ôhmicos sejam posicionados simetricamente em fragmentos das amostras, que também devem ter geometria simétrica para que erros de medida sejam reduzidos. Os contatos foram feitos com cola de prata e fios de cobre, de acordo com a geometria mostrada na Figura 15.

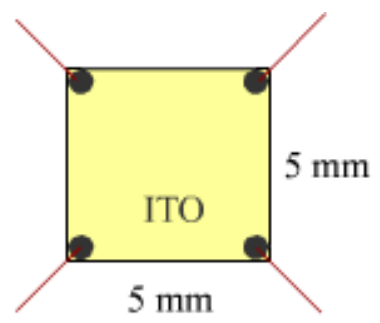

Figura 15 - Contatos de prata e fios de cobre feitos sobre os filmes de ITO em amostras de 5 x 5 mm.

Para a realização das medidas, foi aplicada uma corrente de $3 \mathrm{~mA}$ e um campo magnético de 0,35 T, e a espessura de cada uma das amostras (medida por perfilometria e elipsometria) foi fornecida através do software do equipamento para que fossem realizados os cálculos dos parâmetros. 


\subsubsection{Elipsometria $(t, n)$}

A espessura $t$ das amostras foi medida a princípio por perfilometria, por meio do degrau deixado entre o filme e o substrato. No entanto, pode haver uma ligeira variação de $t$ na região do degrau em relação ao restante da superfície do filme. Portanto, a análise por elipsometria, realizada em regiões centrais das lâminas, garante um resultado mais preciso da espessura das amostras.

A elipsometria é um método de caracterização óptico não destrutivo que permite medir o índice de refração $(n)$ e o coeficiente de extinção $(\kappa)$ de um substrato e também a espessura $(t)$ e o índice de refração de filmes finos transparentes sobre um substrato altamente absorvente, cujos valores de $n$ e $\kappa$ sejam conhecidos.

O equipamento utilizado é um Rudolph Research Auto-EL NIR3, que trabalha com três comprimentos de onda $(405,0 ; 632,8$ e $830,0 \mathrm{~nm})$ proporcionados por uma fonte de lâmpada alógena com filtros interferenciais, que passa através de um polarizador circular (para obter um feixe de polarização circular e de intensidade máxima). Essa polarização circular é, em seguida, transformada em polarização linear por um polarizador. Finalmente, a luz chega sobre a amostra. Após reflexão, a luz passa por um analisador, e depois através de um filtro selecionando apenas o comprimento de onda desejado, isso para evitar qualquer perturbação da luz ambiente. Enfim, a luz chega sobre o fotodetetor. O método consiste em avaliar as mudanças no estado de polarização da luz causada pela reflexão na superfície da $\operatorname{amostra}^{89}$.

Para a realização das medidas, é necessária a indicação de parâmetros aproximados de $t$ e $n$ dos filmes. Foram indicadas as medidas de espessura previamente obtidas por perfilometria e índice de refração $=2$, condizente com a literatura.

\subsubsection{Espectrofotometria UV-Vis-NIR}

Com a utilização do espectrofotômetro CARY 500, da Varian, foram obtidos os espectros de absorção e transmissão das películas de ITO depositadas sobre substratos transparentes. 
O espectrofotômetro é um equipamento geralmente utilizado para fazer medidas de transmitância, absorbância e reflectância. Na configuração utilizada para medidas de transmitância (e também absorbância), a medida se dá através de uma fonte de radiação, que emite sobre a superfície da amostra ondas eletromagnéticas de comprimentos de onda específicos, e de um fotodetetor, que capta a intensidade de energia luminosa que conseguiu atravessar a amostra. O cálculo da transmitância é feito por software, de acordo com a eq.(12), e o gráfico de $\% T$ em função do $\lambda$ aplicado é automaticamente gerado.

No equipamento utilizado, ocorre a mudança de detetor em $\lambda=800$ e $1200 \mathrm{~nm}$. Por isso, pode haver algumas falhas no gráfico nas faixas próximas a esses comprimentos de onda.

\subsubsection{Microanálise}

Para as medidas de porcentagem atômica dos elementos constituintes dos filmes de ITO, foi utilizado um microscópio eletrônico de varredura 6460LV, da Jeol.

O funcionamento do equipamento se dá através de um feixe de elétrons que é emitido sobre as amostras, excitando os átomos que as compõem. Quando estes voltam ao seu estado fundamental, fótons são emitidos com energias características do átomo. Os fótons são identificados de acordo com sua energia e coletados pelo detector de raios-X localizado dentro da câmara de vácuo. $\mathrm{O}$ espectro relativo ao número de contagens em função da energia são então gerados, identificando os elementos químicos presentes na amostra ${ }^{89}$.

\subsubsection{Difratômetro de Raios-X}

Para as medidas de difração de raios-X, foi utilizado um difratômetro Ultima + , da Rigaku, com fonte de raios-x de cobre e monocromador ajustado para radiação $\mathrm{Cu} \mathrm{K} \alpha$. O cristal utilizado é o mosaico de grafite.

A difração de raios-X ocorre quando há interferência construtiva no processo de espalhamento dos fótons pelos átomos de uma estrutura cristalina. Esquematizando a estrutura periódica dos cristais por planos cristalográficos, tem-se condições de difração ou reflexão de 
Bragg $\left(\theta_{B}\right)$ quando há a relação mostrada na eq.(27) (onde $\theta_{I}$ e $\theta_{R}$ são os ângulos de incidência e de espalhamento) e a relação apresentada na eq.(28), onde $d$ é a distância interplanar dos planos cristalográficos e $n_{r}$ é a ordem de reflexão $\left(n_{r}=1\right.$ para $1^{\mathrm{a}}$ ordem, $n_{r}=2$ para $2^{\mathrm{a}}$ ordem, etc). A eq.(28) é conhecida como lei de Bragg.

$$
\begin{gathered}
\theta_{B}=\theta_{I}=\theta_{R} \\
2 d \operatorname{sen} \theta=n_{r} \lambda
\end{gathered}
$$

A lei de Bragg implica, quando é satisfeita, que a diferença de caminho óptico entre os feixes espalhados pelos diversos planos cristalográficos é igual ao comprimento de onda $\lambda$ ou a um múltiplo dele. Nas direções tais em que essa relação não se verifica, a interferência entre as ondas espalhadas é destrutiva e não se observa intensidade de espalhamento.

O cristal, orientado de tal maneira a satisfazer a eq.(27), é utilizado como analisador do espectro de emissão de raios-X. Numa varredura do ângulo, o cristal atua como um filtro que reflete apenas a radiação com comprimento de onda que satisfaz a lei de Bragg.

O software que opera o difratômetro de raios-X gera automaticamente o gráfico de intensidade em função do ângulo $2 \theta$, sendo que os picos esperados para filmes de ITO foram discutidos na seção 2.3.1.10. 


\section{RESULTADOS E DISCUSSÕES}

Neste capítulo são apresentados os resultados da caracterização física, elétrica, óptica, química e estrutural de todas as amostras obtidas neste trabalho.

\subsection{Deposição de ITO/Si variando potência RF de 25 a $100 \mathrm{~W}$}

Nesta seção, são discutidos os resultados da caracterização das amostras de ITO depositadas sobre Si obtidas com $P_{R F}$ variando de 25 a $100 \mathrm{~W}$, obtidas na primeira série de deposições, descrita na seção 3.1.2.1.

\subsubsection{Perfilometria}

Os resultados da espessura $(t)$, rugosidade média $\left(R_{A}\right)$ e rugosidade pico-vale $\left(R_{P V}\right)$ obtidos por perfilometria para as amostras de ITO/Si encontram-se na Tabela 5. Também foram obtidas as rugosidades do substrato de silício.

Tabela 5 - Espessura, rugosidade média e rugosidade pico-vale das amostras de ITO/Si obtidas de

\begin{tabular}{cccccc}
\hline Substrato & \multicolumn{6}{c}{$\mathbf{2 5} \mathbf{a} \mathbf{1 0 0} \mathbf{W}$} & & \\
& $\mathbf{P}_{\mathbf{R F}}(\mathbf{W})$ & $\mathbf{T}_{\mathbf{D}}(\mathbf{m i n})$ & $\mathbf{t}(\mathbf{n m})$ & $\mathbf{R}_{\mathbf{A}}(\mathbf{n m})$ & $\mathbf{R}_{\mathbf{P V}}(\mathbf{n m})$ \\
& Substrato & - & - & $1,81 \pm 0,01$ & $7,2 \pm 0,2$ \\
\multirow{4}{*}{ Silício } & 25 & 30 & $28,51 \pm 0,06$ & $2,7 \pm 0,2$ & $17 \pm 3$ \\
& 50 & 120 & $158 \pm 1$ & $2,9 \pm 0,3$ & $18 \pm 2$ \\
& 75 & 30 & $110,9 \pm 0,9$ & $2,7 \pm 0,3$ & $18 \pm 3$ \\
& 100 & 30 & $168 \pm 1$ & $3,1 \pm 0,4$ & $18 \pm 2$ \\
& 30 & $198 \pm 1$ & $3,4 \pm 0,6$ & $21 \pm 4$ \\
\hline
\end{tabular}

Pelos resultados, percebe-se que $P_{R F}$ não exerce influência muito significativa nas rugosidades das amostras. No entanto, a rugosidade tende a aumentar discretamente com o aumento de $P_{R F}$, provavelmente devido à temperatura de deposição ligeiramente mais elevada, o que causa uma melhora na cristalinidade das amostras. Espessuras mais altas também tendem a resultar em rugosidades maiores. 


\subsubsection{Elipsometria}

Os resultados da espessura $(t)$ e índice de refração $(n)$ obtidos por meio da elipsometria para as amostras de ITO/Si obtidas com $P_{R F}$ variando de 25 a $100 \mathrm{~W}$ encontramse na Tabela 6. Com base nestes resultados, foi obtida a taxa de deposição de cada $P_{R F}$ empregada, como é mostrado na Figura 16.

Tabela 6 - Espessura e índice de refração obtidos por elipsometria das amostras de ITO/Si obtidas com $P_{R F}$ variando de 25 a $100 \mathrm{~W}$

\begin{tabular}{cccc}
\hline $\mathbf{P}_{\mathbf{R F}}(\mathbf{W})$ & $\mathbf{T}_{\mathbf{D}}(\mathbf{m i n} \mathbf{)}$ & $\mathbf{t}(\mathbf{n m})$ & $\mathbf{n}$ \\
Substrato & - & - & $3,85 \pm 0,01$ \\
25 & 30 & $29,05 \pm 0,02$ & $1,90 \pm 0,01$ \\
50 & 120 & $114,1 \pm 0,2$ & $1,97 \pm 0,01$ \\
75 & 30 & $99,3 \pm 0,1$ & $2,00 \pm 0,02$ \\
100 & 30 & $159,0 \pm 0,2$ & $1,94 \pm 0,01$ \\
& 30 & $201,1 \pm 0,3$ & $1,97 \pm 0,01$ \\
\hline
\end{tabular}

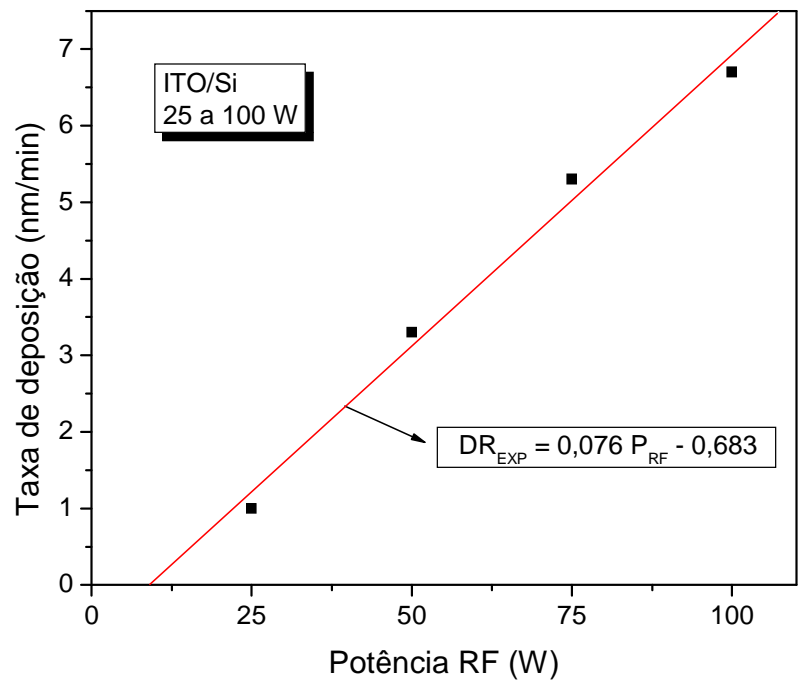

Figura 16 - Taxa de deposição em funcão da $P_{R F}$ para fluxo de argônio em 5 mTorr, com destaque da equação da reta de ajuste linear dos pontos experimentais $\left(D R_{E X P}\right)$

Foi traçada uma reta de ajuste dos pontos experimentais, e a equação da taxa de deposição experimental $\left(D R_{E X P}\right)$ foi obtida, como apresenta a eq.(29). 


$$
D R_{E X P}=0,076 P_{R F}-0,683\left[\frac{n m}{\min }\right]
$$

Como previsto, a taxa de deposição aumenta linearmente de acordo com o aumento da $P_{R F}$, devido ao maior bombardeamento do alvo ${ }^{90}$. Os desvios no padrão linear podem ser causados pela variação de pressão que ocorre dentro da câmara ao longo da deposição, causada pelo eventual desvio do fluxo de gás de processo (já que a pressão é controlada por fluxo de gás).

A taxa de deposição é proporcional à pressão de processo. Este tipo de comportamento é usualmente visto em processos de deposição por sputtering, pois um aumento na pressão causa um maior bombardeamento de íons de argônio na superfície do alvo, causando uma maior pulverização do material ${ }^{91}$. Os erros nas medidas de espessura dos filmes, demonstrados na tabela, também devem influenciar no desvio do padrão esperado.

A reta de ajuste linear não passa pela origem do gráfico porque há uma potência mínima requerida para a formação do plasma no sistema de vácuo. Portanto, abaixo desta potência mínima, não há taxa de deposição, o que resulta em um coeficiente linear na equação da reta.

A partir da eq.(29), é possível estimar a taxa de deposição de processos feitos com potências diferentes das empregadas neste experimento, desde que a pressão (5 mTorr) e o gás de processo (100\% argônio) sejam os mesmos, assim como o substrato (silício). No entanto, mesmo para as mesmas condições, a taxa de deposição pode assumir um padrão não linear para potências mais altas devido ao aumento de temperatura no substrato, que tende a aumentar a taxa de deposição ${ }^{62}$.

\subsubsection{Prova de quatro pontas}

Os resultados de resistência de folha $\left(R_{S}\right)$ obtidos pela prova de quatro pontas, já com o fator de correção considerado, são apresentados na Tabela 7. Também é mostrada a resistividade $(\rho)$ das amostras, calculada de acordo com a eq.(5), comentada na seção 2.3.1.2. As espessuras utilizadas para os cálculos foram as obtidas por elipsometria, e foram considerados apenas os valores médios das medidas. A Figura 17 mostra os resultados de $R_{S} \mathrm{e}$ 
$\rho$ graficamente, sendo que para $P_{R F}=25 \mathrm{~W}$, foi considerada a amostra obtida com $T_{D}=120 \mathrm{~min}$.

Tabela 7 - Resistência de folha e resistividade das amostras de ITO/Si com $P_{R F}$ variando de 25 a $100 \mathrm{~W}$

\begin{tabular}{ccccc}
\hline $\mathbf{P}_{\mathbf{R F}}(\mathbf{W})$ & $\mathbf{T}_{\mathbf{D}}(\mathbf{m i n} \mathbf{)}$ & $\mathbf{t}(\mathbf{n m})$ & $\mathbf{R}_{\mathbf{S}}(\boldsymbol{\Omega} / \square)$ & $\boldsymbol{\rho}(\mathbf{\Omega . c m})$ \\
25 & 30 & 29,05 & $109,2 \pm 0,1$ & $3,2 \times 10^{-4}$ \\
50 & 120 & 114,1 & $377,1 \pm 0,4$ & $4,3 \times 10^{-3}$ \\
75 & 30 & 99,3 & $246,0 \pm 0,3$ & $2,4 \times 10^{-3}$ \\
100 & 30 & 159,0 & $36,0 \pm 0,1$ & $5,7 \times 10^{-4}$ \\
\hline
\end{tabular}

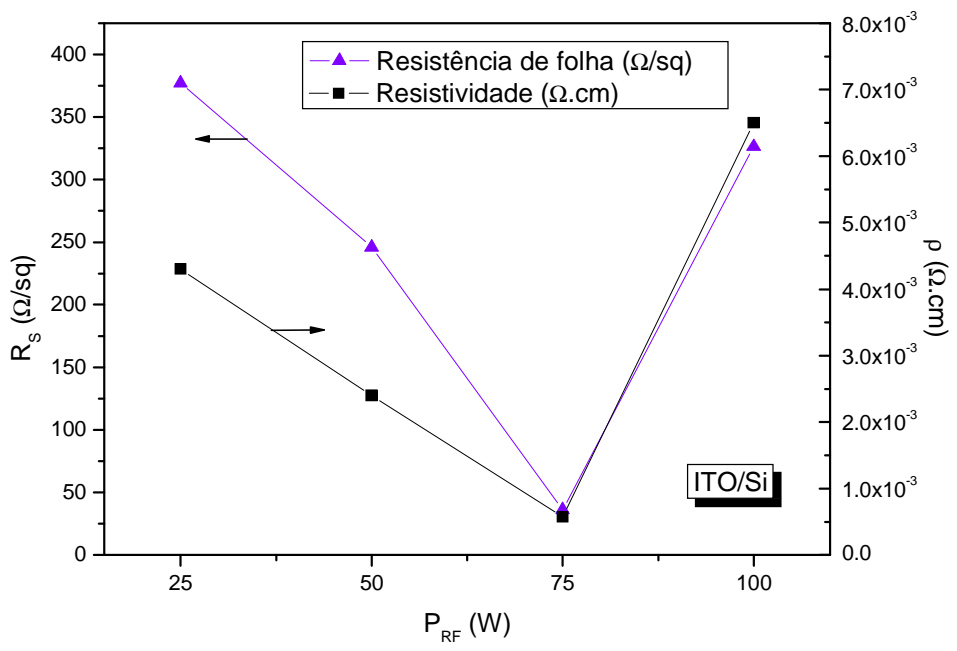

Figura 17 - Resistência de folha e resitividades das amostras de ITO/Si obtidas com $P_{R F}$ variando de 25 a $100 \mathrm{~W}$. Para $P_{R F}=25 \mathrm{~W}$, foi condiderada a amostra obtida com $T_{D}=120 \mathrm{~min}$

Pelos resultados da Tabela 7, nota-se que os menores valores de resistividade foram encontrados para as amostras de $P_{R F}=25 \mathrm{~W}(30 \mathrm{~min})$ e $75 \mathrm{~W}$. No entanto, é possível que o substrato de silício tenha influenciado a medida da prova de quatro pontas de $25 \mathrm{~W}$ (30 min), devido à baixa espessura $(29 \mathrm{~nm})$ da camada de ITO. Além disso, como já havia sido comentado anteriormente, este parâmetro de deposição é inviável para deposição sobre os substratos transparentes usados neste trabalho.

Espera-se que o valor da resistividade dos filmes diminua conforme a $P_{R F}$ aumenta, pois estruturalmente, possíveis estruturas cristalinas dos filmes de ITO são beneficiadas por potências mais altas 90 .

No entanto, observa-se que a maior resistividade foi encontrada para a amostra de $100 \mathrm{~W}$, que apresentou resistividade de folha muito mais alta do que as outras amostras. Uma 
possível causa para este fenômeno é a baixa aderência do filme ao substrato, que pode ter ocorrido devido a uma falha na limpeza do substrato.

\subsubsection{Microanálise}

Os resultados da microanálise para as amostras de ITO/Si obtidas com $P_{R F}$ variando de 25 a $100 \mathrm{~W}$ são apresentados na

Tabela 8, indicando a porcentagem atômica de oxigênio (O), índio (In) e estanho (Sn) na composição dos filmes de ITO, além das contaminações por carbono $(\mathrm{C})$ e nitrogênio $(\mathrm{N})$. Na Figura 18, são mostrados os espectros obtidos durante as medidas. Para uma melhor visualização dos resultados, o gráfico da porcentagem atômica em função da $P_{R F}$ aplicada é mostrado na Figura 19, considerando apenas os elementos constituintes dos filmes de ITO (In, Sn e O).

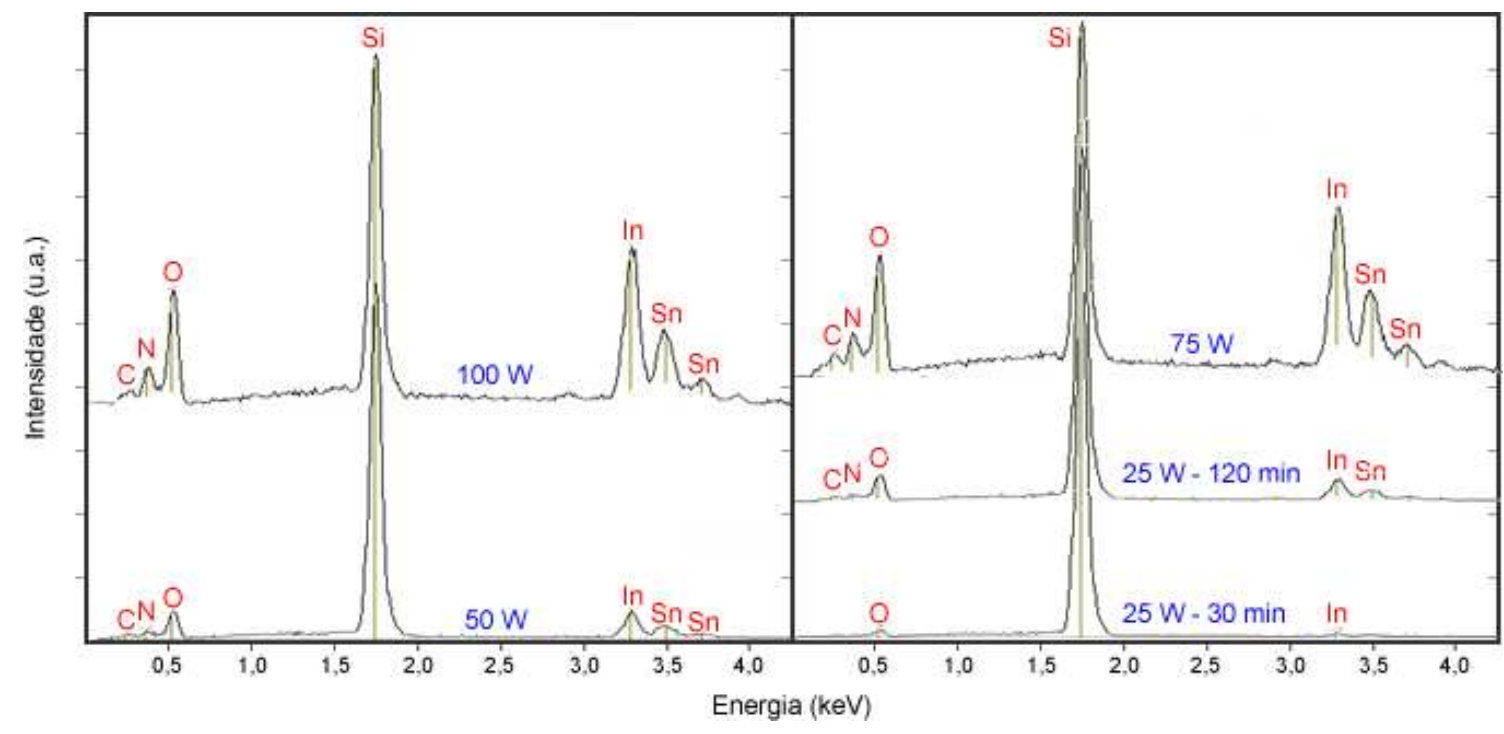

Figura 18 - Espectro de contagens em função da energia obtido pelo microscópio eletrônico de varredura para as amostra de ITO/Si obtidas $\operatorname{com} P_{R F}=75 \mathrm{~W}$.

É perceptível uma maior concentração de oxigênio e menor concentração de dopantes para amostras depositadas em baixas potências. Do ponto de vista químico, esta análise sugere que, dentro da faixa de potência adotada, filmes depositados com $P_{R F}=25 \mathrm{~W}$ tenham a pior característica elétrica (baixa condutividade) e a melhor característica óptica (alta transmitância), enquanto filmes depositados com $P_{R F}=100 \mathrm{~W}$ tenham a melhor característica 
elétrica e a pior característica óptica. No entanto, a amostra obtida a $100 \mathrm{~W}$ foi a mais resistiva, como comentado na seção 4.1.3.

Tabela 8 - Porcentagem atômica dos filmes de ITO/Si de obtidos com $P_{R F}$ variando de 25 a $100 \mathrm{~W}$

\begin{tabular}{ccccc}
$\mathbf{P}_{\mathbf{R F}}(\mathbf{W})$ & $\mathbf{T}_{\mathbf{D}}(\mathbf{m i n})$. & $\mathbf{O}(\boldsymbol{\%})$ & $\mathbf{I n}(\boldsymbol{\%})$ & $\mathbf{S n}(\boldsymbol{\%})$ \\
25 & 30 & 82,5 & 17,5 & - \\
50 & 120 & 80,7 & 18,0 & 1,3 \\
75 & 30 & 78,0 & 19,8 & 2,2 \\
100 & 30 & 70,4 & 26,0 & 3,6 \\
\hline
\end{tabular}

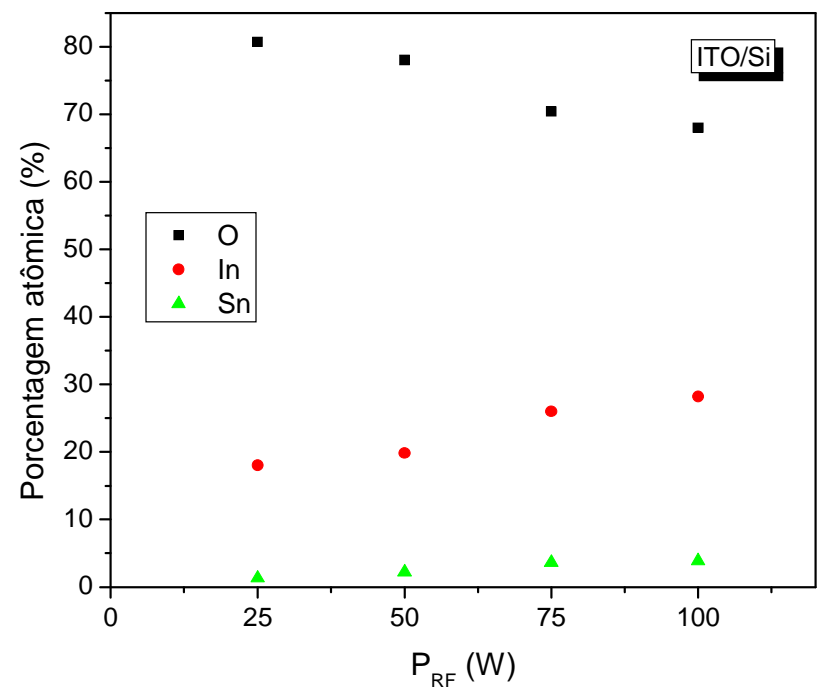

Figura 19 - Porcentagem atômica (considerando apenas In, Sn e O) em função da $P_{R F}$ para as amostras de ITO/Si obtidas com $P_{R F}$ variando de 25 a $100 \mathrm{~W}$

\subsubsection{Difração de raios-X}

Os gráficos de intensidade em função do ângulo $2 \theta$ obtidos pela análise de difração de raios-X para as amostras de ITO/Si obtidas com $P_{R F}$ variando de 25 a $100 \mathrm{~W}$ são mostrados na Figura 20 e na Figura 21.

$\mathrm{O}$ pico de difração encontrado em $2 \theta=32,9^{\circ}$ refere-se à incorporação de índio metálico na composição do filme, de acordo com Kobayashi et al ${ }^{92}$. Isto é atribuído à ausência de oxigênio no gás de sputtering, que fez com que a deposição se fizesse em um estado não completamente oxidado. Segundo Ryabova et al $^{93}$, o mesmo pico é encontrado 
para estruturas de $\mathrm{Sn}_{3} \mathrm{O}_{4}$, que poderiam ter sido formadas devido à não incorporação do dopante. No entanto, o pico foi associado ao índio metálico devido à aparição do mesmo em todas as amostras, inclusive na amostra obtida com $P_{R F}=25 \mathrm{~W}$ e $T_{D}=30 \mathrm{~min}$, que não possui estanho em sua composição, de acordo com os resultados da microanálise, apresentados na seção 4.1.4.

Os picos de maior intensidade esperados para estruturas policristalinas de ITO são $2 \theta=30,5^{\circ}$ e $2 \theta=35,4^{\circ}$, referentes aos planos cristalográficos (222) e (400) de $\operatorname{In}_{2} \mathrm{O}_{3}$, respectivamente. No entanto, como os picos não foram observados para amostras obtidas com $P_{R F}$ variando de 25 a $75 \mathrm{~W}$, conclui-se que a estrutura destes filmes de ITO não apresenta perfil policristalino. Isto é esperado para filmes depositados por sputtering em baixas temperaturas e baixas potências.

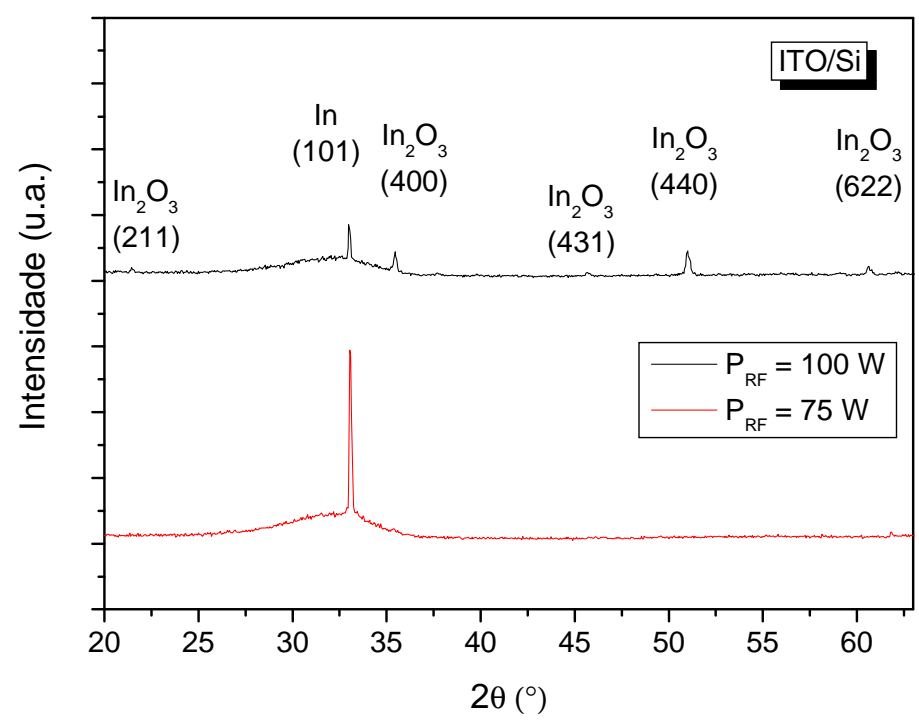

Figura 20 - Difração de raios-X de 20 a $65^{\circ}$ para amostras de ITO/Si obtidas com $P_{R F}=75$ e $100 \mathrm{~W}$

Percebe-se que a intensidade do pico em $2 \theta=32,9^{\circ}$ aumenta de $25 \mathrm{~W}$ a $75 \mathrm{~W}$. Isto é condizente com o resultado da microanálise, que aponta aumento da porcentagem de índio na composição dos filmes proporcionalmente à $P_{R F}$.

A amostra de $P_{R F}=100 \mathrm{~W}$ teve um padrão diferente das demais. Pode-se observar picos cristalográficos também em $2 \theta=21,4^{\circ}, 35,4^{\circ}, 45,6^{\circ}, 50,9^{\circ}$ e $60,6^{\circ}$, indicando uma ordenação cristalina de $\mathrm{In}_{2} \mathrm{O}_{3}$ nos planos (211), (400), (431), (440) e (622), respectivamente. Isto é provavelmente devido à maior energia cinética dos átomos e/ou moléculas que chegam ao substrato na formação do filme para potências mais elevadas, mesmo em baixas 
temperaturas. Estes resultados coincidem com o conceito de que maiores potências favorecem a cristalinidade dos filmes.

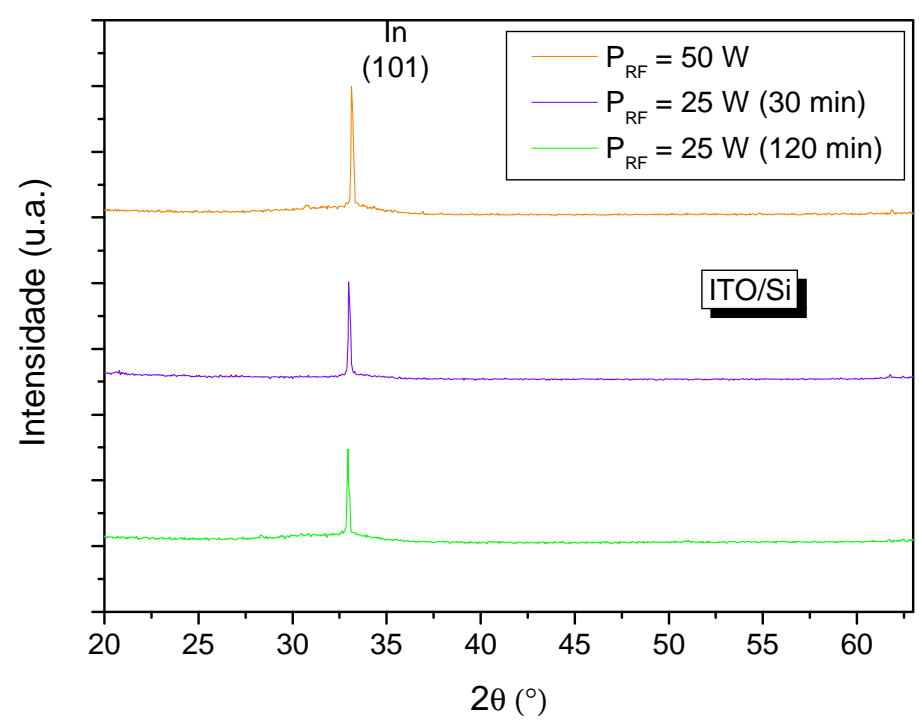

Figura 21 - Difração de raios-X de 20 a $65^{\circ}$ para amostras de ITO/Si obtidas com $P_{R F}=25$ e $50 \mathrm{~W}$

Geralmente, energias mais altas tendem a pulverizar clusters do material, enquanto energias mais baixas pulverizam átomos separadamente. Isto explica por que, para a amostra de $P_{R F}=100 \mathrm{~W}$, a intensidade do pico referente ao índio metálico diminuiu. Provavelmente, a quantidade de índio metálico é menor nesta amostra.

Segundo os resultados da análise de difração de raios-X, a amostra de $P_{R F}=100 \mathrm{~W}$ deveria ter as melhores características elétricas, devido ao início da incorporação do dopante no filme. No entanto, como já comentado anteriormente, esta amostra não se apresentou dentro dos padrões esperados.

\subsection{Deposição de ITO sobre vidro e ITO sobre silício a com potência $R F=75 \mathrm{~W}$ variando o tempo de deposição}

Nesta seção são discutidos os resultados da caracterização das lâminas obtidas com $P_{R F}=75 \mathrm{~W}$ a partir dos processos de deposição descritos na seção 3.1.2.2, com o intuito de analisar a influência da espessura nas características dos filmes. Para amostra de ITO/Si, 
análises de propriedades elétrica, química e de elipsometria foram feitas. Para as amostras de ITO/vidro, a caracterização óptica foi mais detalhada devido à transparência do substrato.

\subsubsection{Perfilometria}

Na Tabela 9 são apresentados os resultados da análise de perfilometria realizado nas amostras de ITO/Si e ITO/vidro obtidas com $P_{R F}=75 \mathrm{~W}$ e $T_{D}$ variando de 30 a $120 \mathrm{~min}$. A tabela mostra a espessura $(t)$, o erro quadrático relativo da espessura $(\% \Delta t)$, a rugosidade média $\left(R_{A}\right)$ e a rugosidade pico-vale $\left(R_{P V}\right)$.

Tabela 9 - Espessura, erro quadrático da espessura, rugosidade média e rugosidade pico-vale das amostras de ITO/Si e ITO/Vidro obtidas $\operatorname{com} P_{R F}=75 \mathrm{~W}$ e diferentes tempos de deposição

\begin{tabular}{cccccc}
\hline Substrato & $\mathbf{T}_{\mathbf{D}}(\mathbf{m i n})$ & $\mathbf{t}(\mathbf{n m})$ & $\mathbf{\% \Delta t} \mathbf{( \% )}$ & $\mathbf{R}_{\mathbf{A}}(\mathbf{n m})$ & $\mathbf{R}_{\mathbf{P V}}(\mathbf{n m})$ \\
& Substrato puro & - & - & $5,5 \pm 0,1$ & $28,9 \pm 0,8$ \\
Vidro & 30 & $197 \pm 3$ & 1,5 & $3,2 \pm 0,4$ & $18 \pm 3$ \\
& 60 & $349 \pm 17$ & 4,9 & $3,4 \pm 0,2$ & $24 \pm 2$ \\
& 90 & $514 \pm 28$ & 5,4 & $3,1 \pm 0,2$ & $23 \pm 2$ \\
& 120 & $675 \pm 47$ & 7,0 & $3,4 \pm 0,6$ & $26 \pm 3$ \\
Silício & Substrato puro & - & - & $1,8 \pm 0,1$ & $7,2 \pm 0,3$ \\
& 30 & $185 \pm 2$ & 1,1 & $2,4 \pm 0,2$ & $14,5 \pm 0,4$ \\
& 60 & $370 \pm 16$ & 4,3 & $2,2 \pm 0,3$ & $21 \pm 3$ \\
& 90 & $440 \pm 21$ & 4,7 & $2,7 \pm 0,6$ & $25 \pm 4$ \\
& 120 & $610 \pm 38$ & 6,2 & $2,6 \pm 0,5$ & $24 \pm 4$ \\
\hline
\end{tabular}

Os resultados da perfilometria indicam que a rugosidade dos filmes de ITO depende da rugosidade do substrato onde foram depositados. Como o substrato de vidro óptico possui rugosidade muito alta, é aconselhável que seja depositada uma camada de planarização entre o substrato e o filme pra aplicações que exijam a superfície do filme pouco rugosa.

As espessuras médias obtidas para amostras de ITO/Si são próximas às esperadas, de acordo com o gráfico da taxa de deposição em função de $P_{R F}$, apresentado na seção 4.1.2. Para as amostras de vidro, as espessuras também não se mostraram muito discrepantes, apesar de se apresentarem, de forma geral, um pouco mais altas do que as de silício. De acordo com Chebotareva et $a l^{94}$, isto ocorre porque as ligações químicas do ITO, que são iônicas, têm uma maior afinidade com o substrato de vidro do que com o de silício, geralmente resultando em espessuras maiores para filmes depositados sobre vidro, mesmo que com processos idênticos. 
O erro absoluto da espessura $(\Delta t)$ tende a aumentar com o aumento da espessura, sugerindo que filmes mais finos têm uma melhor uniformidade. Para uma melhor comparação, é mostrado na Figura 22 o erro relativo da espessura $(\% \Delta t)$ e a espessura $(t)$ em função do tempo de deposição para as amostras de ITO/Vidro. Apesar de $\Delta t$ ser alto para espessuras maiores, os valores médios de $t$ terem apresentado um padrão bem linear.

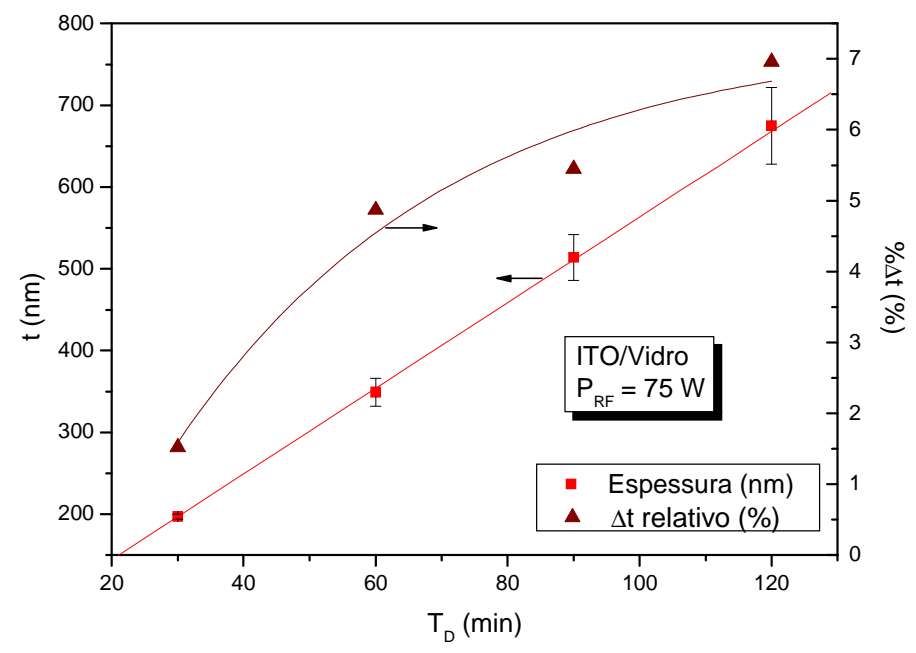

Figura 22 - Espessura e erro relativo da espessura em função do tempo de deposição para amostras de ITO/Vidro obtidas com $P_{R F}=75 \mathrm{~W}$ e $T_{D}$ variando de 30 a 120 min

\subsubsection{Elipsometria}

A elipsometria foi feita apenas para as amostras depositadas sobre silício, pois o equipamento é idealmente utilizado para medir filmes depositados sobre substratos opticamente absorventes no comprimento de onda utilizado $(\lambda=632,8 \mathrm{~nm})$. Os resultados de espessura $(t)$, erro quadrático relativo da espessura $(\% \Delta t)$ e índice de refração $(n)$ para amostras obtidas com $P_{R F}=75 \mathrm{~W}$ e $T_{D}$ variando de 30 a 120 min são mostrados na Tabela 10.

De acordo com os resultados da elipsometria, nota-se que os valores de espessura e de índice de refração das amostras estão dentro da faixa de valores esperada, confirmando a reprodutibilidade dos resultados. Nota-se que $n$ tende a aumentar com o aumento da espessura, mas ainda assim fica em torno de 2. 
Tabela 10 - Espessura e índice de refração obtidos por elipsometria das amostras de ITO/Si obtidas com

\begin{tabular}{|c|c|c|c|c|}
\hline Substrato & $\mathbf{T}_{\mathrm{D}}(\mathbf{m i n})$ & t (nm) & $\% \Delta t(\%)$ & $n$ \\
\hline \multirow{5}{*}{ Silício } & Substrato puro & - & - & 3,85 \\
\hline & 30 & $201,6 \pm 0,3$ & 0,1 & 1,94 \\
\hline & 60 & $355 \pm 13$ & 3,6 & 2,05 \\
\hline & 90 & $480 \pm 19$ & 3,8 & 2,33 \\
\hline & 120 & $650 \pm 27$ & 4,1 & 2,28 \\
\hline
\end{tabular}

Na Figura 23 são apresentados o erro relativo da espessura $(\% \Delta t)$ e a espessura $(t)$ em função do tempo de deposição para as amostras de ITO/Vidro. Apesar de do erro quadrático absoluto $(\Delta t)$ ser alto para espessuras maiores, os valores médios de $t$ terem apresentado um padrão bem linear. Os resultados obtiveram padrão parecido com as amostras de ITO/Vidro, mostrados na Figura 22.

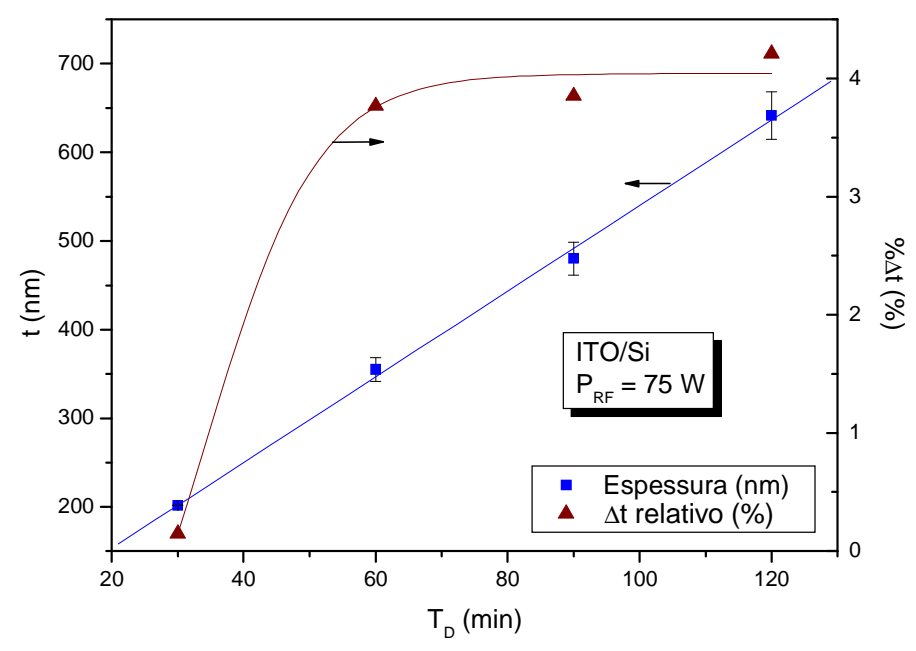

Figura 23 - Espessura e erro relativo da espessura em função do tempo de deposição para amostras de ITO/Si obtidas com $P_{R F}=75 \mathrm{~W}$ e $T_{D}$ variando de 30 a $120 \mathrm{~min}$

\subsubsection{Prova de quatro pontas}

São mostrados na Tabela 11 os valores de resistência de folha $\left(R_{S}\right)$ obtidos pela prova de quatro pontas e o valor da resistividade ( $\rho)$, calculado por meio da eq.(5) (comentada na seção 2.3.1.2) para amostra depositadas com $P_{R F}=75 \mathrm{~W}$ e $T_{D}$ variando de 30 a 120 min. 
Também é apresentado o erro quadrático relativo das medidas de resistência de folha $\left(\% \Delta R_{S}\right)$. Para o cálculo de $\rho$ das amostras, foram utilizados os valores médios de espessura e resistência de folha.

Tabela 11 - Resistência de folha e resistividade das amostras de ITO/Si e ITO/vidro obtidas $\boldsymbol{P}_{R F}=75 \mathrm{~W}$

\begin{tabular}{cccccc}
\hline Substrato & $\mathbf{T}_{\mathbf{D}}(\mathbf{m i n})$ & $\mathbf{t}(\mathbf{n m})$ & $\mathbf{R}_{\mathbf{S}}(\boldsymbol{\Omega} / \square)$ & $\boldsymbol{\%} \Delta \mathbf{R}_{\mathbf{S}}(\boldsymbol{\%})$ & $\boldsymbol{\rho}(\mathbf{\Omega . c m})$ \\
& 30 & 197 & $70 \pm 1$ & 1,4 & $1,4 \times 10^{-3}$ \\
Vidro & 60 & 349 & $33,1 \pm 0,7$ & 2,1 & $1,2 \times 10^{-3}$ \\
& 90 & 514 & $25 \pm 2$ & 8,0 & $1,2 \times 10^{-3}$ \\
& 120 & 675 & $14,3 \pm 0,5$ & 3,4 & $9,6 \times 10^{-4}$ \\
\cline { 2 - 6 } Silício & 30 & 201,6 & $32,7 \pm 0,2$ & 0,6 & $6,6 \times 10^{-4}$ \\
& 60 & 355 & $12,1 \pm 0,2$ & 1,6 & $4,3 \times 10^{-4}$ \\
& 90 & 480 & $7,8 \pm 0,1$ & 1,2 & $3,7 \times 10^{-4}$ \\
& 120 & 650 & $8,3 \pm 0,2$ & 2,4 & $5,4 \times 10^{-4}$ \\
\hline
\end{tabular}

Nota-se que as amostras ITO/vidro apresentaram valores de resistência de folha e resistividade mais elevados do que as de ITO/Si. Isto é provavelmente devido à alta rugosidade do substrato, já que a condutividade elétrica dos filmes de ITO é afetada negativamente pelo espalhamento dos portadores em superfícies rugosas ${ }^{95}$. Sabe-se também que impurezas metálicas contidas nos substratos de vidro podem se difundir para a camada de ITO, aumentando a resistividade de filmes de ITO/vidro comparados a filmes depositados em substratos mais puros ${ }^{96}$. Os resultados reforçam a idéia de que um substrato planarizado apresentaria características melhores para os parâmetros utilizados. Também é possível que haja influência do substrato de silício nas medidas de $R_{S}$.

Utilizando os valores da Tabela 11, são apresentados na Figura 24 os resultados de $R_{S}$ para amostras de ITO/Si, para uma melhor visualização dos resultados. Também é mostrado o erro quadrático relativo das medidas de resistência de folha $\left(\% \Delta R_{S}\right)$, mostrando que filmes com valores mais baixos de espessura tendem a apresentar valores de $R_{S}$ mais uniformes.

Percebe-se que $R_{S}$ tende a diminuir com o aumento da espessura até valores próximos de $t=500 \mathrm{~nm}$. Para espessuras maiores, $R_{S}$ tende a permanecer com um valor constante. Em consequência, $\rho$ tende a diminuir suavemente (levando em consideração que o range de variação do valor de $\rho$ é pequeno em relação ao range de variação de $R_{S}$ ) apenas até este valor de espessura, como é mostrado no gráfico da Figura 25. 


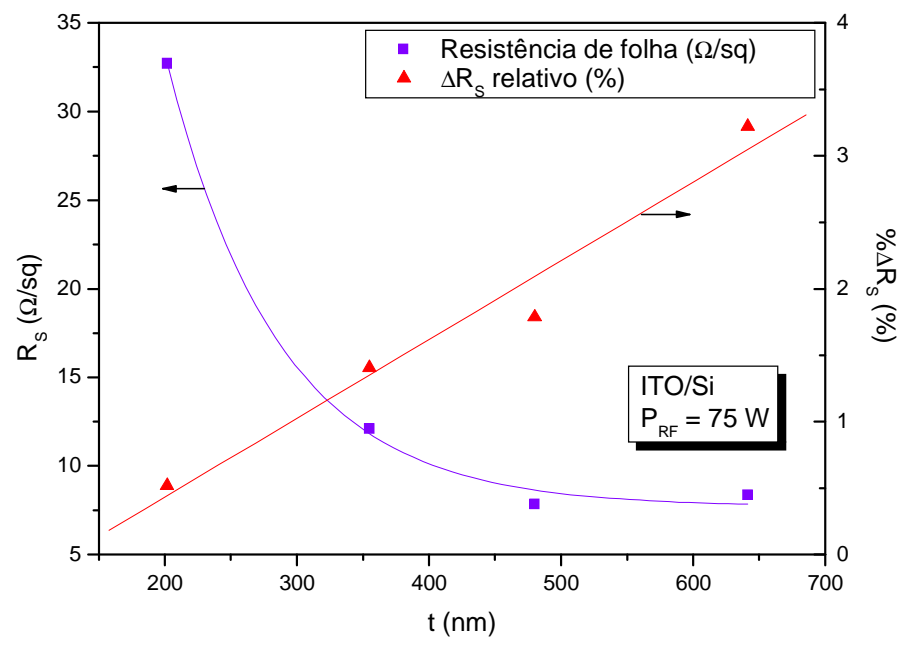

Figura 24 - Resistência de folha e erro relativo da resistência de folha em função do tempo de deposição para amostras de ITO/Si obtidas $\operatorname{com} P_{R F}=75 \mathrm{~W}$ e $T_{D}$ variando de 30 a 120 min

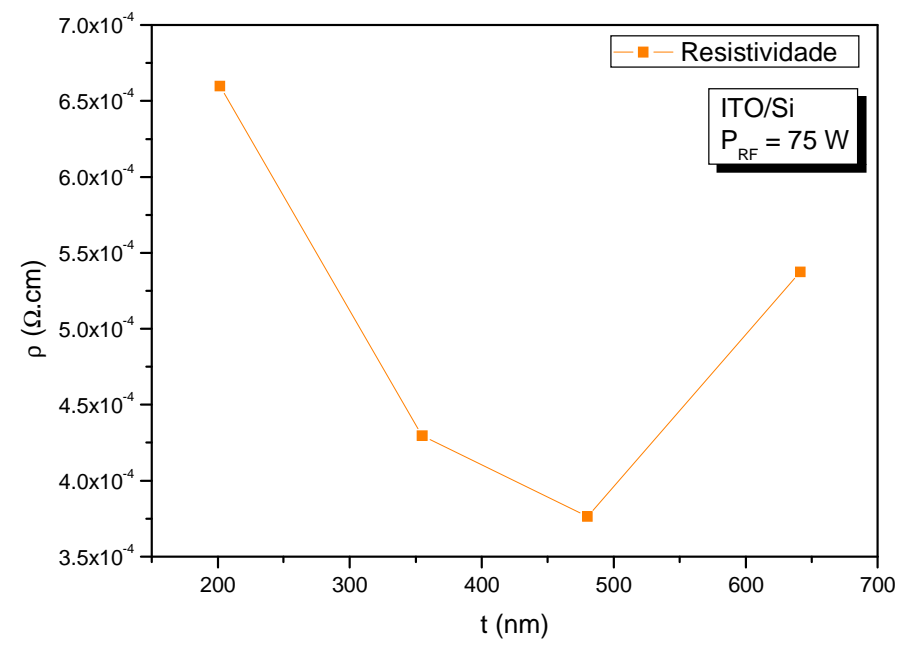

Figura 25 - Resistividade das amostras de ITO/Si $\operatorname{com} P_{R F}=75 \mathrm{~W}$ e $T_{D}$ variando de 30 a $120 \mathrm{~min}$

O gráfico de $R_{S}$ e $\% \Delta R_{S}$ em função da espessura para amostras de ITO/Vidro é apresentado na Figura 26, e $\rho$ para as mesmas amostras é mostrada na Figura 27. Os resultados demonstraram quase os mesmos padrões das amostras de ITO/Si, a não ser pelo fato de que $\rho$ não chegou ao ponto de aumentar. Provavelmente, se amostras com espessuras maiores fossem obtidas, o mesmo fenômeno ocorreria devido à estabilização de $R_{S}$. 


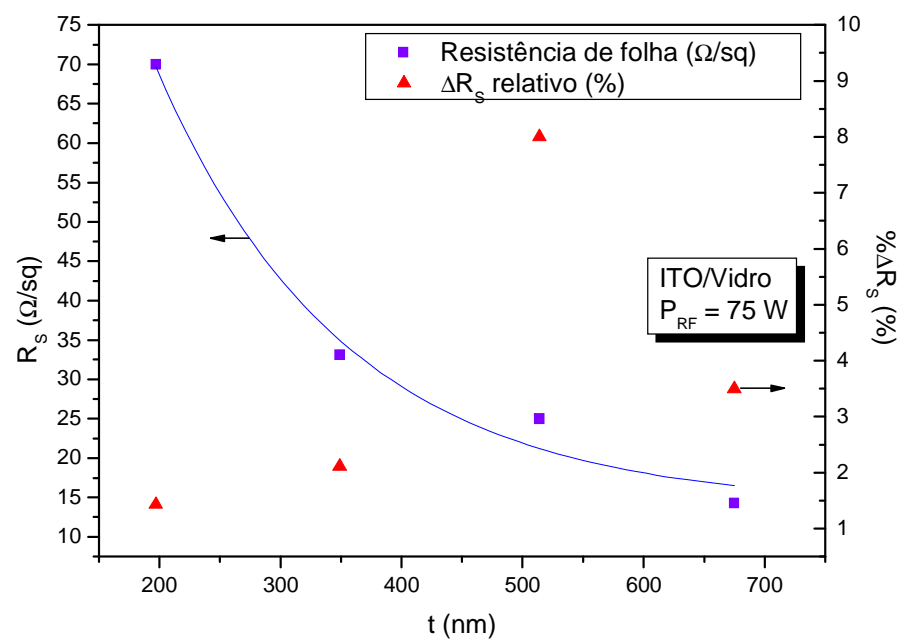

Figura 26 - Resistência de folha e erro relativo da resistência de folha em função do tempo de deposição para amostras de ITO/Vidro obtidas com $P_{R F}=75 \mathrm{~W}$ e $T_{D}$ variando de 30 a $120 \mathrm{~min}$

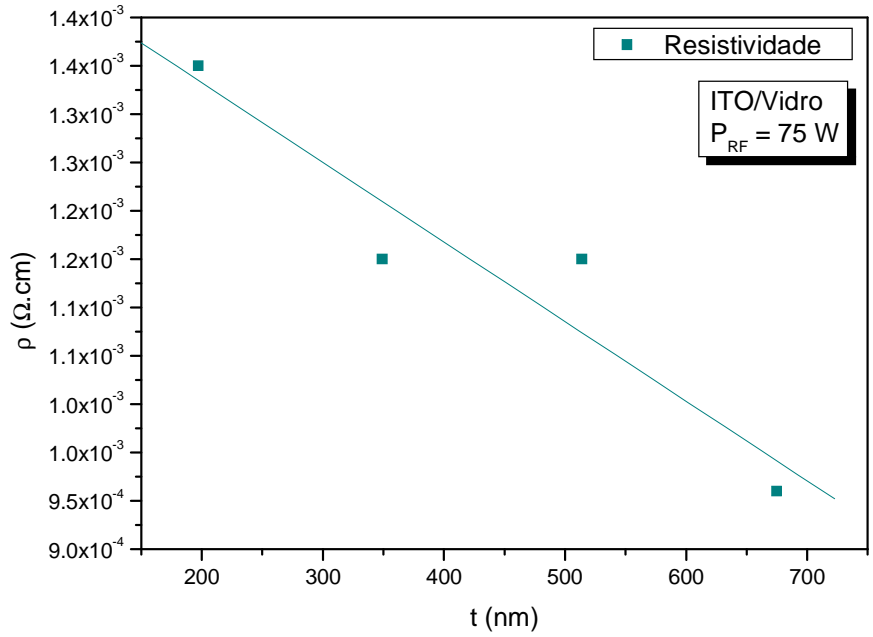

Figura 27 - Resistividade das amostras de ITO/Si com $P_{R F}=75 \mathrm{~W}$ e $T_{D}$ variando de 30 a 120 min

\subsubsection{Microanálise}

São apresentados na Tabela 12 os resultados de porcentagem atômica em função da espessura $(t)$ para as amostras de ITO/Si obtidas com $P_{R F}=75 \mathrm{~W}$ e $T_{D}$ variando de 30 a 120 min, mostrando a porcentagem de oxigênio (O), índio (In) e estanho (Sn) na composição dos filmes. A Figura 28 mostra graficamente os resultados. 
Tabela 12 - Porcentagem atômica dos filmes de ITO/Si obtidos $\operatorname{com} P_{R F}=75 \mathrm{~W}$ e $T_{D}$ variando de 30 a 120 min

\begin{tabular}{cccccc}
\hline Substrato & $\mathbf{T}_{\mathbf{D}}(\mathbf{m i n})$ & $\mathbf{t}(\mathbf{n m})$ & $\mathbf{O}(\boldsymbol{\%})$ & $\mathbf{I n}(\boldsymbol{\%})$ & $\mathbf{S n}(\boldsymbol{\%})$ \\
& 30 & 201,6 & 77,3 & 20,8 & 1,9 \\
\multirow{3}{*}{ Silício } & 60 & 355 & 67,8 & 28,7 & 3,5 \\
& 90 & 480 & 65,7 & 30,8 & 3,5 \\
& 120 & 650 & 67,1 & 30,3 & 2,6 \\
\hline
\end{tabular}

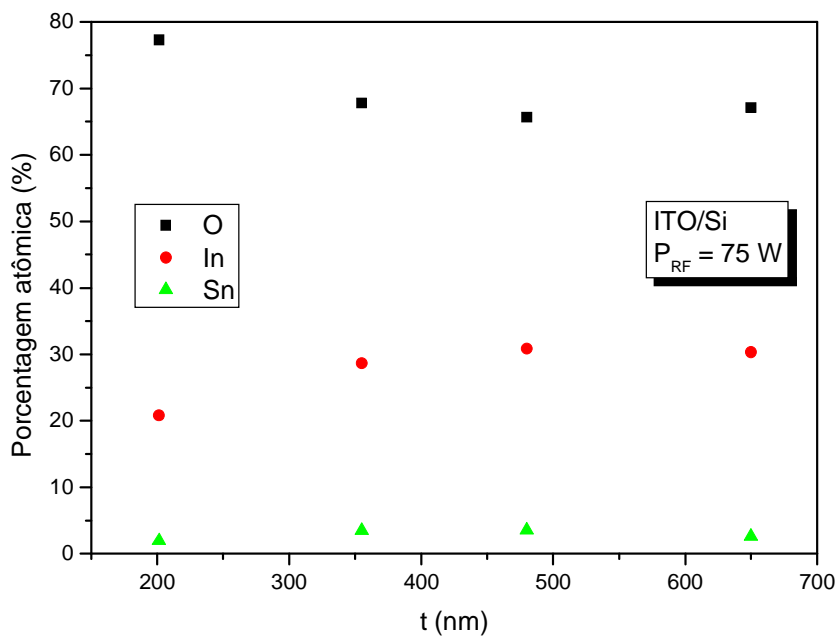

Figura 28 - Porcentagem atômica em função da espessura para amostras de ITO/Si obtidas com $P_{R F}=75 \mathrm{~W}$ e $T_{D}$ variando de 30 a $120 \mathrm{~min}$

Nota-se que a amostra obtida a $P_{R F}=75 \mathrm{~W}$ e $T_{D}=30 \mathrm{~min}$ (em processo idêntico à amostra obtida na primeira série de deposições) obteve resultado muito parecido com o apresentado na seção 4.1.4 para a amostra correspondente. Com o aumento da espessura, o filme tende a apresentar mais metais (In e Sn) em sua composição, similarmente ao que aconteceu com o aumento da $P_{R F}$ no processo anterior. A partir da amostra de $t=480 \mathrm{~nm}$, a porcentagem atômica pareceu estabilizar, mudando pouco com o aumento da espessura. Talvez por isso a resistividade dos filmes passe a aumentar após esta espessura para as amostras de ITO/Si, como foi apresentado na Figura 25, da seção 4.2.3.

Os resultados da porcentagem de oxigênio nos filmes se mostrou similar aos resultados da resistência de folha $\left(R_{S}\right)$, também apresentados na seção 4.2.3 (Figura 24), mostrando que a quantidade de oxigênio na composição do filme influencia diretamente as características elétricas das amostras. 


\subsubsection{Efeito Hall}

$\mathrm{Na}$ Tabela 13, são apresentados os valores de densidade de portadores $(N)$ e mobilidade de portadores $(\mu)$ para as amostras de ITO/vidro.

Tabela 13 - Densidade e mobilidade de portadores das amostras de ITO/Vidro obtidas com $P_{R F}=75 \mathrm{~W}$ e $T_{D}$ variando de 30 a $120 \mathrm{~min}$

\begin{tabular}{ccccc}
\hline Substrato & $\mathbf{T}_{\mathbf{D}}(\mathbf{m i n})$ & $\mathbf{t}(\mathbf{n m})$ & $\mathbf{N}\left(\mathbf{c m}^{-3}\right)$ & $\boldsymbol{\mu}\left(\mathbf{c m}^{2} / \mathbf{V} . \mathbf{s}\right)$ \\
& 30 & 197 & $3,2 \times 10^{20}$ & 10,4 \\
\multirow{3}{*}{ Vidro } & 60 & 349 & $2,3 \times 10^{20}$ & 17,9 \\
& 90 & 514 & $2,9 \times 10^{20}$ & 13,9 \\
& 120 & 675 & $8,9 \times 10^{19}$ & 56,4 \\
\hline
\end{tabular}

Os valores de $N$ e $\mu$ afetam diretamente a condutividade do material, de acordo com a eq.(1). Pela análise dos resultados, observa-se que o aumento da espessura, em geral, favorece a mobilidade e prejudica a concentração de portadores. $\mathrm{O}$ aumento de $N$ não é favorecido por baixas espessuras, possivelmente pela quantidade elevada de oxigênio que se incorpora ao filme durante a deposição. No entanto, este padrão não é seguido tão diretamente. $\mu$ é favorecida pela diminuição da concentração devido à maior facilidade de movimentação dos portadores, mas não a ponto de compensar as perdas causadas na condutividade.

Os valores de $\mu$ se mostraram análogos à melhora da cristalinidade do filme, aumentando muito com o surgimento do pico (400) para a amostra obtida com $T_{D}=120 \mathrm{~min}$, como será comentado na seção 4.2.6. No entanto, o filme ainda parece estar na fase amorfa em sua maior parte. Uma melhora na cristalinidade do material provavelmente favoreceria as medidas de efeito Hall, pois permitiria que a concentração de portadores aumentasse com a ativação dos dopantes sem prejudicar tanto a mobilidade, que seria favorecida pela redução do espalhamento de portadores por defeitos. 


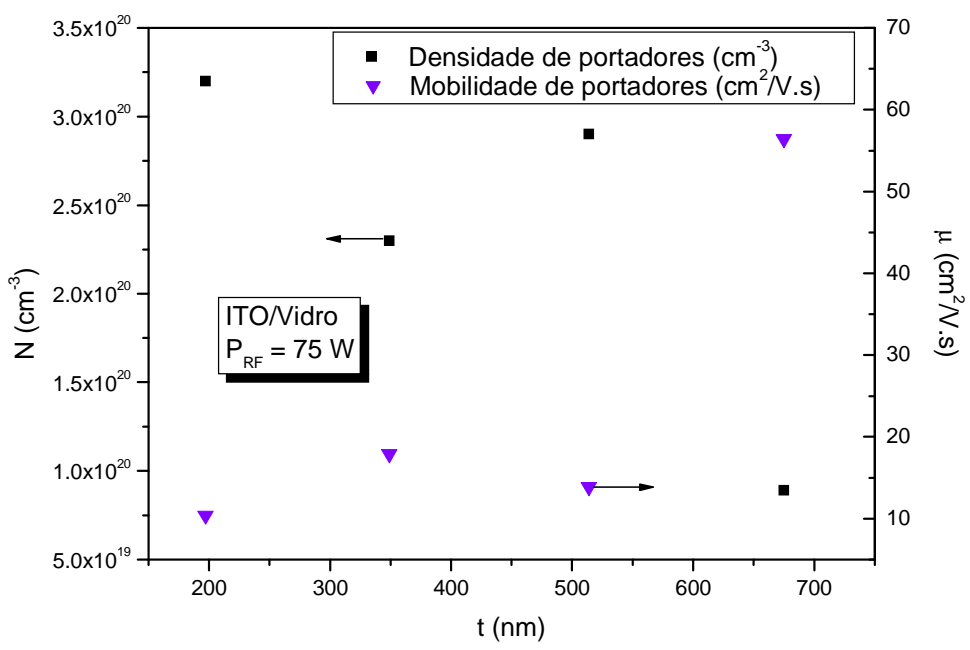

Figura 29 - Densidade $(N)$ e mobilidade $(\mu)$ de portadores das amostras de ITO/Vidro obtidas com $P_{R F}=75 \mathrm{~W}$ e $T_{D}$ variando de 30 a $120 \mathrm{~min}$

\subsubsection{Difração de Raios-X}

Na Figura 30 é apresentado o gráfico de intensidade em função do ângulo $2 \theta$ obtido pela análise de difração de raios-X para as amostras de ITO/Si obtidas com $P_{R F}=75 \mathrm{~W}$ e $T_{D}$ variando de 30 a 120 min.

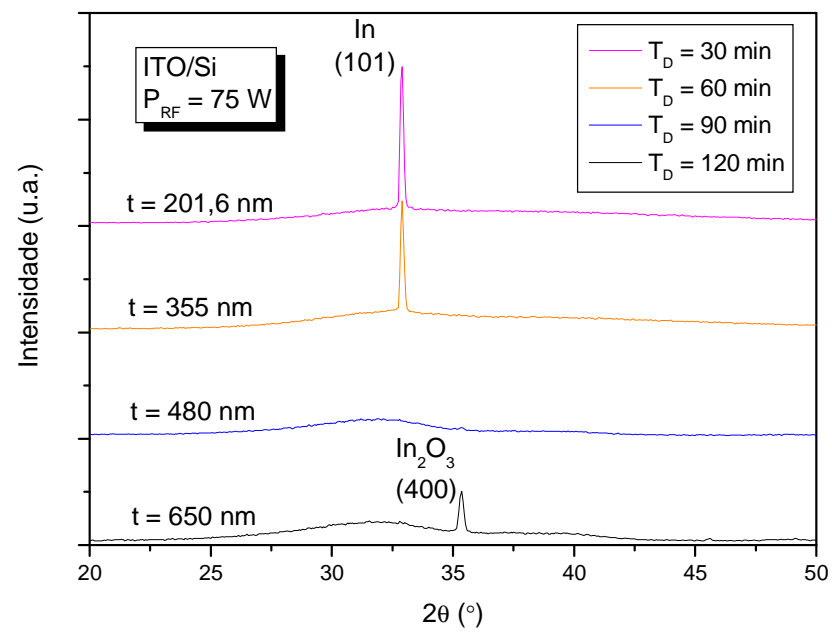

Figura 30 - Difração de raios-X das amostras de ITO/Si obtidas $\operatorname{com} P_{R F}=75 \mathrm{~W}$ e $T_{D}$ variando de 30 a 120 min 
Pela análise do gráfico, percebe-se o mesmo pico (101) de índio metálico em $2 \theta \approx 33^{\circ}$, discutido na seção 4.1.5, apenas para as amostras obtidas com $T_{D}=30$ e $60 \mathrm{~min}$. Nota-se que a intensidade do pico (101) diminui com o aumento de $T_{D}$. Isto é provavelmente devido ao aumento da temperatura do processo (de acordo com a Tabela 3), que facilita a oxidação do índio metálico. Para $T_{D}=90 \mathrm{~min}$, não foi observado nenhum pico de difração (apenas uma banda amorfa), e para $T_{D}=120 \mathrm{~min}$, é observado apenas o pico em $2 \theta=35,4^{\circ}$, associado ao plano (400) de $\operatorname{In}_{2} \mathrm{O}_{3}$, indicando orientação preferencial ao longo da direção [100].

Logo, o aumento da espessura favorece a cristalinidade de filmes de ITO obtidos com uma $P_{R F}$ fixa. Segundo Kim et al ${ }^{97}$, isto ocorre porque, na interface com o substrato, é formado um filme de ITO de estrutura amorfa, e apenas após uma espessura crítica, a fase cristalina se desenvolve no topo da fase amorfa. Essa espessura crítica depende das condições em que os filmes foram depositados, tendendo a diminuir com o aumento da temperatura de processo e potência empregada.

O gráfico de intensidade em função do ângulo $2 \theta$ obtido pela análise de difração de raios-X para a amostra de ITO/vidro obtida com $T_{D}=120$ min é mostrado na Figura 31.

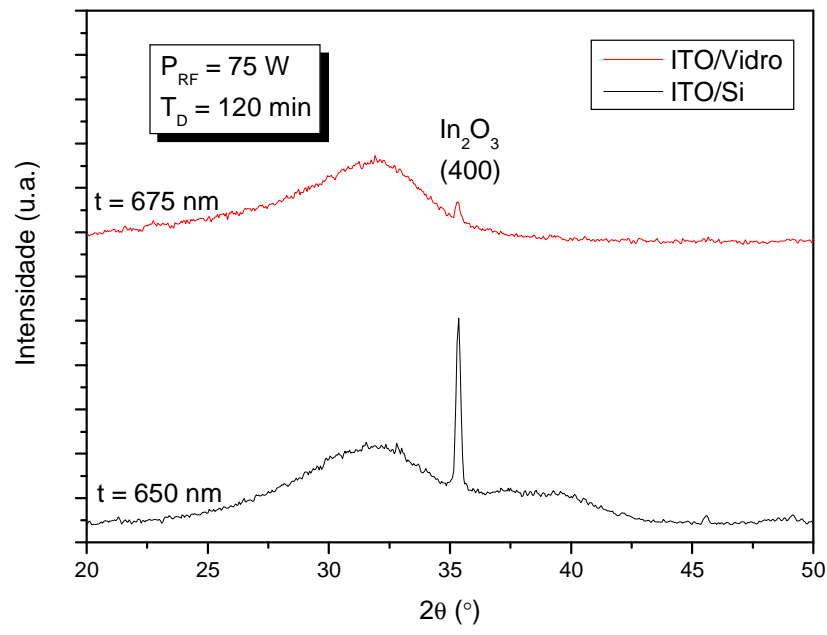

Figura 31 - Difração de raios-X das amostras de ITO/vidro obtidas com $P_{R F}=75 \mathrm{~W}$ e $T_{D}=120 \mathrm{~min}$

Para comparação, foi apresentado também o espectro da amostra obtida em silício com as mesmas condições de processo (que já havia sido apresentado na Figura 30, mas com escala diferente). Os filmes de ITO/vidro com espessuras menores não apresentaram nenhum pico, apenas a banda amorfa característica, e por isso não foram apresentados. 
Através da observação do gráfico, nota-se que as amostras apresentam apenas uma larga banda, típica de filmes amorfos de ITO ${ }^{98}$, indicando que a fase amorfa existe para estas condições de deposição, independente do substrato. Para as duas amostras, é possível observar o pico (400) de $\mathrm{In}_{2} \mathrm{O}_{3}$, porém com intensidades diferentes. Isto indica que há mais cristalitos orientados na direção [100] para o filme de ITO/Si, mostrando que o filme se torna cristalino mais facilmente quando depositado sobre silício.

Gao et al ${ }^{99}$ reportou que filmes de ITO depositados em temperatura ambiente sobre substratos de vidro necessitam de espessuras maiores para se tornarem policristalinos do que filmes depositados sobre silício, usando os mesmos parâmetros de deposição. Shigesato et $a l^{100}$ depositou filmes de ITO por DC magnetron sputtering em vidro utilizando parâmetros semelhantes aos usados nestas amostras, e conseguiu estruturas policristalinas para amostras com espessuras a partir de $170 \mathrm{~nm}$, com melhoras na cristalinidade conforme o aumento da espessura (170-330 nm). A alta rugosidade do substrato de vidro em relação do silício é uma possível causa pela qual a cristalização do filme se torna mais difícil.

Portanto, conclui-se que energias e espessuras mais altas são necessárias para a formação de filmes policristalinos de ITO sobre substratos de vidro.

\subsubsection{Curvas $I-V$}

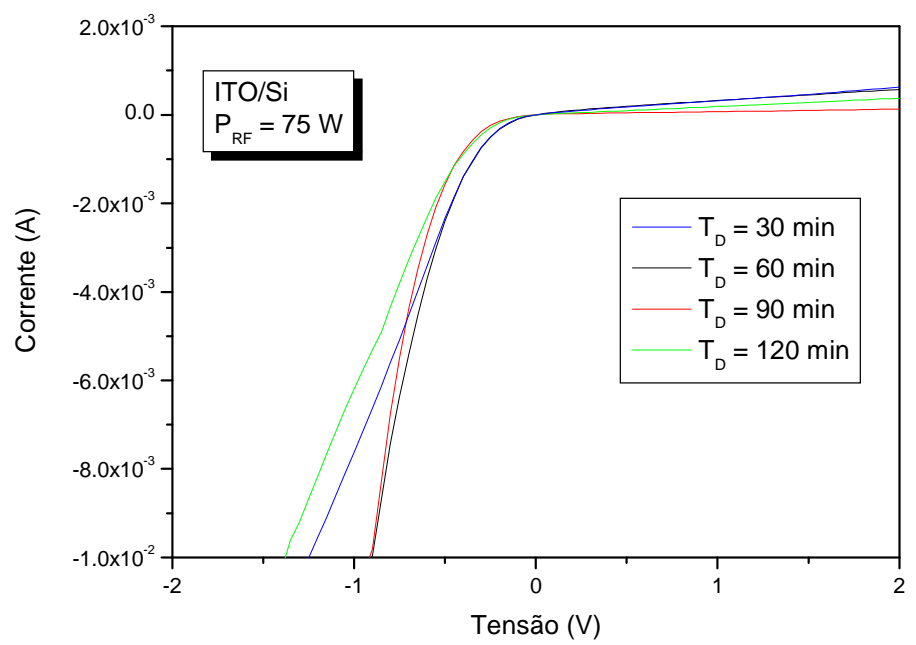

Figura 32 - Curvas $I-V$ das amostras de ITO/Si obtidas com $P_{R F}=75 \mathrm{~W}$ e $T_{D}$ variando de 30 a 120 min 
O contato entre ITO e um semicondutor pode ser caracterizado como ôhmico ou retificador. Contatos ôhmicos são definidos como contatos metal-semicondutor, com curva I-V linear. Neste tipo de contato, a corrente flui em ambas as direções. O contato retificador, também conhecido como contato Schottky, corresponde ao contato no qual a corrente apenas flui em uma direção ${ }^{101}$.

Saim et al ${ }^{102}$ utilizou contatos retificadores de ITO/p-Si para a fabricação de células solares de heterojunção, onde o ITO atua como material tipo n e camada antirrefletora . Sueva et al ${ }^{103}$ fabricou diodos ITO/p-Si para atuarem como detector de nêutron. No entanto, há relatos de trabalhos, como os de Malik et al ${ }^{104}$ e Ashok et al ${ }^{105}$, que fabricaram diodos com a estrutura ITO/n-Si. O tipo de contato formado, portanto, depende do método e dos parâmetros de deposição empregados.

Para as amostras obtidas com $P_{R F}=75 \mathrm{~W}$, o comportamento dos contatos ITO/p-Si é parecido com o de um diodo de junção, onde a corrente flui em apenas uma direção. É observada uma grande variação na resistência de acordo com a tensão aplicada. Portanto, é observado um contato retificador. Como a tensão é aplicada pela camada de ITO (de acordo com a Figura 14, da seção 3.2.3), os diodos tendem a conduzir com a aplicação de tensão negativa. No entanto, não há um padrão definido nas curvas obtidas em função do tempo de deposição empregado.

\subsubsection{Transmitância óptica}

O gráfico da porcentagem de transmitância óptica $(\% T)$ em função do comprimento de onda $(\lambda)$ e o cálculo da porcentagem de transmitância média $\left(\% T_{a}\right)$ no espectro visível $(380<\lambda<750 \mathrm{~nm})$ das amostras de ITO/vidro obtidas com $P_{R F}=75 \mathrm{~W}$ e $T_{D}$ variando de 30 a 120 min são mostrados na Figura 33. Foram apresentados apenas os espectros relativos aos filmes de ITO, sendo que as perdas por absorção e reflexão devidas ao substrato foram subtraídas do gráfico. Se tivessem sido consideradas, as perdas causadas pelo substrato de vidro óptico causam uma redução de aproximadamente $10 \%$ na $\% T$ das amostras, para o espectro visível.

Também é possível notar que a borda de absorção óptica é baixa, se comparada a trabalhos anteriores de amostras amorfas ${ }^{51}$. Isto indica que os filmes possuem boa 
transmitância para baixos valores de $\lambda$ no espectro visível, e sugere que os valores de $E_{\text {opt }}$ destas amostras sejam altos, comparáveis aos de filmes policristalinos.

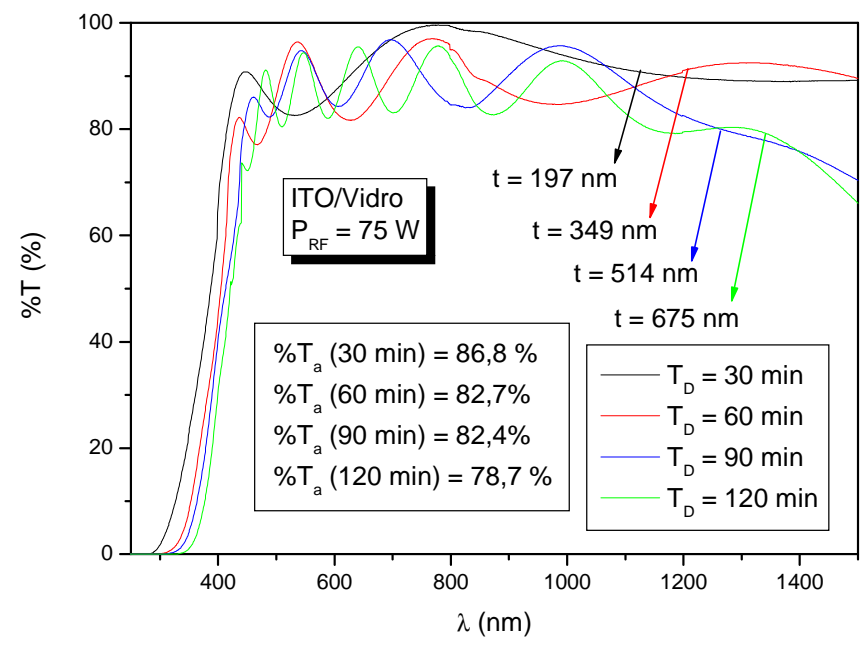

Figura 33 - Porcentagem de transmitância óptica (\%T) em função do comprimento de onda $(\lambda)$ das amostras de ITO/vidro obtidas $\operatorname{com} P_{R F}=75 \mathrm{~W}$ e $T_{D}$ variando de 30 a $120 \mathrm{~min}$, assim como a transmitância média $\left(\% T_{a}\right)$ calculada para o espectro visível $(380<\lambda<750 \mathrm{~nm})$

Na Figura 34, são apresentados os resultados de porcentagem de transmitância média no espectro visível $\left(\% T_{a}\right)$, considerando a faixa $380<\lambda<750 \mathrm{~nm}$, em função da espessura $(t)$. Para comparação, foram também apresentados os dados de resistividade $(\rho)$.

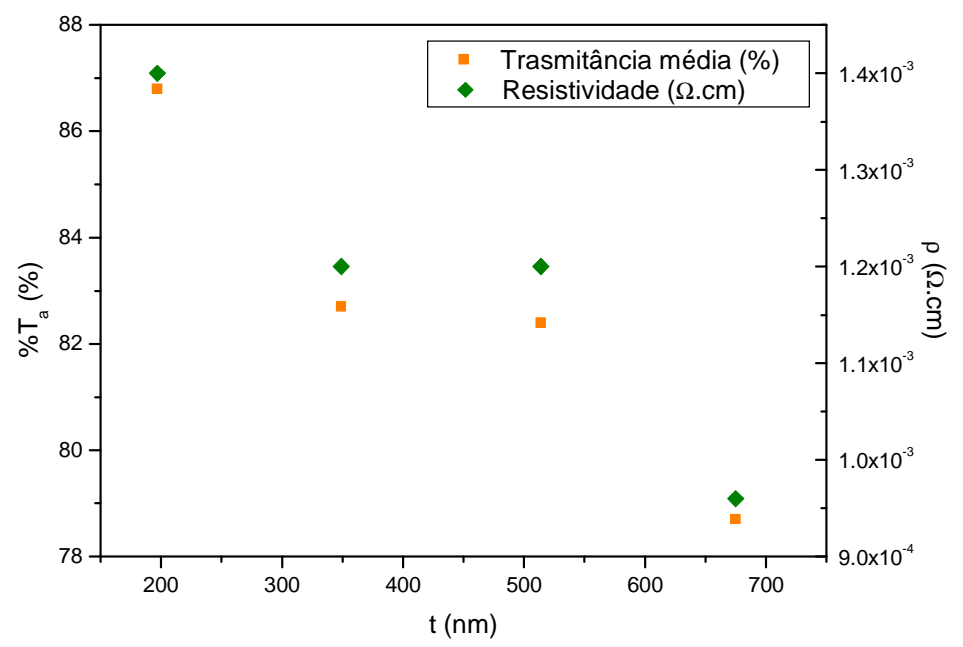

Figura 34 - Porcentagem de transmitância média no espectro visível $\left(\% T_{a}\right)$ em função da espessura $(t)$, em comparação com a resistividade $(\rho)$ das amostras obtidas $\operatorname{com} P_{R F}=75 \mathrm{~W}$ e $T_{D}$ variando de 30 a 120 min 
Nota-se que a transmitância média tende a decrescer com o aumento da espessura. No entanto, o decréscimo provavelmente seria maior caso os filmes não tendessem a incorporar menos oxigênio à sua composição com o aumento da espessura, como foi discutido na seção 4.2.4. Os gráficos de $\% T_{a}$ e $\rho$ apresentam padrões muito parecidos, confirmando o conceito de que altos valores de transmitância, de forma geral, resultam em piores características elétricas.

A partir do gráfico de $\% T$, foram obtidos os gráficos do coeficiente de absorção $(\alpha)$, mostrado na Figura 35, e do coeficiente de extinção ( $\kappa)$, mostrado na Figura 36, de acordo com as equações (7) e (8) comentadas na seção 2.3.1.5.

\subsubsection{Coeficiente de absorção}

A partir da observação da Figura 35, percebe-se que coeficiente de absorção $(\alpha)$ da amostra $T_{D}=30 \mathrm{~min}$ apresenta-se bem mais elevado do que o das outras amostras, sendo que a tendência é $\alpha$ diminuir com o aumento da espessura.

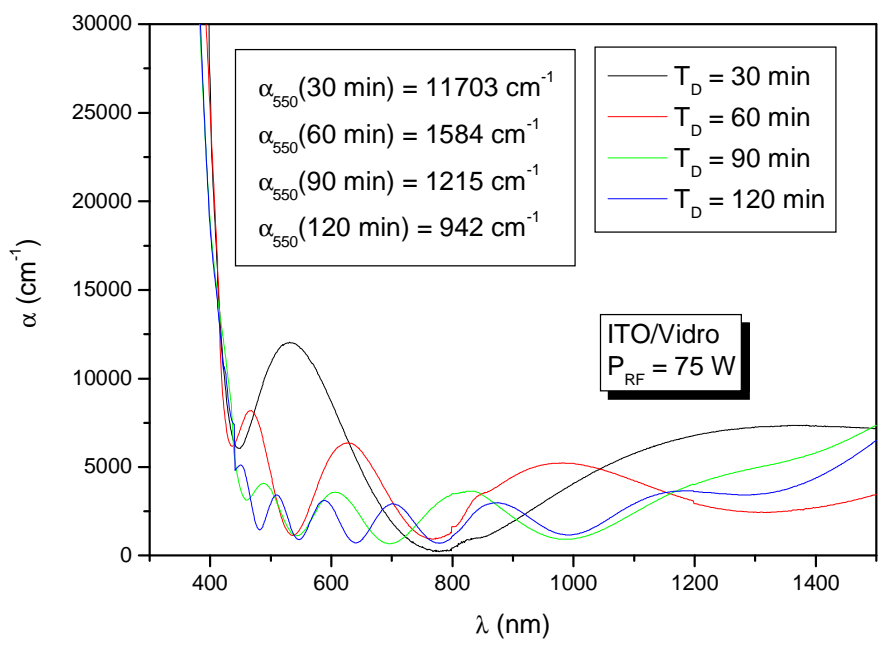

Figura 35 - Gráfico do coeficiente de absorção $(\alpha)$ em função do comprimento de onda $(\lambda)$ para as amostras de ITO/vidro obtidas $\operatorname{com} P_{R F}=75 \mathrm{~W}$ e $T_{D}$ variando de 30 a 120 min, destacando $\alpha$ para $550 \mathrm{~nm}$

Isto não é condizente com o conceito de que maiores espessuras geram maior absorção nos filmes de ITO, mesmo que, para $\lambda=550 \mathrm{~nm}$ (ponto do espectro de luz visível de maior sensibilidade do olho humano), o valor de $\% T_{a}$ seja mais alto para amostra de $T_{D}=30 \mathrm{~min}$. O 
resultado também não condiz com a provável quantidade de oxigênio das amostras, mostrando menor absorção para a amostra de menor $T_{D}$ que, de acordo com os resultados anteriores (seção 4.2.4), produz filmes com maior concentração de oxigênio. Isto indica que, neste trabalho, o espalhamento óptico causado por caminhos ópticos mais longos de acordo com o aumento da espessura é o principal motivo pelo qual o valor de $\% T_{a}$ se mostra decrescente em relação ao aumento de $t$.

\subsubsection{Coeficiente de extinção}

Analisando a Figura 36, nota-se que os valores de $\kappa$ para filmes obtidos com os parâmetros apresentados não passam de 0,1 para o espectro visível, justificando as medidas do índice de refração feitas por elipsometria, que considera apenas a parte real. Como esperado, os valores de $\kappa$ para a amostra de $T_{D}=30$ min mantiveram-se mais elevados, devido à sua maior absorção óptica. No entanto, todos os filmes apresentam coeficientes de extinção típicos de filmes transparentes.

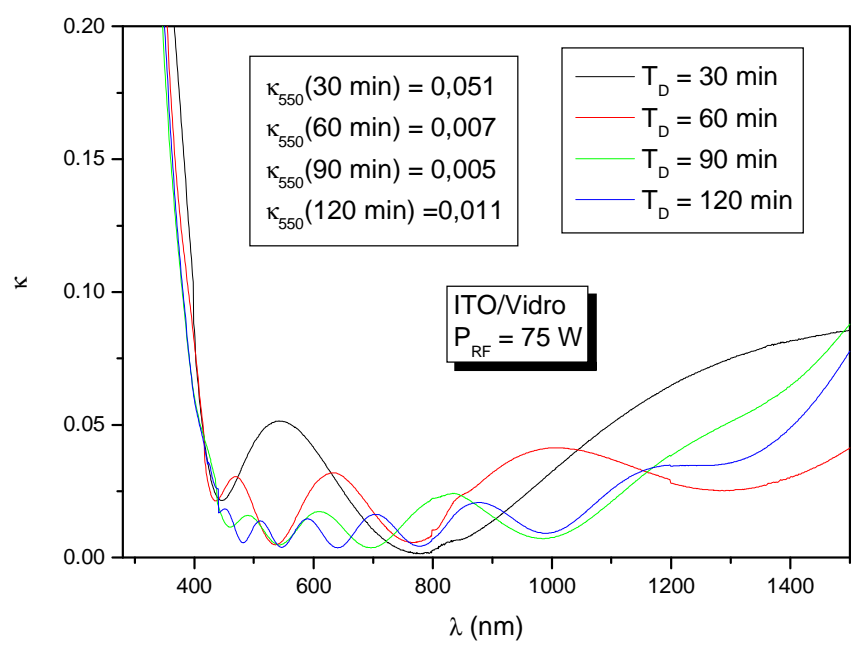

Figura 36 - Gráfico do coeficiente de extinção $(\kappa)$ em função do comprimento de onda para as amostras de ITO/vidro obtidas com $P_{R F}=75 \mathrm{~W}$ e $T_{D}$ variando de 30 a $120 \mathrm{~min}$, destacando $\kappa$ para $550 \mathrm{~nm}$ 


\subsubsection{Band gap óptico}

O band gap óptico das amostras de ITO/vidro, apresentado na Figura 37, foi obtido através da extrapolação da reta presente no gráfico da absorbância em função da energia $(E)$. De acordo com a borda de absorção observada no gráfico de \%T das amostras (Figura 33), esperava-se que os valores de $E_{\text {opt }}$ aumentassem com a espessura. Isto de fato foi observado.

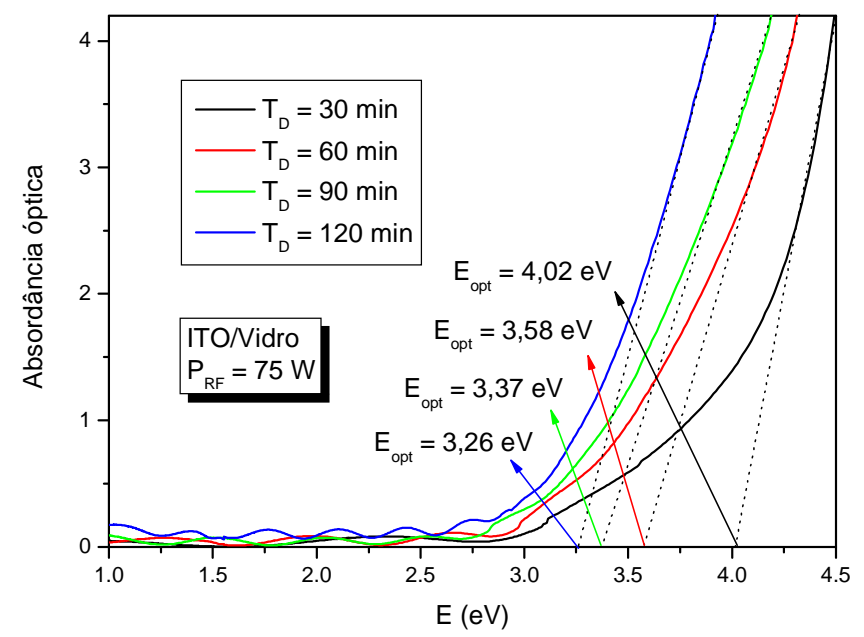

Figura 37 - Absorbância óptica em função da energia $(E)$ das amostras de ITO/vidro obtidas com $P_{R F}=75 \mathrm{~W}$ e $T_{D}$ variando de 30 a $120 \mathrm{~min}$, com a indicação do band gap óptico obtido pela extrapolação da reta

A densidade de portadores, que tendeu a cair com o aumento da espessura, também pode ter proporcionado uma vantagem no $E_{\text {opt }}$ para amostras de menor espessura devido ao efeito Burstein-Moss.

Para filmes amorfos (comparados a filmes cristalinos de espessuras similares), geralmente $E_{\text {opt }}$ apresenta valores menores devido aos defeitos presentes, que aumentam a borda de absorção óptica e diminuem e a transmitância para comprimentos de onda próximos aos do ultravioleta. No entanto, todos os valores de $E_{\text {opt }}$ encontram-se condizentes com a literatura, apresentando valores altos.

No geral, os valores de $E_{\text {opt }}$ aumentam de acordo com o aumento de $\% T_{a}$, sugerindo que filmes que possuem altos valores de $E_{\text {opt }}$ tenham melhores características ópticas. Isto também pode ser observado neste experimento. 


\subsubsection{Figura de mérito}

As figuras de mérito $(\Phi)$ das amostras de ITO/Vidro obtidas com $P_{R F}=75 \mathrm{~W}$ e $T_{D}$ variando de 30 a 120 min, obtidas através da eq.(20) (descrita na seção 2.3.2), são apresentadas na Tabela 14, juntamente com os parâmetros utilizados para o cálculo. Os parâmetros são resistência de folha $\left(R_{S}\right)$ e transmitância média no espectro visível $\left(T_{a}\right)$. Também há uma coluna com os valores de $T_{a}$ já elevados à décima potência $\left(T_{a}{ }^{10}\right)$, para comparação. É notável que, apesar de mais baixos, os valores de $T_{a}{ }^{10}$ apresentam variação muito maior, se comparados aos de $T_{a}$. Isto possibilita que os valores elétricos $\left(R_{S}\right)$ e ópticos $\left(T_{a}^{10}\right)$ utilizados no cálculo tenham importância similar na figura de mérito.

Tabela 14 - Figura de mérito das amostras de ITO/vidro obtidas com $P_{R F}=75 \mathrm{~W}$ e $T_{D}$ variando de 30 a 120 min, juntamente com os parâmetro utilizados no cálculo

\begin{tabular}{cccccc}
\hline Substrato & $\mathbf{T}_{\mathbf{D}}(\mathbf{m i n})$ & $\mathbf{R s}(\boldsymbol{\Omega} / \square)$ & $\mathbf{T}_{\mathbf{a}}$ & $\mathbf{T}_{\mathbf{a}}{ }^{\mathbf{1 0}}$ & $\mathbf{\Phi}\left(\boldsymbol{\Omega}^{-1}\right)$ \\
& 30 & 70 & 0,868 & 0,243 & $3,47 \times 10^{-3}$ \\
Vidro & 60 & 33,1 & 0,827 & 0,150 & $4,53 \times 10^{-3}$ \\
& 90 & 25 & 0,824 & 0,144 & $5,76 \times 10^{-3}$ \\
& 120 & 14,3 & 0,787 & 0,091 & $6,36 \times 10^{-3}$ \\
\hline
\end{tabular}

Os valores de $\Phi$ tenderam a aumentar proporcionalmente ao aumento da espessura das lâminas, como é apresentado graficamente na Figura 38.

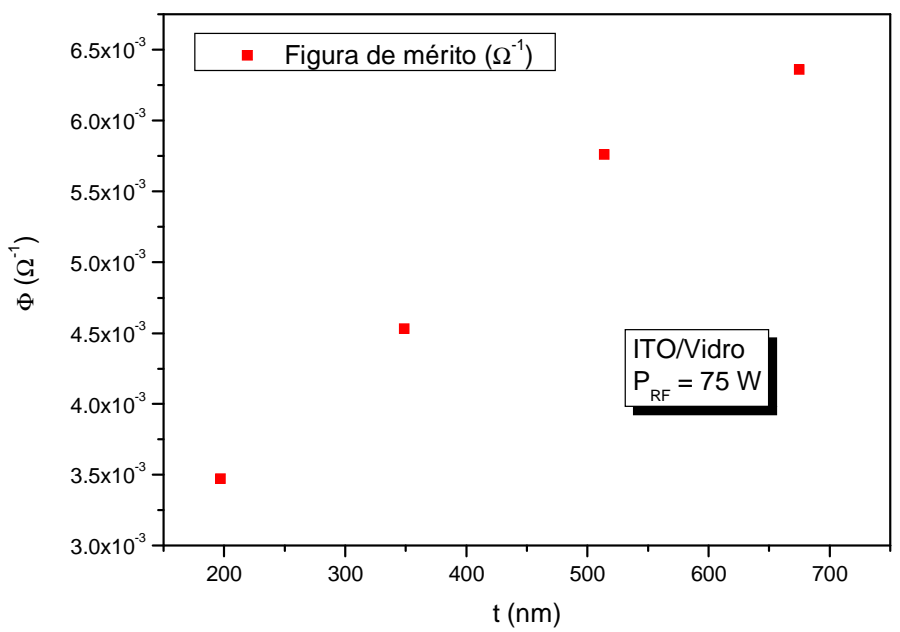

Figura 38 - Figura de mérito das amostras de ITO/Vidro obtidas com $P_{R F}=75 \mathrm{~W}$ e $T_{D}$ variando de 30 a $120 \mathrm{~min}$ 
Levando em consideração apenas dois dos principais parâmetros ópticos e elétricos, conclui-se que a amostra obtida com $T_{D}=120$ min possui características melhores para ser utilizada como eletrodo transparente.

No entanto, é válido lembrar que, por ser um cálculo simples que envolve apenas dois parâmetros, $\Phi$ não deve ser considerado um dado decisivo para a escolha da melhor amostra, e sim ser analisado como referência.

\subsection{Deposição de ITO sobre vidro e ITO sobre silício com potência RF variando de 100 a $200 \mathrm{~W}$}

Serão discutidos aqui os resultados da caracterização das lâminas obtidas com $P_{R F}$ variando de 100 a $200 \mathrm{~W}$ a partir dos processos de deposição descritos na seção 3.1.2.3, com o intuito de analisar a influência de altas potências nas características dos filmes. Para amostra de ITO/Si, análises de propriedades elétrica, química e de elipsometria foram feitas. Para as amostras de ITO/vidro, a caracterização óptica foi mais detalhada devido à transparência do substrato.

\subsubsection{Perfilometria}

São mostrados na Tabela 15 os resultados da análise de perfilometria realizado nas amostras de ITO/Si e ITO/vidro obtidas com $P_{R F}$ variando de 100 a $200 \mathrm{~W}$. A tabela mostra a espessura $(t)$, a rugosidade média $\left(R_{A}\right)$ e a rugosidade pico-vale $\left(R_{P V}\right)$.

Os tempos de deposição, que foram calculados de acordo com o gráfico apresentado na Figura 16 (seção 4.1.2), indicavam que os filmes teoricamente teriam espessuras em torno de $300 \mathrm{~nm}$. Isto de fato ocorreu para as amostras de ITO/Si, com exceção da amostra obtida a $P_{R F}=150 \mathrm{~W}$. O desvio da espessura foi atribuído a erros no processo de deposição, e não à $P_{R F}$ aplicada.

No entanto, para as amostras de ITO/Vidro, todas os filmes obtiveram espessuras em torno de $400 \mathrm{~nm}$. Isto pode ocorrer porque as ligações químicas do ITO, que são iônicas, têm uma maior afinidade com o substrato de vidro do que com o de silício, geralmente resultando 
em espessuras maiores para filmes depositados sobre vidro, mesmo que com processos idênticos ${ }^{94}$. Apesar de o resultado ter se apresentado diferente do esperado, o objetivo do experimento era obter valores similares de $t$ para as amostras obtidas sobre o mesmo substrato, o que não foi muito comprometido.

Tabela 15 - Espessura, rugosidade média e rugosidade pico-vale das amostras de ITO/Si e ITO/Vidro obtidas com $P_{R F}$ variando de 100 a $200 \mathrm{~W}$

\begin{tabular}{ccccc}
\hline Substrato & $\mathbf{P}_{\mathbf{R F}}(\mathbf{W})$ & $\mathbf{t}(\mathbf{n m})$ & $\mathbf{R}_{\mathbf{A}}(\mathbf{n m})$ & $\mathbf{R}_{\mathbf{P V}}(\mathbf{n m})$ \\
& Substrato puro & - & $5,5 \pm 0,1$ & $28,9 \pm 0,8$ \\
& 100 & $390 \pm 19$ & $3,1 \pm 0,4$ & $25 \pm 1$ \\
Vidro & 125 & $410 \pm 21$ & $3,0 \pm 0,3$ & $21 \pm 2$ \\
& 150 & $380 \pm 19$ & $3,4 \pm 0,4$ & $22 \pm 2$ \\
& 175 & $420 \pm 15$ & $4,3 \pm 0,5$ & $25 \pm 2$ \\
& 200 & $410 \pm 20$ & $4,1 \pm 0,3$ & $29 \pm 1$ \\
& Substrato puro & - & 1,8 & 7,2 \\
Silício & 100 & $290 \pm 16$ & $2,0 \pm 0,3$ & $11 \pm 1$ \\
& 125 & $300 \pm 21$ & $2,2 \pm 0,2$ & $12 \pm 1$ \\
& 150 & $257 \pm 9$ & $1,9 \pm 0,1$ & $14 \pm 1$ \\
& 175 & $290 \pm 13$ & $2,2 \pm 0,3$ & $14 \pm 1$ \\
& 200 & $310 \pm 12$ & $2,5 \pm 0,1$ & $16 \pm 1$ \\
\hline
\end{tabular}

Para as amostras de ITO/Si, os valores de rugosidade tenderam a aumentar discretamente com o aumento da $P_{R F}$, apesar de o padrão não estar bem definido. Isto é observado especialmente para $R_{P V}$. Isto pode estar atribuído à mudança das características estruturais das amostras de acordo com o aumento de $P_{R F}$.

\subsubsection{Elipsometria}

A elipsometria foi feita apenas para as amostras depositadas sobre silício, pois o equipamento é idealmente utilizado para medir filmes depositados sobre substratos opticamente absorventes no comprimento de onda utilizado $(\lambda=628 \mathrm{~nm})$. Os resultados de espessura $(t)$, erro quadrático absoluto da espessura $(\Delta t)$ e índice de refração $(n)$ para amostras obtidas com $P_{R F}$ variando de 100 a $200 \mathrm{~W}$ são mostrados na Tabela 16. Observa-se que os valores de $n$ não se apresentam dependentes da $P_{R F}$ aplicada. Como foi observado anteriormente (seção 4.2.2), os valores de $n$ parecem aumentar com o aumento da espessura, mas não tendem a variar muito. 
Tabela 16 - Espessura e índice de refração obtidos por elipsometria das amostras de ITO/Si obtidas com $P_{R F}$ variando de 100 a $200 \mathrm{~W}$

\begin{tabular}{cccc}
\hline Substrato & $\mathbf{P}_{\mathbf{R F}}(\mathbf{W})$ & $\mathbf{t}(\mathbf{n m})$ & $\mathbf{n}$ \\
& Substrato puro & - & 3,85 \\
& 100 & $300 \pm 15$ & 2,30 \\
Silício & 125 & $300 \pm 17$ & 2,22 \\
& 150 & $243 \pm 4$ & 2,03 \\
& 175 & $308 \pm 9$ & 2,27 \\
& 200 & $327 \pm 9$ & 2,35 \\
\hline
\end{tabular}

\subsubsection{Prova de quatro pontas}

Na Tabela 17 são mostrados os valores de resistência de folha $\left(R_{S}\right)$ obtidos pela prova de quatro pontas e o valor da resistividade $(\rho)$, calculado por meio da eq.(5) (comentada na seção 2.3.1.2) para amostra depositadas com $P_{R F}=75 \mathrm{~W}$ e $T_{D}$ variando de 30 a $120 \mathrm{~min}$. Para o cálculo de $\rho$ das amostras, foram utilizados os valores médios de espessura e resistência de folha. A Figura 39 mostra os resultados de $R_{S}$ e $\rho$ para as amostras de ITO/Vidro, e a Figura 40 mostra os mesmos resultados para amostras de ITO/Si.

Espera-se que o valor da resistividade dos filmes diminua conforme a $P_{R F}$ aumenta, pois possíveis estruturas cristalinas dos filmes de ITO são beneficiadas por potências mais altas ${ }^{90}$. Também foi observada a tendência de menor incorporação de oxigênio em filmes depositados a potências altas (seção 4.1.4).

Tabela 17 - Resistência de folha e resistividade das amostras de ITO/Vidro e ITO/Si obtidas com $\boldsymbol{P}_{R F}$ variando de 100 a $200 \mathrm{~W}$

\begin{tabular}{ccccc}
\hline Substrato & $\mathbf{P}_{\mathbf{R F}}(\mathbf{W})$ & $\mathbf{t}(\mathbf{n m})$ & $\mathbf{R}_{\mathbf{S}}(\mathbf{\Omega} / \square)$ & $\boldsymbol{\rho}(\mathbf{\Omega . c m})$ \\
& 100 & 390 & $29,7 \pm 0,3$ & $1,2 \times 10^{-3}$ \\
\multirow{3}{*}{ Vidro } & 125 & 410 & $9,3 \pm 0,2$ & $3,8 \times 10^{-4}$ \\
& 150 & 380 & $8,5 \pm 0,2$ & $3,2 \times 10^{-4}$ \\
& 175 & 420 & $8,0 \pm 0,2$ & $3,4 \times 10^{-4}$ \\
& 200 & 410 & $7,51 \pm 0,06$ & $3,1 \times 10^{-4}$ \\
\cline { 2 - 5 } Silício & 100 & 300 & $10,24 \pm 0,04$ & $3,1 \times 10^{-4}$ \\
& 125 & 300 & $7,25 \pm 0,03$ & $2,2 \times 10^{-4}$ \\
& 150 & 243 & $7,28 \pm 0,04$ & $1,8 \times 10^{-4}$ \\
& 175 & 308 & $7,13 \pm 0,03$ & $2,2 \times 10^{-4}$ \\
& 200 & 327 & $6,40 \pm 0,08$ & $2,1 \times 10^{-4}$ \\
\hline
\end{tabular}

Os valores de $R_{S}$ e $\rho$ se mostraram muito parecidos, devido à similaridade da espessura das amostras. Para os filmes de ITO/Vidro, houve uma grande melhora nas características 
elétricas a partir de $P_{R F}=125 \mathrm{~W}$, que se manteve relativamente estável para potências mais altas. Para as amostras de ITO/Si, os resultados foram mais uniformes, mas mantiveram o mesmo padrão. Esta análise sugere que, do ponto de vista elétrico, energias maiores (aumento da $P_{R F}$ e, consequentemente, da temperatura do substrato) são favoráveis para deposições de filmes de ITO sobre vidro, pois é possível que, nestas condições, haja menor influência da rugosidade do substrato nas características elétricas.

Estes resultados reforçam que as características elétricas da amostra de ITO/Si obtida com $P_{R F}=100 \mathrm{~W}$ na primeira série de deposições (discutidas na seção 4.1.3) não se mostraram condizentes com o padrão obtido na literatura e nas outras amostras deste trabalho.

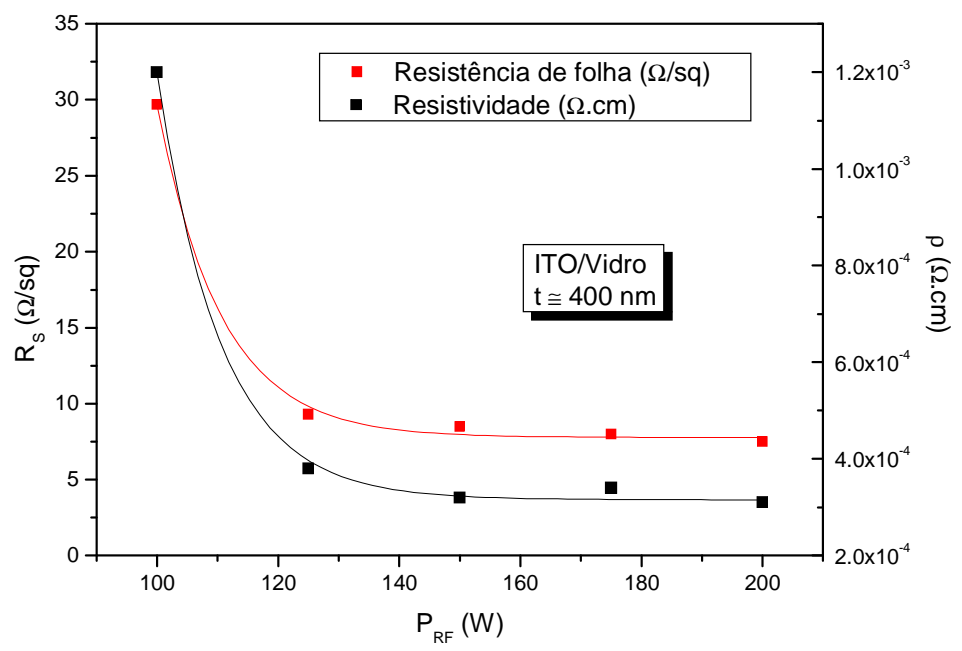

Figura 39 - Resistência de folha e resistividade em função da $\boldsymbol{P}_{R F}$ para amostras de ITO/Vidro obtidas $\operatorname{com} P_{R F}$ variando de 100 a $200 \mathrm{~W}$ 


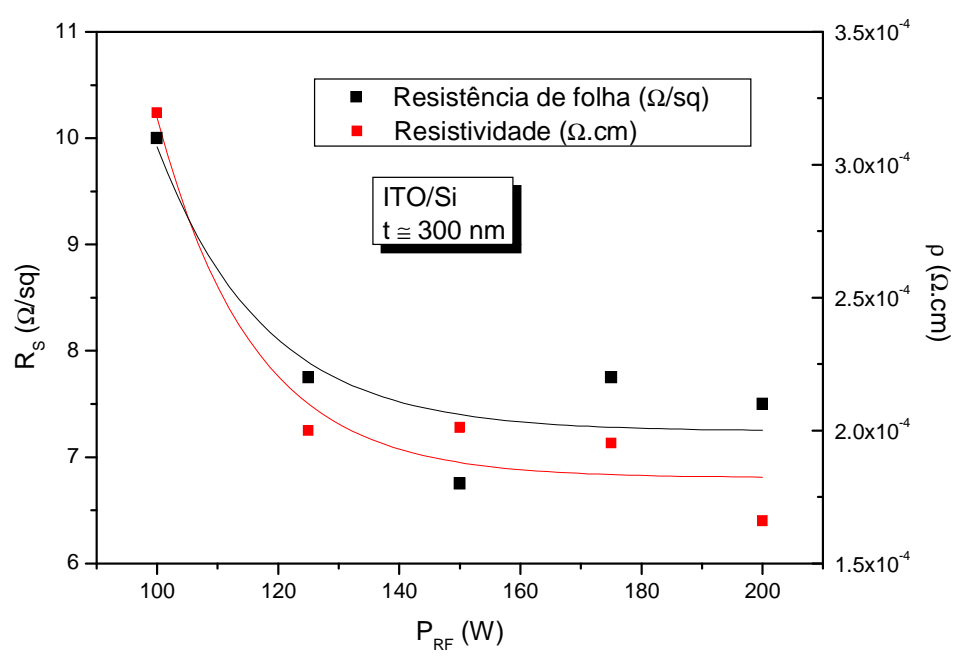

Figura 40 - Resistência de folha e resistividade em função da $\boldsymbol{P}_{R F}$ para amostras de ITO/Si obtidas com $P_{R F}$ variando de 100 a $200 \mathrm{~W}$

\subsubsection{Microanálise}

Na Tabela 18 são apresentados os resultados de porcentagem atômica em função da $P_{R F}$ aplicada para as amostras de ITO/Si obtidas com $P_{R F}$ variando de 100 a $200 \mathrm{~W}$, mostrando a porcentagem de oxigênio (O), índio (In) e estanho (Sn) na composição dos filmes de ITO/Si obtidos com $P_{R F}$ variando de 100 a $200 \mathrm{~W}$. A análise foi feita apenas para amostras depositadas sobre silício devido à maior pureza do substrato. A Figura 41 mostra graficamente os resultados.

Como havia sido observado anteriormente (seção 4.1.4), a incorporação de oxigênio tende a decrescer e a incorporação dos metais tende a crescer com o aumento da $P_{R F}$ aplicada. No entanto, a variação é muito mais discreta para estas potências, e a partir de $P_{R F}=150 \mathrm{~W}$, os valores tendem a estabilizar. Isto sugere que as mudanças nas características elétricas e ópticas dos filmes a partir de uma $P_{R F}$ crítica (próxima de $150 \mathrm{~W}$, para estas amostras) ocorrem principalmente por fatores estruturais dos filmes ou pelo tipo de ligações químicas formada. 
Tabela 18 - Porcentagem atômica das amostras de ITO/Si obtidas com $P_{R F}$ variando de 100 a $200 \mathrm{~W}$

\begin{tabular}{cccccc}
\hline Substrato & $\mathbf{P}_{\mathbf{R F}}(\mathbf{W})$ & $\mathbf{t}(\mathbf{n m})$ & $\mathbf{O}(\boldsymbol{\%})$ & $\mathbf{I n}(\boldsymbol{\%})$ & Sn $(\boldsymbol{\%})$ \\
& 100 & 300 & 67,7 & 29,4 & 2,9 \\
\multirow{3}{*}{ Silício } & 125 & 300 & 69,0 & 28,3 & 2,7 \\
& 150 & 243 & 64,8 & 31,9 & 3,3 \\
& 175 & 308 & 65,3 & 31,6 & 3,1 \\
& 200 & 327 & 65,3 & 31,7 & 3,0 \\
\hline
\end{tabular}

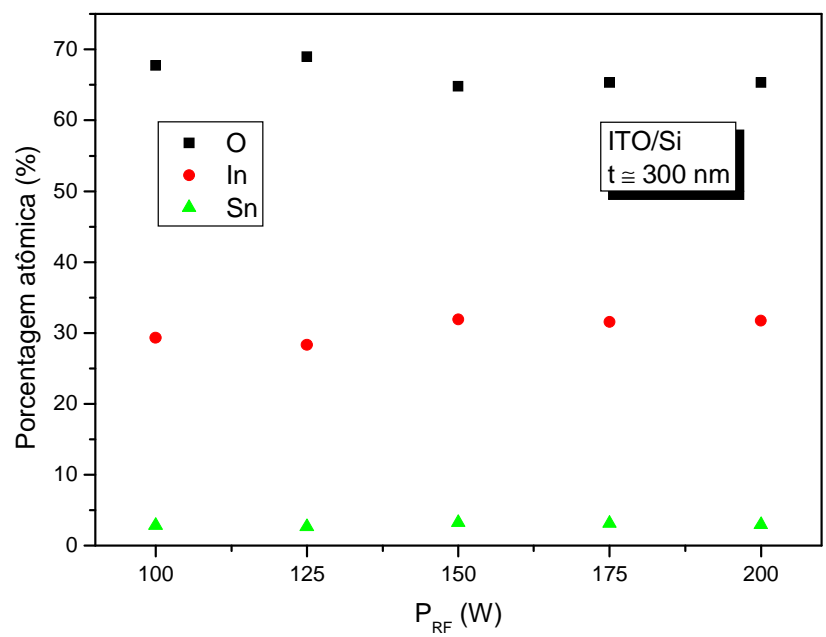

Figura 41 - Porcentagem atômica das amostras de ITO/Si obtidas com $P_{R F}$ variando de 100 a $200 \mathrm{~W}$

\subsubsection{Efeito Hall}

$\mathrm{Na}$ Tabela 19, são apresentados os valores de densidade de portadores $(N)$ e mobilidade de portadores $(\mu)$ para as amostras de ITO/Vidro obtidas com $P_{R F}$ variando de 100 a $200 \mathrm{~W}$.

Tabela 19 - Densidade e mobilidade de portadores das amostras de ITO/Vidro obtidas com $P_{R F}$ variando de 100 a $200 \mathrm{~W}$

\begin{tabular}{ccccc}
\hline Substrato & $\mathbf{P}_{\mathbf{R F}}(\mathbf{W})$ & $\mathbf{t}(\mathbf{n m})$ & $\mathbf{N}\left(\mathbf{c m}^{-3}\right)$ & $\boldsymbol{\mu}\left(\mathbf{c m}^{2} / \mathbf{V} . \mathbf{s}\right)$ \\
& 100 & 390 & $6,6 \times 10^{20}$ & 12,4 \\
\multirow{3}{*}{ Vidro } & 125 & 410 & $4,4 \times 10^{21}$ & 10,3 \\
& 150 & 380 & $3,9 \times 10^{21}$ & 12,7 \\
& 175 & 420 & $2,3 \times 10^{21}$ & 20,0 \\
& 200 & 410 & $1,3 \times 10^{21}$ & 21,3 \\
\hline
\end{tabular}




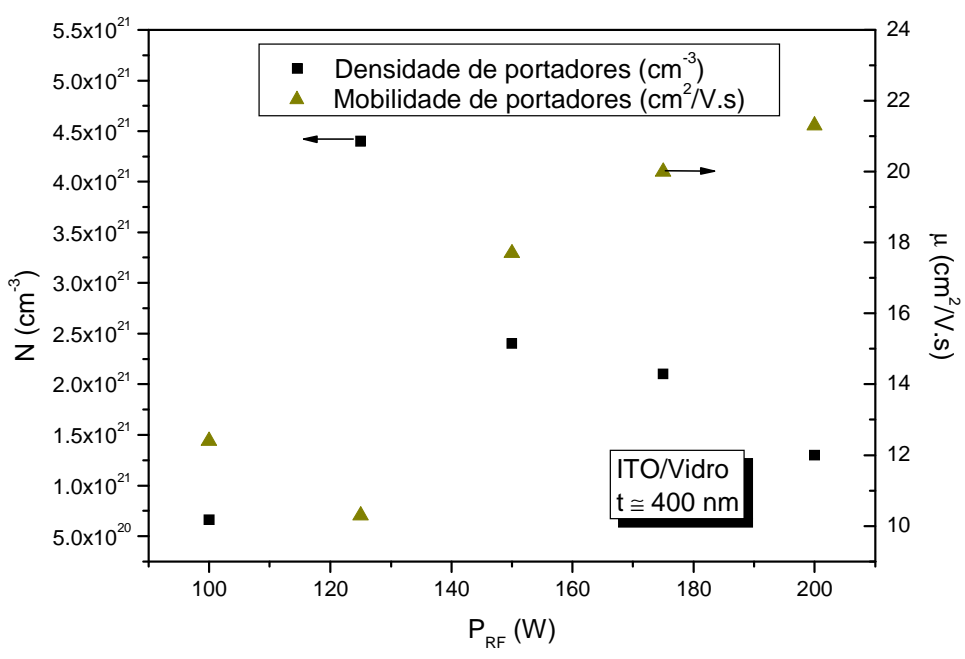

Figura 42 - Densidade e mobilidade de portadores das amostras de ITO/Vidro obtidas com $P_{R F}$ variando de 100 a $200 \mathrm{~W}$

Percebe-se que, com exceção da amostra obtida com $P_{R F}=125 \mathrm{~W}$, as amostras tendem a apresentar valores de mobilidade mais altos com o aumento da $P_{R F}$. Isto está ligado à melhora na cristalinidade do material, favorecendo a mobilidade pela redução do espalhamento de portadores por defeitos nos filmes. Isto será observado na seção 4.3.6. Os valores de $N$ tenderam a ser contrários aos de $\mu$, resultando em resistividades similares.

\subsubsection{Difração de Raios-X}

Na Figura 43 e na Figura 44 são apresentados os gráficos de intensidade em função do ângulo $2 \theta$ obtido pela análise de difração de raios-X para as amostras de ITO/Si obtidas com $P_{R F}$ variando de 100 a $200 \mathrm{~W}$ e também da amostra de ITO/Vidro com $P_{R F}=200 \mathrm{~W}$.

Pela análise do gráfico, percebe-se o mesmo pico (101) de índio metálico em $2 \theta \approx 33^{\circ}$, discutido na seção 4.1.5, apenas para as amostras de ITO/Si obtidas com até $175 \mathrm{~W}$. Isto reforça a idéia de que potências maiores tendem a pulverizar moléculas do material do alvo, e não átomos individualmente. De forma geral, pode-se notar que a intensidade do pico (101) diminui com o aumento da $P_{R F}$.

Para todas as amostras é observado o pico em $2 \theta=35,4^{\circ}$, associado ao plano (400) de $\mathrm{In}_{2} \mathrm{O}_{3}$, indicando orientação preferencial ao longo da direção [100]. 
Para a amotra de ITO/Si obtida com $P_{R F}=200 \mathrm{~W}$, também é possível observar o surgimento do pico (222) em $2 \theta=30,5^{\circ}$, também muito encontrado na literatura, indicando orientação ao longo da direção [111]. Também para esta amostra, a intensidade do pico de índio metálico é muito baixa, e a banda amorfa presente tem sua intensidade muito reduzida, indicando que a maior parte do filme se encontra em estado policristalino.

Outros dois picos, (411) e (211) foram observados para as amostras de ITO/Si, mas não se mostraram condizentes com o aumento da $P_{R F}$.

A amostra de ITO/Vidro apresenta apenas o pico de baixa intensidade (400) e uma banda amorfa, indicando que maior parte do filme ainda se encontra em estado amorfo. Isto condiz com os resultados obtidos anteriormente para amostras de ITO/Vidro, que mostram uma grande dificuldade de cristalização, provavelmente devido à alta rugosidade do substrato.

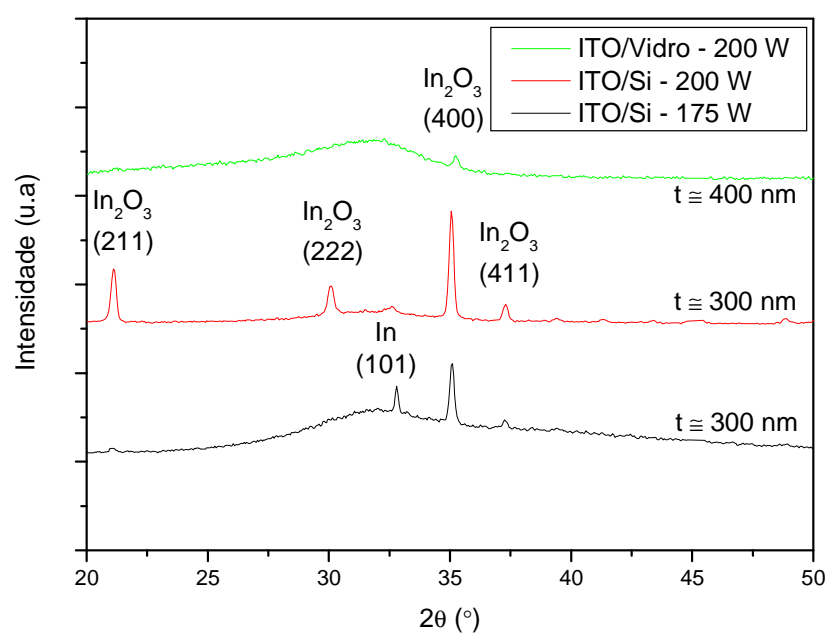

Figura 43 - Difração de raios-X das amostras de ITO/Si obtidas com $P_{R F}=175 \mathrm{~W}$ e $200 \mathrm{~W}$ e ITO/Vidro obtida $\operatorname{com} P_{R F}=200 \mathrm{~W}$ 


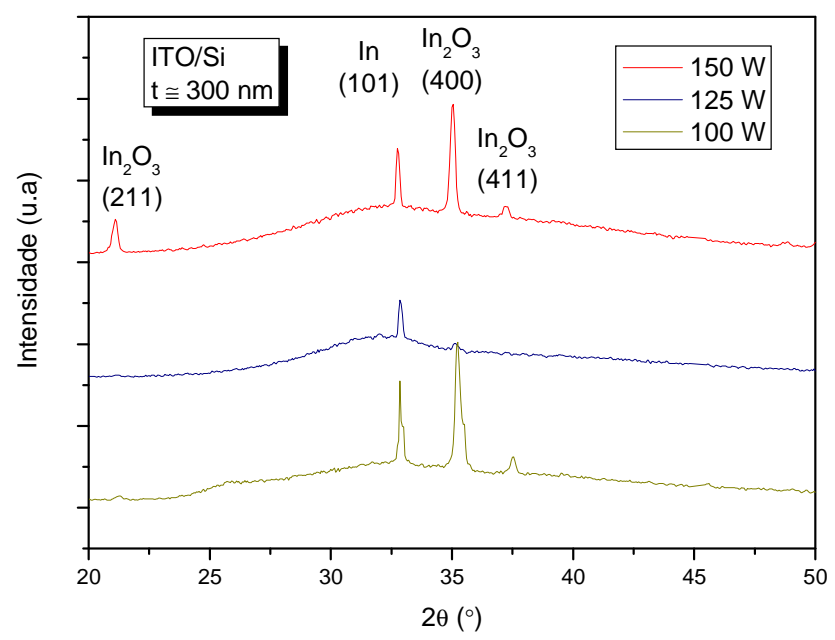

Figura 44 - Difração de raios-X das amostras de ITO/Si obtidas com $P_{R F}=100,125$ e $150 \mathrm{~W}$

\subsubsection{Curvas $I-V$}

Na Figura 45 é apresentado o gráfico de curvas $I-V$ para as amostras de ITO/Si obtidas com $P_{R F}$ variando de 100 a $200 \mathrm{~W}$. Os contatos de ITO/p-Si tenderam a se tornar ôhmicos com o aumento da $P_{R F}$, mas este padrão não é observado linearmente. Os resultados também não se mostram análogos aos de densidade de portadores, apresentados na seção 4.3.5.

Como já havia sido discutido na seção 4.2.7, ainda não é claro o comportamento dos contatos de ITO/p-Si, havendo grandes variações nos trabalhos encontrados na literatura, e com grande dependência no método e nos parâmetros de deposição empregados. Para este trabalho, potências de $75 \mathrm{~W}$ se mostraram eficientes para fabricar contatos retificadores de ITO/p-Si, mas não potências mais altas. 


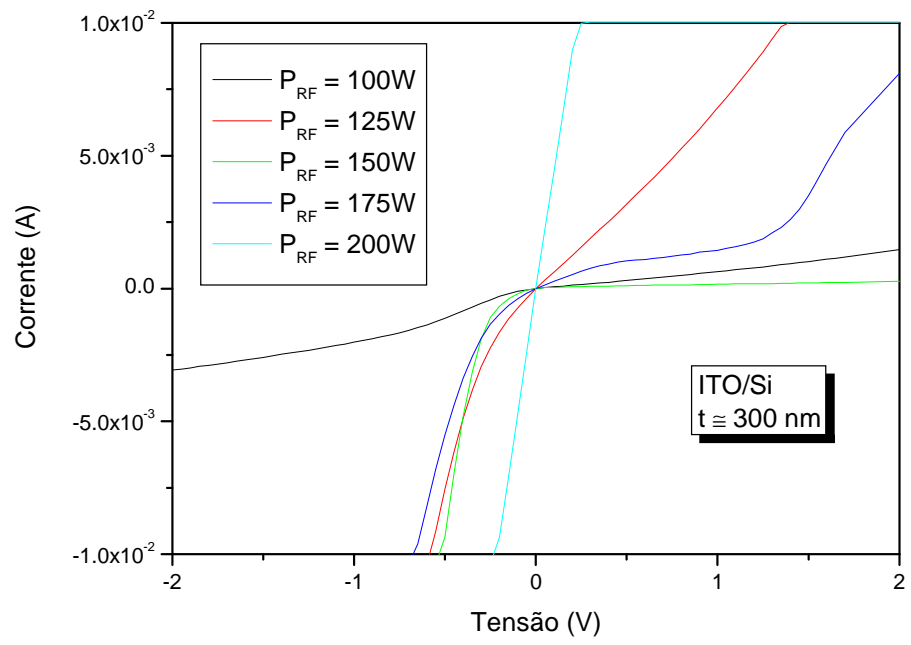

Figura 45 - Curvas $I-V$ das amostras de ITO/Si obtidas com $P_{R F}$ variando de 100 a $200 \mathrm{~W}$

\subsubsection{Transmitância óptica}

O gráfico da porcentagem de transmitância óptica $(\% T)$ em função do comprimento de onda $(\lambda)$ das amostras de ITO/Vidro obtidas com $P_{R F}$ variando de 100 a $200 \mathrm{~W}$ é mostrado na Figura 46. Foram plotados apenas os espectros relativos aos filmes de ITO, sendo que as perdas por absorção e reflexão devidas ao substrato foram subtraídas do gráfico. Se tivessem sido consideradas, as perdas causadas pelo substrato de vidro óptico causariam uma redução de aproximadamente $10 \%$ na $\% T$ das amostras, para o espectro visível.

Nota-se que a transmitância óptica tende a diminuir no espectro visível com o aumento da $P_{R F}$, mesmo com os filmes tendo porcentagens atômicas parecidas. Isto sugere que energias maiores causem mais absorção nos filmes, mesmo para espessuras e porcentagem atômicas similares. Uma possível causa para o padrão observado é que haja mais ligações metálicas nos filmes obtidos com $P_{R F}$ mais altas, pois as amostras se tornaram visivelmente mais acinzentadas de acordo com o aumento da $P_{R F}$.

A partir do gráfico de $\% T$, foram obtidos os gráficos do coeficiente de absorção $(\alpha)$, mostrado na Figura 46, e do coeficiente de extinção ( $\kappa)$, mostrado na Figura 47, de acordo com as equações (7) e (8) comentadas na seção 2.3.1.5. 


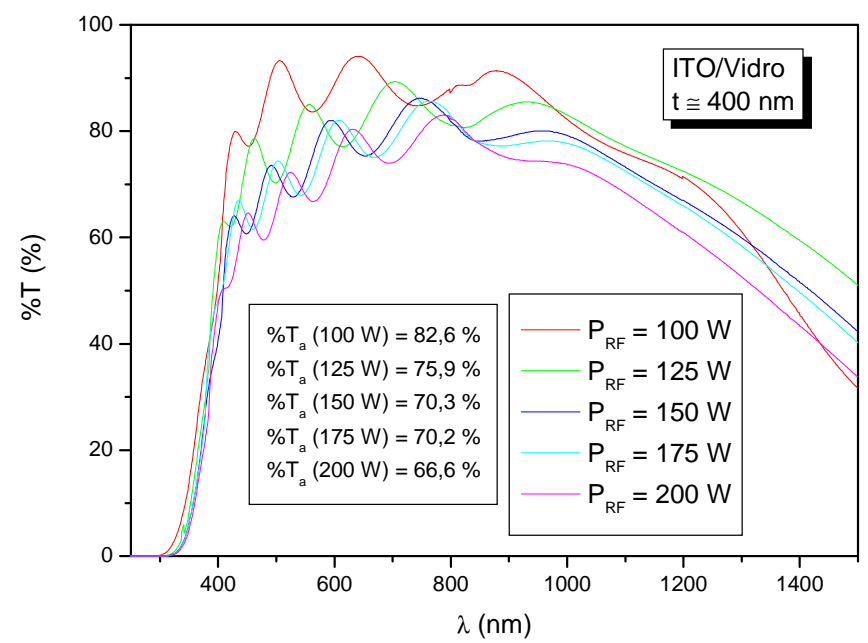

Figura 46 - Porcentagem de transmitância óptica (\%T) em função do comprimento de onda $(\lambda)$ das amostras de ITO/vidro obtidas com $P_{R F}$ variando de 100 a $200 \mathrm{~W}$, assim como a transmitância média $\left(\% T_{a}\right)$ calculada para o espectro visível $(380<\lambda<750 \mathrm{~nm})$

\subsubsection{Coeficiente de absorção}

Observando a Figura 47, percebe-se uma maior absorção óptica para potências mais altas, independentemente da espessura do filme. Isto indica que o aumento da energia de deposição causou maior absorção óptica neste trabalho, mesmo com resultados de porcentagem atômica parecidos. Como foi discutido na seção anterior, apesar de a porcentagem atômica das amostras serem semelhantes, talvez haja mais ligações metálicas nas amostras de maior $P_{R F}$, o que contribui para o aumento da absorção óptica dos filmes. 


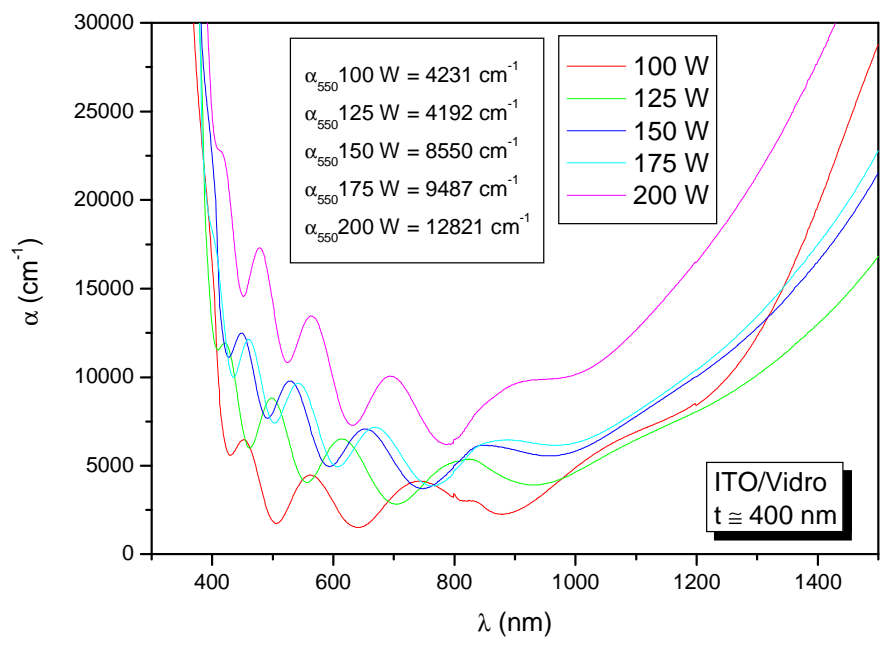

Figura 47 - Gráfico do coeficiente de absorção $(\alpha)$ em função do comprimento de onda $(\lambda)$ para as amostras de ITO/vidro obtidas com $P_{R F}$ variando de 100 a $200 \mathrm{~W}$, destacando $\alpha$ para $550 \mathrm{~nm}$

\subsubsection{Coeficiente de extinção}

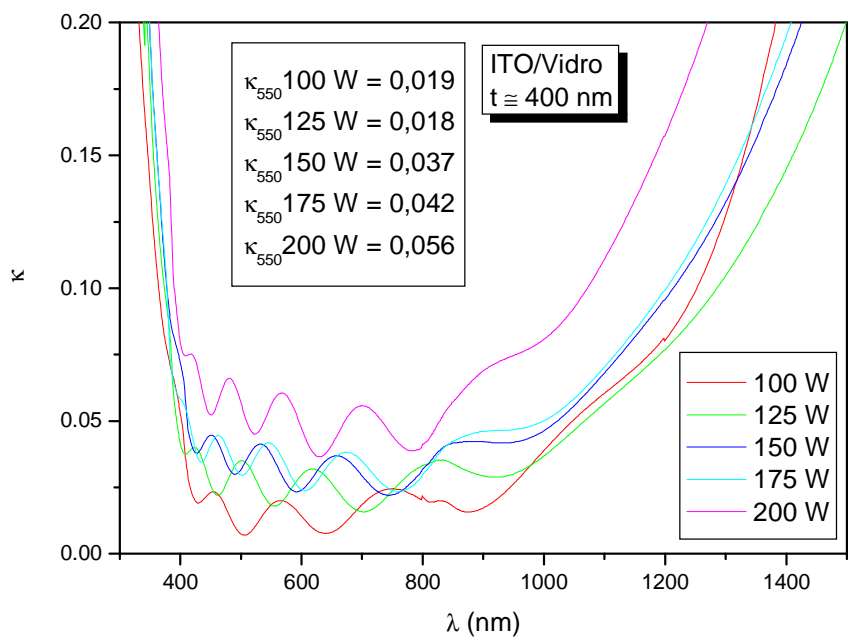

Figura 48 - Gráfico do coeficiente de extinção ( $\kappa$ ) em função do comprimento de onda para as amostras de ITO/vidro obtidas com $P_{R F}$ variando de 100 a $200 \mathrm{~W}$, destacando $\kappa$ para $550 \mathrm{~nm}$ 
Analisando a Figura 48, nota-se que os valores de $\kappa$ para filmes obtidos com os parâmetros apresentados não passam de 0,1 para o espectro visível, justificando as medidas do índice de refração feitas por elipsometria, que considera apenas a parte real.

Como esperado, os valores de $\kappa$ para a amostras obtidas com $P_{R F}$ maiores mantiveramse mais elevados, devido à sua maior absorção óptica. No entanto, todos os filmes apresentam coeficientes de extinção típicos de filmes transparentes.

\subsubsection{Band gap óptico}

O band gap óptico das amostras de ITO/vidro, apresentado na Figura 37, foi obtido através da extrapolação da reta presente no gráfico da absorbância em função da energia $(E)$. Como a borda de absorção observada no gráfico de \%T (Figura 46) das amostras era similar, esperava-se que os valores de $E_{\text {opt }}$ fossem similares, com vantagem aos filmes de maior $\% T_{a}$.

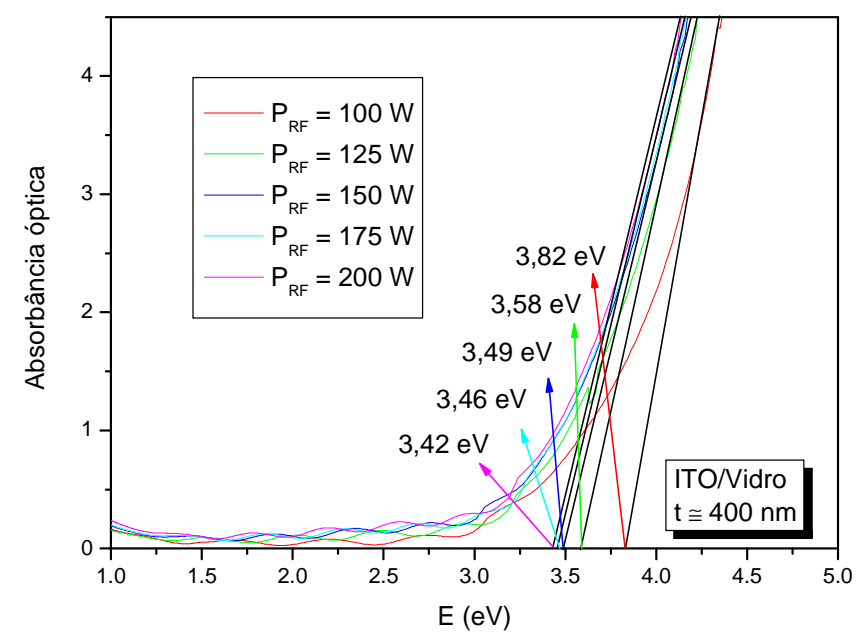

Figura 49 - Absorbância óptica das amostras de ITO/vidro obtidas $P_{R F}$ variando de 100 a $200 \mathrm{~W}$, com a indicação do band gap óptico obtido pela extrapolação da reta

No geral, os valores de $E_{\text {opt }}$ aumentam de acordo com o aumento de $\% T_{a}$, sugerindo que filmes que possuem altos valores de $E_{\text {opt }}$ tenham melhores características ópticas. Isto também pode ser observado neste experimento. 


\subsubsection{Figura de mérito}

As figuras de mérito $(\Phi)$ das amostras de ITO/Vidro obtidas com $P_{R F}$ variando de 100 a 200 W, obtidas através da eq.(20) (descrita na seção 2.3.2), são apresentadas na Tabela 20, juntamente com os parâmetros utilizados para o cálculo. Os parâmetros são resistência de folha $\left(R_{S}\right)$ e transmitância média no espectro visível $\left(T_{a}\right)$. Também há uma coluna com os valores de $T_{a}$ já elevados à décima potência $\left(T_{a}{ }^{10}\right)$, para comparação. A Figura 50 mostra graficamente os resultados de $\Phi$ em função da $P_{R F}$.

Tabela 20 - Figura de mérito das amostras de ITO/Vidro obtidas com $P_{R F}$ variando de 100 a $200 \mathrm{~W}$

\begin{tabular}{cccccc}
\hline Substrato & $\mathbf{T}_{\mathbf{D}}(\mathbf{m i n})$ & $\mathbf{R s}(\boldsymbol{\Omega} / \square)$ & $\mathbf{T}_{\mathbf{a}}$ & $\mathbf{T}_{\mathbf{a}}^{\mathbf{1 0}}$ & $\mathbf{\Phi}\left(\boldsymbol{\Omega}^{-1}\right)$ \\
& 100 & 29,7 & 0,826 & 0,148 & $4,98 \times 10^{-3}$ \\
\multirow{3}{*}{ Vidro } & 125 & 9,3 & 0,759 & 0,063 & $6,77 \times 10^{-3}$ \\
& 150 & 8,5 & 0,703 & 0,029 & $3,41 \times 10^{-3}$ \\
& 175 & 8,0 & 0,702 & 0,029 & $3,63 \times 10^{-3}$ \\
& 200 & 7,51 & 0,666 & 0,017 & $2,26 \times 10^{-3}$ \\
\hline
\end{tabular}

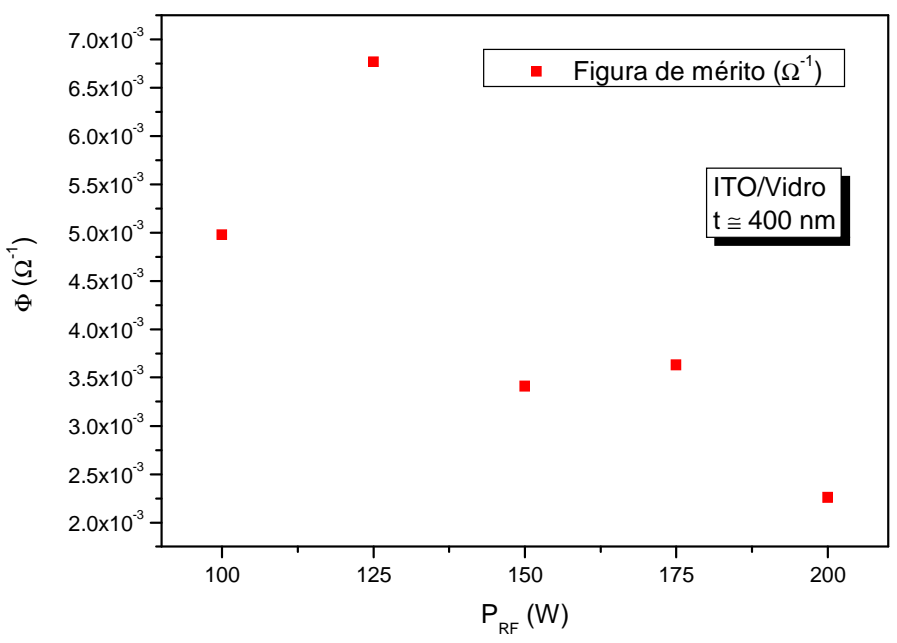

Figura 50 - Figura de mérito das amostras de ITO/Vidro obtidas com $P_{R F}$ variando de 100 a $200 \mathrm{~W}$

Nota-se que resultados melhores foram obtidos para as amostras de potências mais baixas na faixa de potência adotada, devido à grande absorção óptica causada pelas potências maiores. A amostra obtida a $P_{R F}=125 \mathrm{~W}$ mostrou os melhores resultados neste experimento, dosando qualidades elétricas e ópticas satisfatoriamente. 
No entanto, é válido lembrar que, por ser um cálculo simples que envolve apenas dois parâmetros, $\Phi$ não deve ser considerado um dado decisivo para a escolha da melhor amostra, e sim ser analisado como referência.

\subsection{Deposição de ITO sobre policarbonato $\left(\operatorname{Lexan}^{\circledR}\right)$ com potência $R F=75$ W}

Nesta seção, são apresentadas apenas as principais análises elétricas e ópticas para o filme de ITO/Lexan ${ }^{\circledR}$ obtido com $P_{R F}=75 \mathrm{~W}$ e $T_{D}=90 \mathrm{~min}$, com o intuito de justificar as deposições em baixas temperaturas. A amostra é comparada à amostra de ITO/Vidro obtida com os mesmos parâmetros de deposição.

\subsubsection{Perfilometria}

São apresentados na Tabela 9 os resultados da análise de perfilometria realizado nas amostras de ITO/Lexan ${ }^{\circledR}$ e ITO/vidro obtidas com $P_{R F}=75 \mathrm{~W}$ e $T_{D}=90 \mathrm{~min}$. A tabela mostra a espessura $(t)$, a rugosidade média $\left(R_{A}\right)$ e a rugosidade pico-vale $\left(R_{P V}\right)$.

Tabela 21 - Espessura, rugosidade média e rugosidade pico-vale das amostras de ITO/Lexan ${ }^{\circledR}$ e ITO/vidro obtidas com $P_{R F}=75 \mathrm{~W}$ e $T_{D}=90 \mathrm{~min}$

\begin{tabular}{ccccc}
\hline Substrato & $\mathbf{T}_{\mathbf{D}}(\mathbf{m i n})$ & $\mathbf{t}(\mathbf{n m})$ & $\mathbf{R}_{\mathbf{A}}(\mathbf{n m})$ & $\mathbf{R}_{\mathbf{P V}}(\mathbf{n m})$ \\
Lexan $^{\circledR}$ & Substrato puro & - & $14,5 \pm 0,5$ & $74 \pm 3$ \\
& 90 & $492 \pm 20$ & $22 \pm 1$ & $83 \pm 4$ \\
\multirow{2}{*}{ Vidro } & Substrato puro & - & $5,5 \pm 0,1$ & $28,9 \pm 0,8$ \\
& 90 & $514 \pm 28$ & $3,1 \pm 0,2$ & $23 \pm 2$ \\
\hline
\end{tabular}

Pelos resultados, nota-se que o substrato polimérico tem uma rugosidade bem mais elevada do que o substrato de vidro, influenciando assim na rugosidade dos filmes. Por este motivo, as características elétricas do filme de ITO/Lexan ${ }^{\circledR}$ são prejudicadas. A taxa de deposição não se mostrou muito alterada devido à mudança do substrato. 


\subsubsection{Prova de quatro pontas}

Na Tabela 22 são mostrados os valores médios de resistência de folha $\left(R_{S}\right)$ obtidos pela prova de quatro pontas e o valor da resistividade $(\rho)$, calculado por meio da eq.(5) (comentada na seção 2.3.1.2) para as amostras de ITO/Lexan ${ }^{\circledR}$ e ITO/vidro obtidas com $P_{R F}=75 \mathrm{~W}$ e $T_{D}=90 \mathrm{~min}$. Para o cálculo de $\rho$ das amostras, foram utilizados os valores médios de espessura e resistência de folha.

Tabela 22 - Resistência de folha e resistividade das amostras de ITO/Lexan ${ }^{\circledR}$ e ITO/vidro obtidas com $P_{R F}=75 \mathrm{~W}$ e $T_{D}=90 \mathrm{~min}$

\begin{tabular}{ccccc}
\hline Substrato & $\mathbf{T}_{\mathbf{D}}(\mathbf{m i n})$ & $\mathbf{t}(\mathbf{n m})$ & $\mathbf{R}_{\mathbf{S}}(\boldsymbol{\Omega} / \square)$ & $\boldsymbol{\rho}(\boldsymbol{\Omega . c m})$ \\
Lexan ${ }^{\circledR}$ & 90 & 492 & $62 \pm 3$ & $3,1 \times 10^{-3}$ \\
Vidro & 90 & 514 & $25 \pm 2$ & $1,2 \times 10^{-3}$ \\
\hline
\end{tabular}

É notável que o valor da resistência de folha da amostra de ITO/Lexan ${ }^{\circledR}$ se mostrou muito mais elevado em relação á amostra de ITO/Vidro. Isto foi atribuído à rugosidade do substrato, já que a condutividade elétrica dos filmes de ITO é afetada negativamente pelo espalhamento dos portadores em superfícies rugosas. Em consequência, o valor de resistividade também se mostrou mais elevado devido às espessuras similares. No entanto, os valores se encontram na mesma ordem de grandeza.

\subsubsection{Transmitância óptica}

O gráfico da porcentagem de transmitância óptica $(\% T)$ em função do comprimento de onda $(\lambda)$ e o cálculo da porcentagem de transmitância média $\left(\% T_{a}\right)$ no espectro visível $(380<\lambda<750 \mathrm{~nm})$ da amostra de ITO/Lexan ${ }^{\circledR}$ obtida com $P_{R F}=75 \mathrm{~W}$ e $T_{D}=90$ min são mostrados na Figura 51. Foram apresentados apenas os espectros relativos aos filmes de ITO, sendo que as perdas por absorção e reflexão devidas ao substrato foram subtraídas do gráfico. Se tivessem sido consideradas, as perdas causadas pelo substrato de vidro óptico causam uma redução de aproximadamente $15 \%$ na $\% T$ das amostras, para o espectro visível. 
A transmitância média desta amostra $\left(\% T_{a}=83,5 \%\right)$ foi muito parecida com a amostra de ITO/Vidro correspondente $\left(\% T_{a}=82,4 \%\right)$. Presume-se que o substrato não influencie na absorção óptica do filme depositado.

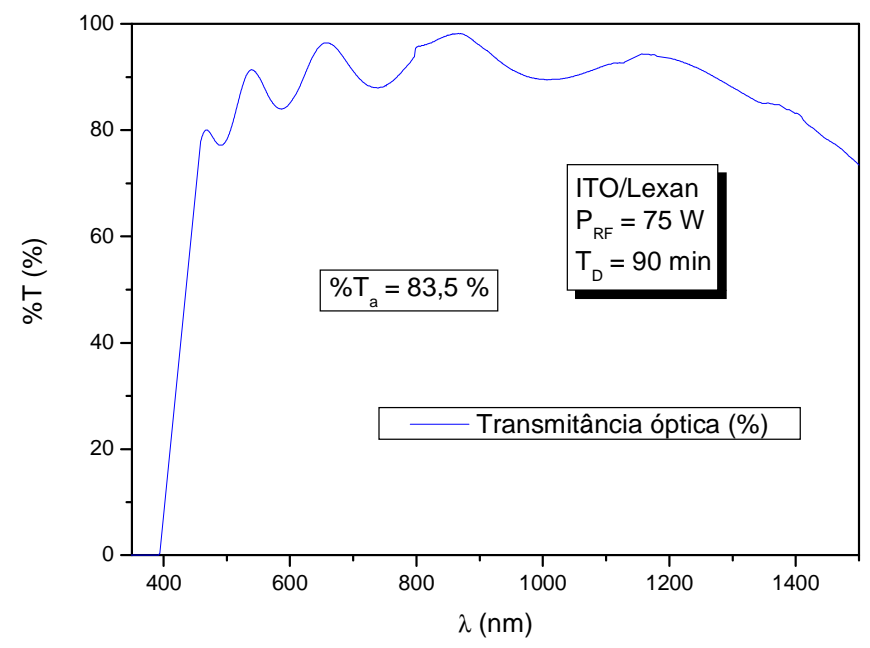

Figura 51 - Porcentagem de transmitância óptica $(\% T)$ em função do comprimento de onda $(\lambda)$ da amostra de ITO/Lexan ${ }^{\circledR}$ obtida com $P_{R F}=75 \mathrm{~W}$ e $T_{D}=90 \mathrm{~min}$, assim como a transmitância média $\left(\% T_{a}\right)$ calculada para o espectro visível $(380<\lambda<750 \mathrm{~nm})$

\subsubsection{Figura de mérito}

As figuras de mérito $(\Phi)$ das amostras de ITO/Lexan ${ }^{\circledR}$ e ITO/Vidro obtidas com $P_{R F}=75 \mathrm{~W}$ e $T_{D}=90 \mathrm{~min}$, obtidas através da eq.(20) (descrita na seção 2.3.2), são apresentadas na Tabela 23, juntamente com os parâmetros utilizados para o cálculo. Os parâmetros são resistência de folha $\left(R_{S}\right)$ e transmitância média no espectro visível $\left(T_{a}\right)$. Também há uma coluna com os valores de $T_{a}$ já elevados à décima potência $\left(T_{a}{ }^{10}\right)$, para comparação.

Tabela 23 - Figura de mérito das amostras de ITO/Lexan ${ }^{\circledR}$ e ITO/vidro obtidas com $P_{R F}=75 \mathrm{~W}$ e $T_{D}=90 \mathrm{~min}$, juntamente com os parâmetro utilizados no cálculo

\begin{tabular}{cccccc}
\hline Substrato & $\mathbf{T}_{\mathbf{D}}(\mathbf{m i n})$ & $\mathbf{R s}(\boldsymbol{\Omega} / \square)$ & $\mathbf{T}_{\mathbf{a}}$ & $\mathbf{T}_{\mathbf{a}}{ }^{\mathbf{1 0}}$ & $\mathbf{\Phi}\left(\boldsymbol{\Omega}^{-1}\right)$ \\
Lexan $^{\circledR}$ & 90 & 62 & 0,835 & 0,164 & $2,64 \times 10^{-3}$ \\
Vidro & 90 & 25 & 0,824 & 0,144 & $5,76 \times 10^{-3}$ \\
\hline
\end{tabular}


Como a transmitância média das amostras foi parecida, $\Phi$ foi maior para a amostra de ITO/Vidro devido ao seu menor valor de $R_{S}$. No entanto, $\Phi$ mostra-se na mesma ordem de grandeza, e apresenta valor parecido a outras amostras de ITO/Vidro obtidas anteriormente neste trabalho (ver seções 4.2.9 e 4.3.9).

Conclui-se, portanto, que é possível depositar filmes de ITO sobre substratos poliméricos utilizando estes parâmetros. 


\section{CONCLUSÕES}

Filmes finos de ITO foram depositados sobre substratos de silício e vidro óptico pela técnica de RF magnetron sputtering, com potência RF variando de 25 a $100 \mathrm{~W}$ em ambiente inerte (100\% argônio). Os substratos não foram intencionalmente aquecidos, caracterizando o processo como sendo de baixa temperatura. Características elétricas, físicas, ópticas, químicas e estruturais dos filmes foram analisadas.

Foram obtidas amostras de ITO/Si e ITO/vidro com resistividade mínima na ordem de $10^{-4} \Omega$.cm e uma amostra de ITO/Lexan com resistividade na ordem de $10^{-3} \Omega$.cm. A mudança na resistividade de acordo com o substrato foi atribuída à rugosidade e às impurezas contidas nos substratos. De modo geral, a quantidade de oxigênio na composição dos filmes influencia diretamente as características elétricas das amostras, com a tendência de possuir menor resistividade filmes com menor concentração de oxigênio. Maiores espessuras também melhoram as propriedades elétricas pela redução da resistência de folha. As melhores características elétricas foram observadas para amostras obtidas com $200 \mathrm{~W}$ de potência RF.

A análise das características ópticas feita para amostras de ITO/vidro e ITO/Lexam mostra que, dentro da faixa do espectro visível, os filmes de ITO (subtraindo a absorção óptica dos substratos) têm transmitância óptica de 66 a $87 \%$. De acordo com o índice de absorção calculado, o aumento na potência RF aumenta também a absorção óptica do material. A espessura das amostras também se mostrou relevante às características ópticas, sendo que o aumento da absorção acontece proporcionalmente ao aumento da espessura. As melhores características ópticas foram observadas para amostras obtidas com $75 \mathrm{~W}$ de potência RF.

Do ponto de vista estrutural, as amostras tenderam a apresentar fase amorfa e cristalina, com orientação preferencial ao longo da direção [100]. De forma geral, o aumento da potência RF propicia a transição da fase amorfa para a fase cristalina, e pode ser observada uma melhora nas características elétricas com o início do surgimento dos picos. Esta melhora não foi observada para as características ópticas dos filmes.

De modo geral, as amostras obtidas de 75 a $125 \mathrm{~W}$ tiveram as melhores propriedades para serem utilizadas em aplicações que exijam eletrodos transparentes, considerando aspectos elétricos e ópticos. 


\section{TRABALHOS FUTUROS}

Como sugestão para trabalhos futuros, seria interessante uma análise mais detalhada da rugosidade das amostras, através da caracterização por microscópio de força atômica (AFM, Atomic Force Microscope) devido à grande imprecisão da rugosidade obtida por perfilometria. Também podem ser feitas análises de ligações químicas por espectroscopia FTIR (Fourier Tranform Infrared).

Pode-se também explorar a influência de diferentes espessuras em amostras obtidas com potências de 100 e $125 \mathrm{~W}$ (que apresentaram resultados satisfatórios), assim como um estudo mais detalhado da influência da composição química e de diferentes potências nas características ópticas dos filmes, já que alguns resultados não se apresentaram condizentes com o esperado.

Seria útil também um melhor estudo sobre filmes de ITO depositados sobre substratos poliméricos, destacando as limitações impostas aos processos devido à fragilidade dos substratos, incluindo análises do stress causado nos substratos pela pulverização catódica.

Como há necessidade hoje de encontrar substitutos ao ITO, também é interessante um estudo sobre a deposição de outros tipos de TCOs e outros materiais transparentes condutores, 


\section{PUBLICAÇÕES}

\section{Trabalhos completos publicados em anais de congressos:}

DAMIANI, L. R. ; MANSANO, R. D. . Deposition and Characterization of Indium-Tin Oxide Thin Films Deposited by RF Sputtering. 22nd Symposium on Microelectronics Technology and Devices. Microelectonics Technology and Devices SBMICRO 2007, v. 9. p. 251-258.

\section{Resumos expandidos publicados em anais de congressos:}

RASIA, L. A. ; MANSANO, R. D. ; DAMIANI, L. R. ; VIANA, C. E. ; ORDONEZ, N. ; ZAMBOM, L. S. . Electrical and mechanical properties of ITO thin films investigated by cantilever deflection technique. VII Encontro da SBPMat, 2008.

DAMIANI, L. R. ; MANSANO, R. D. . Deposition and characterization of indium-tin-oxide thin films deposited by RF sputtering. $13^{\text {th }}$ International Conference on Solid Films and Surfaces (ICSFS-13), Bariloche, 2006.

\section{Resumos publicados em anais de congressos:}

DAMIANI, L. R. ; MANSANO, R. D. . Study of the properties of magnetron sputtered indium-tin oxide thin films. In: 11th International Conference on Advanced Materials ICAM 2009.

DAMIANI, L. R. ; MANSANO, R. D. ; MEDEIROS, M. S. . Thickness dependence of the properties of magnetron sputtered indium-tin oxide thin films. In: XXXII Encontro Nacional de Física da Matéria Condensada, 2009.

DAMIANI, L. R. ; MANSANO, R. D. . Influência do tratamento térmico em lâminas de ITO depositadas por sputtering RF. In: XI Escola brasileira de Estrutura Eletrônica, 2008.

DAMIANI, L. R. ; MANSANO, R. D. ; MEDEIROS, M. S. . Deposição e caracterização de filmes de ITO por sputtering RF. In: XI Escola brasileira de Estrutura Eletrônica, 2008.

DAMIANI, L. R. ; MANSANO, R. D. . Deposition of indium-tin oxide thin films using RF reactive sputtering. In: XXXI Encontro Nacional de Física da Matéria Condensada, 2008. 


\section{REFERÊNCIAS BIBLIOGRÁFICAS}

${ }^{1}$ ZHU, F.; ZHANG, K.; GUENTHER, E.; JIN, C. S. Optimized indium tin oxide contact for organic light emitting diode applications. Thin Solid Films 363, 314-317 (2000).

${ }^{2}$ SCHULZE, K.; MAENNIG, B.; LEO, K. Organic solar cells on indium tin oxide and aluminum doped zinc oxide anodes. Applied Physics Letters 91, 073521 (2007).

${ }^{3}$ SESHADRI, V.; PADILLA, J.; BIRCAN, H.; RADMARD, B.; DRAPER, R.; WOOD, M.; OTERO, T. F.; SOTZING, G. A. Optimization, preparation, and electrical short evaluation for $30 \mathrm{~cm}^{2}$ active area dual conjugated polymer electrochromic windows. Organic Electronics 8, 367-381 (2007).

${ }^{4}$ HAMBERG, I.; GRANQVIST, C. G. Optical properties of transparent and heatreflecting indium tin oxide films: The role of ionized impurity scattering. Appl. Phys. Lett. 44, 721 (1984).

${ }^{5}$ LIN, H.; YU, J.; LOU, S.; WANG, J.; JIANG, Y. Low Temperature DC Sputtering Deposition on Indium-Tin Oxide Film and Its Application to Inverted Top-emitting Organic Light-emitting Diodes. J. Mater. Sci. Technol. 24, 179-182 (2008).

${ }^{6}$ CHU, J. B.; ZHU, H. B.; XU, X. B.; SUN, Z.; CHEN, Y. W.; HUANG, S. M. RF magnetron sputtered indium tin oxide thin films for application in solar cells. Nanoelectronics Conference, 2008. INEC 2008. 2nd IEEE International, 728-731 (2008).

${ }^{7}$ ROZATI, S. M.; GANJ, T. Transparent conductive Sn-doped indium oxide thin films deposited by spray pyrolysis technique. Renewable Energy 29, 1671-1676 (2004).

${ }^{8}$ IZUMI, H.; ADURODIJA, F. O.; KANEYOSHI, T.; ISHIHARA, T.; YOSHIOKA, H.; MOTOYAMA, M. Electrical and structural properties of indium tin oxide films prepared by pulsed laser deposition. Journal Of Applied Physics 91, 1213-1218 (2002).

${ }^{9}$ DAS, R.; ADHIKARY, K.; RAY, S. The role of oxygen and hydrogen partial pressures on structural and optical properties of ITO films deposited by reactive rf-magnetron sputtering. Applied Surface Science 253, 6068-6073 (2007).

${ }^{10}$ YIN, X.; TANG, W.; WENG, X.; DENG, L. Energy band calculation of amorphous indium tin oxide films on polyethylene terephthalate substrate with indirect transition. $\mathrm{J}$. Phys. D: Appl. Phys. 42, 025104 (2009).

${ }^{11}$ BÄDEKER, K. Über die elektrische Leitfähigkeit und die thermoelektrische Kraft einiger Schwermetallverbindungen. Annalen der Physik 327, 749-766 (1907).

${ }^{12}$ AUSTRALIAN GOVERNMENT. Cadmium and compounds fact sheet. Disponível em: < http://www.npi.gov.au/database/substance-info/profiles/17.html\#health>. Acesso em: 5 de outubro de 2009. 
${ }^{13}$ ZHOU, Q.; JI, Z.; HU, B.; CHEN, C.; ZHAO, L.; WANG, C. Low resistivity transparent conducting $\mathrm{CdO}$ thin films deposited by $\mathrm{DC}$ reactive magnetron sputtering at room temperature. Materials Letters 61, 531-534 (2007).

${ }^{14}$ KIM, Y. S.; TAI, W. P. Electrical and optical properties of Al-doped ZnO thin films by sol-gel process. Applied Surface Science 253, 4911-4916 (2007).

15 YAMADA, T.; NEBIKI, T.; KISHIMOTO, S.; MAKINO, H.; AWAI, K.; NARUSAWA, T.; YAMAMOTO, T. Dependences of structural and electrical properties on thickness of polycrystalline Ga-doped $\mathrm{ZnO}$ thin films prepared by reactive plasma deposition. Superlattices and Microstructures 42, 68-73 (2007).

16 ILICAN, S.; CAGLAR, Y.; CAGLAR, M.; YAKUPHANOGLU, F. Electrical conductivity, optical and structural properties of indium-doped $\mathrm{ZnO}$ nanofiber thin film deposited by spray pyrolysis method. Physica E 35, 131-138 (2006).

17 YADAV, A. A.; MASUMDAR, E. U.; MOHOLKAR, A. V.; RAJPURE, K. Y.; BHOSALE, C. H. Effect of quantity of spraying solution on the properties of spray deposited fluorine doped tin oxide thin films. Physica B 404, 1874-1877 (2009).

${ }^{18}$ ZHANG, D.; TAO, L.; DENG, Z.; ZHANG, J.; CHEN, L. Surface morphologies and properties of pure and antimony-doped tin oxide films derived by sol-gel dip-coating processing. Materials Chemistry and Physics 100, 275-280 (2006).

${ }^{19}$ GOLSHAHI, S.; ROZATI, S.M.; MARTINS, R.; FORTUNATO, E. P-type ZnO thin film deposited by spray pyrolysis technique: The effect of solution concentration. Article in press. Thin Solid Films (2009).

20 NI, J.; ZHAO, X.; ZHENG, X.; ZHAO, J.; LIU, B. Electrical, structural, photoluminescence and optical properties of p-type conducting, antimony-doped $\mathrm{SnO}_{2}$ thin films. Acta Materialia 57, 278-285 (2009).

${ }^{21}$ DONG, G.; ZHANG, M.; ZHAO, X.; LI, Y.; YAN, H. Influence of working gas pressure on structure and properties of CuAlO2 films. Journal of Crystal Growth 311, 1256-1259 (2009).

22 JANG, W. L.; LU Y. M.; HWANG, W. S.; CHEN, W. C. Electrical properties of Lidoped NiO films. Article in press. Journal of the European Ceramic Society (2009).

${ }^{23}$ PAPADOPOULOU, E.L.; VISKADOURAKIS, Z. A.; PENNOS, A.V.; HUYBERECHTS, G.; APERATHITIS, E. The effect of deposition parameters on the properties of $\mathrm{SrCu}_{2} \mathrm{O}_{2}$ films fabricated by pulsed laser deposition. Thin Solid Films 516, 1449-1452 (2008).

24 CERAC, inc. ITO. Indium-Tin Oxide For Optical Coatings. Disponível em: <http://www.cerac.com/pubs/proddata/ito.htm> Acesso em: 6 de junho de 2008.

25 JIMENEZ, L. C.; MÉNDEZ, H. A.; PÁEZ, B. A.; RAMÍREZ, M. E.; RODRÍGUES, H. Production and characterization of indium oxide and indium nitride. Braz. J. Phys. 36, 1017-1020 (2006). 
${ }^{26}$ TAHAR, R. B. H.; BAN, T.; OHYA, Y.; TAKAHASHI, Y. Tin doped indium oxide thin films: Electrical properties. J. Appl. Phys. 83, 2631-2645 (1998).

${ }^{27}$ FRANZ, G.; LANGE, B.; SOTIER S. Characterization of sputtered indium tin oxide layers as transparent contact material. Journal of Vacuum Science and Technology A 19, 2514-2521 (2001).

${ }^{28}$ DIAMOND COATINGS. Indium Tin Oxide for transparent EMC shielding and Antistatic applications. Disponível em: <http://www.diamondcoatings.co.uk/datasheet/emc_ito_presentation.pdf $>$. Acesso em: 2 de setembro de 2009.

${ }^{29}$ NANOMARKETS. Indium tin oxide and alternative transparent conductor markets. Disponível em:

$<$ http://www.researchandmarkets.com/reports/687028/indium_tin_oxide_and_alternative_tran sparent>. Acesso em: 3 de agosto de 2009.

${ }^{30}$ PARK, K.S.; SATO, W.; GRAUSE, G.; KAMEDA, T.; YOSHIOKA, T. Recovery of indium from $\operatorname{In}_{2} \mathrm{O}_{3}$ and liquid crystal display powder via a chloride volatilization process using polyvinyl chloride. Thermochimica Acta 493, 105-108 (2009).

31 YU, X.; RAJAMANI, R.; STELSON, K. A.; CUI, T. Carbon nanotube-based transparent thin film acoustic actuators and sensors. Sensors and Actuators A 132, 626631 (2006).

${ }^{32}$ ROWELL, M. W.; TOPINKA, M. A.; MCGEHEE, M. D.; PRALL, H. J.; DENNLER, G.; SARICIFTCI, N. S.; HU, L.; GRUNER, G. Organic solar cells with carbon nanotube network electrodes. Applied Physics Letters 88, 233506 (2006).

${ }^{33}$ HAU, S. K.; YIP, H. L.; ZOU, J.; JEN, A. K. Y. Indium tin oxide-free semi-transparent inverted polymer solar cells using conducting polymer as both bottom and top electrodes. Organic Electronics 10, 1401-1407 (2009).

${ }^{34}$ RODITI, I. Dicionário Houaiss de Física. Instituto Antônio Houaiss, (2005).

${ }^{35}$ EDWARDS, P. P.; PORCH, A.; JONES, M. O.; MORGAN, D. V.; PERKS, R. M. Basic materials physics of transparent conducting oxides. Dalton Transactions, 2995-3002 (2004).

${ }^{36}$ MINAMI, T. Transparent conductive oxide semiconductors for transparent electrodes. Semicond. Sci. Technol. 20, S35-S44 (2005).

${ }^{37}$ HAACKE, G. Transparent conducting coatings. Ann. Rev. Mater. Sci. 7, 73-93 (1977).

38 PORCH, A.; MORGAN, D. V.; PERKS, R. M. Electromagnetic absorption in transparent conducting films. JOURNAL OF APPLIED PHYSICS 95, 4734-4737 (2004). 
${ }^{39}$ HAMBERG, I.; GRANQVIST, G.G. Evaporated Sn-doped In2O3 films: Basic optical properties and applications to energy-efficient windows. J. Appl. Phys. 60, R123-R159 (1986).

40 OLIVEIRA, N. Hall. Disponível em: http://www.fis.ufba.br/ edmar/fis101/roteiros/Efeito_Hall.pdf. Acesso em: 20 de janeiro de 2009.

41 KESHMIRI, S. H.; REZAEE-ROKNABADI, M.; ASHOK, S. A novel technique for increasing electron mobility of indium-tin-oxide transparent conducting films. Thin Solid Films 413, 167-170 (2002).

42 ANGUitA, J. V.; THWAITES, M.; HOLTON, B.; HOCKLEY, P.; RAND, S.; HAUGHTON, S. Room temperature growth of indium-tin oxide on organic flexible polymer substrates using a new reactive-sputter deposition technology. Plasma Processes and Polymers 4, 48-52 (2007).

43 E-FÍSICA. Índice de refração. Disponível em: http://efisica.if.usp.br/otica/basico/refracao/indice_refracao/ Acesso em: 15 de novembro de 2008.

${ }^{44}$ NGAFFO, F. F.; CARICATO, A. P.; FAZZI, A.; FERNANDEZ, M.; LATTANTE, S.; MARTINO, M.; ROMANO, F. Deposition of ITO films on $\mathbf{S i O}_{2}$ substrates. Applied Surface Science 248, 428-432 (2005).

${ }^{45}$ CHEEK, G.; GENIS, A.; DUBOW, J. B. Antireflection properties of indium tin oxide (ITO) on silicon for photovoltaic applications. Appl. Phys. Lett 35, 495-497 (1979).

${ }^{46}$ MAXWELL. Índice de refração. Disponível em: <http://www.maxwell.lambda.ele.pucrio.br/cgi bin/PRG_0599.EXE/3662_3.PDF?NrOcoSis=6743\&CdLinPrg=pt $>$. Acesso em: 20 de dezembro de 2008 .

${ }^{47}$ GUILLÉN, C.; HERRERO, J. Polycrystalline growth and recrystallization processes in sputtered ITO thin films. Thin Solid Films 510, 260-264 (2006).

${ }^{48}$ CHEN, M. C.; CHEN, S. A. Influence of oxygen deficiency in indium tin oxide on the performance of polymer light-emitting diodes. Thin Solid Films 517, 2708-2711 (2009).

${ }^{49}$ ZHANG, B.; DONG, X.; XU, X.; WANG, X.; WU, J. Electrical and optical properties of ITO and ITO:Zr transparent conducting films. Materials Science in Semiconductor Processing 10, 264-269 (2007).

50 IMPERIAL COLLEGE LONDON. Moss-Burstein Effect. Disponível em: <http://www3.imperial.ac.uk/pls/portallive/docs/1/24311696.RTF>. Acesso em: 5 de janeiro de 2009.

${ }^{51}$ GUPTA, R. K.; GHOSH, K.; PATEL, R.; KAHOL, P. K. Effect of substrate temperature on opto-electrical properties of $\mathrm{Nb}$-doped $\mathrm{In}_{2} \mathrm{O}_{\mathbf{3}}$ thin films. Journal of Crystal Growth 310 , 4336-4339 (2008). 
${ }^{52}$ KIM, J. H.; AHN, B. D.; LEE, C. H.; JEON, K. A.; KANG, S. H.; KIM, G. H.; LEE, S. Y. Enhancement in electrical and optical properties of indium tin oxide thin films using a pulsed laser deposition at room temperature by two-step process. Thin Solid Films 515 , 3580-3583 (2007).

53 CARdoso, W. S.; LONGO, C.; DE PAOLI, M. A. Preparação de eletrodos opticamente transparentes. Quim. Nova 28, 345-349 (2005).

${ }^{54}$ KIM, H.; HORWITZ, J. S.; PIQUE, A.; GILMORE, C. M.; CHRISEY, D. B. Electrical and optical properties of indium tin oxide thin films grown by pulsed laser deposition. Applied Physics A 69, 447-450 (1999).

55 CEFET MG. Rugosidade das superfícies. Disponível em: <http://74.125.45.132/search?q=cache:oJ0cS311wkgJ:academicos.cefetmg.br/admin/downloa $\mathrm{ds} / 2104 /$ aula\%2520de\%2520Rugosidades.doc+rugosidade \&hl=en\&ct=clnk\&cd=3\&gl=br $>$.

Acesso em: 19 de dezembro de 2008.

${ }^{56}$ Gadelmawla, E. S.; Koura M. M.; Maksoud, T. M. A.; Elewa, I. M.; Soliman, H. H. Roughness parameters. Journal of Materials Processing Technology 123, 133-145 (2002).

${ }^{57}$ QI, Z. CHEN, X.; FAN, C.; CHAI, W. Low temperature processing of high conductivity and high transparency indium-tin-oxide/Ag alloy/indium-tin-oxide multilayered thin films. Journal of Materials Processing Technology 209, 973-977 (2009).

${ }^{58}$ TAK, Y. H.; KIM, K. B.; PARK, H. G.; LEE, K. H.; LEE, J. R. Criteria for ITO (indiumtin oxide) thin film as the bottom electrode of an organic light emitting diode. Thin Solid Films 411, 12-16 (2002).

59 SILVA, L. F.; LEITE, D. M. G.; PEREIRA, A. L. J.; Silva, J. H. D. Influência dos parâmetros de deposição sobre a estrutura dos filmes de $\mathbf{G a ( 1 - x ) M n ( x ) A s : H ~ c r e s c i d o s ~}$ por sputtering. Congresso Brasileiro de Engenharia e Ciência dos Materiais (2006).

${ }^{60}$ ROGOZIN, A.; VINNICHENKO, M.; SHEVCHENKO, N.; KREISSIG, U.; KOLITSCH, A.; MÖLLER, W. Real-time evolution of electrical properties and structure of indium oxide and indium tin oxide during crystallization. Scripta Materialia 60, 199-202 (2009).

61 FLORES-MENDOZA, M. A.; CASTANEDO-PEREZ, R.; TORRES-DELGADO, G.; MARÍN, J. M.; ZELAYA-ANGEL, O. Influence of the annealing temperature on the properties of undoped indium oxide thin films obtained by the sol-gel method. Thin Solid Films 517, 681-685 (2008).

${ }^{62}$ MENG, L. J.; SANTOS, M.P. Properties of indium tin oxide films prepared by rf reactive magnetron sputtering at different substrate temperature. Thin Solid Films 322, 56-62 (1998).

${ }^{63}$ HAAKE, G. New figure of merit for transparent conductors. Appl. Phys. 47, 4086-4089 (1976). 
${ }^{64}$ NISHA, M.; ANUSHA, S.; ANTONY, A.; MANOJ, R.; JAYARAJ, M. K. Effect of substrate temperature on the growth of ITO thin films. Applied Surface Science 252, 1430-1435 (2005).

${ }^{65}$ YOU, Y. Z.; KIM, Y. S.; CHOI, D. H.; JANG, H. S.; LEE, J. H.; KIM, D. Electrical and optical study of ITO films on glass and polymer substrates prepared by DC magnetron sputtering type negative metal ion beam deposition. Materials Chemistry and Physics 107, 444-448 (2008).

${ }^{66}$ AKKAD, F. E.; PUNNOOSE, A.; PRABU, G. Properties of ITO films prepared by rf magnetron sputtering. Applied Physics A 71, 157-160 (2000).

${ }^{67}$ SHAH, V. G.; WALLACE, D. B. Low-cost Solar Cell Fabrication by Drop-on-Demand Ink-jet Printing. Proc. IMAPS 37th Annual International Symposium on Microelectronics (2004).

68 INSTITUTE OF SCIENCE IN SOCIETY. Organic solar power. Disponível em: < http://www.i-sis.org.uk/OSP.php>. Acesso em: 03 de setembro de 2009.

69 MONTESDEOCA-SANTANA, A.; JIMÉNEZ-RODRÍGUEZ, E.; MARRERO, N.; GONZÁLEZ-DÍAZ, B.; BORCHERT, D.; GUERRERO-LEMUS, R. XPS characterization of different thermal treatments in the ITO-Si interface of a carbonate-textured monocrystalline silicon solar cell. Nucl. Instr. and Meth. in Phys. Res. B (2009).

70 . KONARKA. Konarka power plastic products. Disponível em: <http://www.konarka.com/index.php/power-plastic/power-plastic-products/>. Acesso em: 15 de outubro de 2009.

71 IT - INSTITUTO DE TELECOMUNICAÇÕES. Organic Light Emitting Diodes (OLEDs). Disponível em: <http://www.lx.it.pt/ alcacer/TM_Group/OLEDs.pdf>. Acesso em: 02 de setembro de 2009.

72 SEKI, S.; WAKANA, M.; KASAHARA, Y.; SEKI, Y.; KONDO, T.; WANG, M.; UCHIDA, T.; HAGA, K.; SAWADA, Y. Fabrication of organic light-emitting devices with indium-tin-oxide anode prepared by spray chemical vapor deposition. Jpn. J. Appl. Phys. 46, 6837-6841 (2007).

73 KODAK. About KODAK OLED Technology. Disponível em: 〈http://www.kodak.com/eknec/PageQuerier.jhtml?pq-path=1473/1683\&pq-locale=en_US >. Acesso em: 12 de outubro de 2009.

74 LEMON, S. Sony Unveils First OLED TV. Disponível em: <http://www.pcworld.com/article/137884/sony_unveils_first_oled_tv.html>. Acesso em: 20 de outubro de 2009. 
75 OLED-DISPLAY.NET. OLED Television. Disponível em: <http://www.oleddisplay.net/oled-television>. Acesso em: 20 de outubro de 2009.

${ }^{76}$ K-ENG. LCD. Disponível em: <http://www.k-eng.co.kr/en/biz_01.htm>. Acesso em: 15 de outubro de 2009.

77 SANG-SOO, K. New Evolutionary Theory in LCD Market. Disponível em: <http://www.koreatimes.co.kr/www/news/biz/2009/10/234_14688.html>. Acesso em: 04 de setembro de 2009.

${ }^{78}$ NICHOLLS, C. Panasonic confirms OLED to replace LCD in future. Disponível em: <http://www.current.com.au/2008/05/29/article/RXKLVDONVA.html>. Acesso em: 26 de outubro de 2009.

${ }^{79}$ TOUCHSCREEN GUIDE. Various Resistive Touchscreen Technologies.

Disponível em: <http://www.touchscreenguide.com/touchscreen/res.html>. Acesso em: 20 de outubro de 2009.

${ }^{80}$ NEXTWINDOW. Optical Touch: How it differs from other technologies.

Disponível em: <http://www.nextwindow.com/optical/comparison.html>. Acesso em: 25 de outubro de 2009.

${ }^{81}$ LAMPERT, C. M. Heat mirror coatings for energy conserving windows. Solar Energy Materials 6, 1-41 (1981).

82 TURATTI, L. G. WTProcess: Uma ferramenta para ensino de microfabricação. Dissertação (Mestrado) - Unicamp, Campinas (2003).

${ }^{83}$ HUDACK, J. Safety in the microelectronics fabrication clean room. Disponível em: $<$ http://www.ece.uncc.edu/research/clean_room/safety/safety.pdf $>$. Acesso em: 10 de julho de 2008.

84 WASA, K.; HAYAKAWA, S. Handbook of sputter deposition technology. Noyes Publications, 97-98 (1992).

85 HEAVEnS, O. S. Optical Properties of Thin Solid Films. Courier Dover Publications, 17 (1991).

${ }^{86}$ KURT J. LESKER Company. Indium Tin Oxide (ITO) $\left(\operatorname{In}_{2} \mathbf{O}_{3} / \mathbf{S n O}_{2}, 90 / 10\right.$ wt\%) Circular Sputtering Targets. Disponível em: $<$ http://www.lesker.com/newweb/deposition_materials/depositionmaterials_sputtertargets_1.c fm?pgid=in3>. Acesso em: 28 de junho de 2008.

87 OKA, M. M. Medida de quatro pontas. Disponível em: <http://www.lsi.usp.br/\%7Edmi/manuais/QuatroPontas.pdf> Acesso em: 12 de junho de 2008.

${ }^{88}$ VAN DER PAUW, L. J. A method of measuring specific resistivity and Hall effect of discs of arbitrary shape. Philips Res. Repts. 13, 1-9 (1958). 
${ }^{89}$ MEDEIROS, M. S. Fabricação de elementos ópticos difrativos de modulação completa. Dissertação de mestrado, Universidade de São Paulo, São Paulo (2007).

90 YU, H. H; HWANG, S. J; TSENG, M. C; TSENG, C. C. The effect of ITO films thickness on the properties of flexible organic light emitting diode. Optics Communications 259, 187-193 (2006).

91 SUNDARAM, K. B.; BLANCHARD, J. Southeastcon '97. Deposition and annealing studies of indium tin oxide films. 'Engineering new New Century'., Proceedings. IEEE, 230232 (1997).

92 KOBAYASHI, H; ISHIDA, T; NAKAMURA, K; NAKATO, Y; TSUBOMURA, H. Properties of indium tin oxide films prepared by the electron beam evaporation method in relation to characteristics of indium tin oxide/silicon oxide/silicon junction solar cells. J. Appl. Phys. 72, 5288-5293 (1992).

${ }^{93}$ RYABOVA, L. A.; SALUN, V. S.; SERBINOV, I. A. Transparent conductive films of $\mathrm{In}_{2} \mathbf{O}_{3} \mathrm{Sn}$ prepared by the pyrolysis method. Thin Solid Films 92, 327-332 (1982).

${ }^{94}$ CHEBOTAREVA, A. B.; UNTILA, G. G.; KOST, T. N.; JORGENSEN, S.; ULYASHIN, A. G. ITO deposited by pyrosol for photovoltaic applications. Thin Solid Films 515, 8505-8510 (2007).

${ }^{95}$ LEE, J.; JUNG, H.; LIM, D.; YANG, K.; SONG, W.; YI, J. Effects of bias voltage on the properties of ITO films prepared on polymer substrates. Thin Solid Films 480-481, 157$161(2005)$

${ }^{96}$ YU, Z.; LI, Y.; XIA, F.; ZHAO, Z.; XUE, W. Properties of indium tin oxide films deposited on unheated polymer substrates by ion beam assisted deposition. Thin Solid Films (2009).

${ }^{97}$ KIM, D. H.; PARK, M. R.; LEE, H. J; LEE, G. H. Thickness dependence of electrical properties of ITO film deposited on a plastic substrate by RF magnetron sputtering. Applied Surface Science 253, 409-411 (2006).

${ }^{98}$ GAO, M. Z.; SHI, H. G.; JOB, R.; LI, F. S.; FAHRNER, W. R. Substrate Dependence of Properties of Sputtered ITO Films. Chin.Phys.Lett. 22, 1228-1231 (2005).

${ }^{99}$ GAO, M. Z.; JOB, R.; XUE, D. S.; FAHRNER, W. R. Thickness dependence of resistivity and optical reflectance of ITO films. Chin. Phys. Lett. 25, 1380-1383 (2007).

100 SHIGESATO, Y.; KOSHI-ISHI, R.; KAWASHIMA, T.; OHSAKO, J. Early stages of ITO deposition on glass or polymer substrates. Vacuum 59, 614-621 (2000).

101 ZHOU, J. Indium Tin Oxide (ITO) deposition, patterning and Schottky contact fabrication. Dissertação de mestrado, Rochester - New York (2005). 
102 SAIM, H.B.; CAMPBELL, D. S. Properties of indium-tin-oxide (ITO) /silicon heterojunction solar cells by thick-film techniques. Solar Energy Materials 15, 249-260 (1987).

103 SUEVA, D.; GEORGIEV, S. S.; NEDEV, N.; TONEVA, A.; CHIKOV, N. A neutron detector based on an ITO/p-Si structure. Vacuum 58, 308-314 (2000).

104 MALIK, O.; HIDALGA-W, F.J.; ZÚÑIGA-I, C.; RUIZ-T, G. Efficient ITO-Si solar cells and power modules fabricated with a low temperature technology: Results and perspectives. Journal of Non-Crystalline Solids 354, 2472-2477 (2008).

105 ASHOK, S.; SHARMA, P. P.; FONASH, S. J. Spray-deposited ITO silicon SIS heterojunction solar cells. IEEE Trans. Electron Dev. 27, 725-730 (1980). 